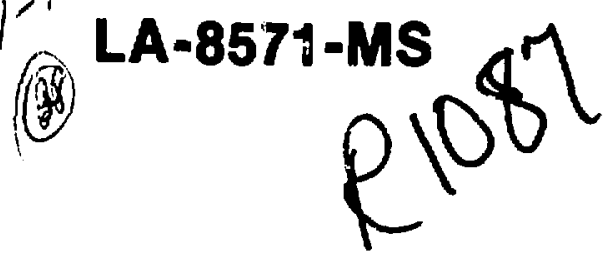

Program MASTERCALC: An Interaciive Computer Program for Radioanalytical Computations Description and Operating Instructions

$\stackrel{2}{5}$ 
UC-32

Issued: October 1980

\title{
Program MASTERCALC:
}

\section{An Interactive Computer Program for Radioanalytical Computations Description and Operating Instructions}

\author{
W. Goode
}
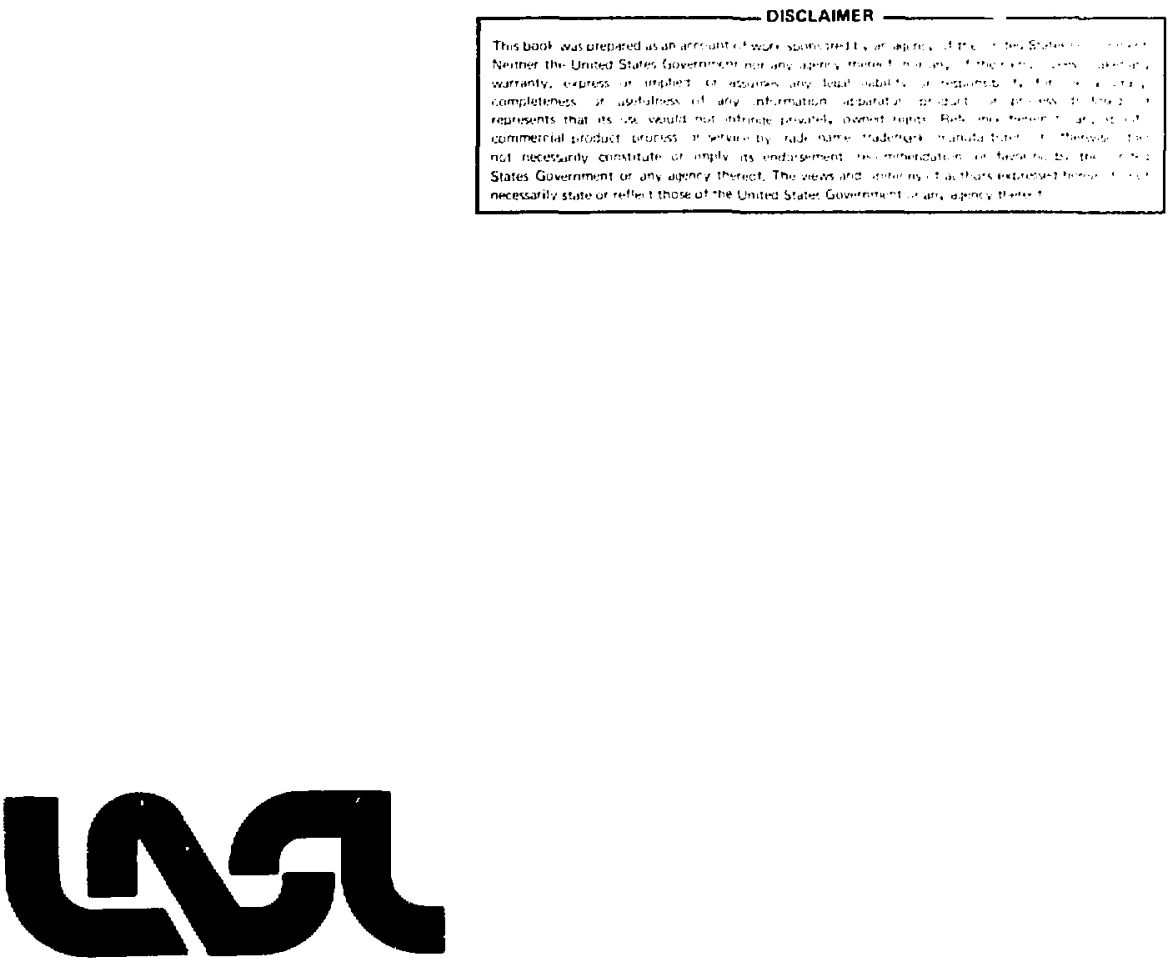


\title{
Program
}

\section{MASTERCALC}

\section{AN INTERACTIVE COMPU'TER PROGRAM FOR RADIOANALYTICAL COMPUTATIONS DESCRIPTION AND OPERATING INSTRUCTIONS}

\author{
by
}

W. Goode

\begin{abstract}
MASTERCALC is a computer program written to support radioanalytical computations in the Los Alamos Scientific Laboratory (LASL) Environmental Surveillance Group. Included in the program are routines for gross alpha and beta, ${ }^{3} \mathrm{H}$, gross gamma, ${ }^{90} \mathrm{Sr}$ and alpha spectroseopic determinations. A description of MASTERCALC is presented and its source listing is included. Operating instructions and example computing sessions are given for each type of analysis.
\end{abstract}

\section{INTRODUCTION}

Program MASTERCALC is the principal tool used for the reduction of nuclear counting data generated from routine radioanalytical work in the Environmental Surveillance Group (H-8). Specifically, it provides computational support for analyses requiring alpha spectroscopy, gross alpha and beta counting, gross gamma counting, and specific ${ }^{\circ} \mathrm{Sr}$ and ${ }^{3} \mathrm{H}$ determinations. MASTERCALC was written in 1976-1977 to provide an automated means of handling data from the analyses mentioned above and at the same time create a convenient link to the computer based data storage facility for $\mathrm{H}-8$ environmental analyses (H8DATA). ${ }^{5}$

MASTERCALC is written in the language PASCAL and is implemented as a set of procedures that handle the specific computations for the analyses listed above; each set of procedures may share routines for such things as output formatting and data management, which are common to H-8 analytical work in general. The program is resident at the Loo Alamos Scientific Laboratory Central Computing Facility (LASL CCF) on machine $M$ and is available from any terminal connected to the CCF network. 


\section{FLOW OF INTERACTION}

MASTFRCALC was designed around the interaction flow shown in Fig. 1. This scheme was chosen as the most effective way to handle the required computationai chores with the equipment available at the time the program was written.

\section{FEATURES COMMON TO ALL MASTERCALC MODULES}

Some basic features, restrictions, and syntactical points are common to all MASTERCALC data analysis procedures.

MASTERCALC was designed to be operated interactively. Although it is possible to use the program in a batch environment, program input and output will normally be through the user's terminal, thus avoiding the delays inherent in batch processing.

Each data analysis procedure (module) within MASTERCALC generally requires three sources of input

1. An "ID" ?hie, which is a Network Operating System (NOS)-a time sharing system in the CCF-disk file containing information about sample identification, owner,quantity, etc.

2. A "DATA" file, which is a NOS disk file containing actual counting data from a given instrument.

3. Terminal keyboard input, which supplies certain instrument parameters, such as date of count, counter backiground, efficiency, etc.

The ID and DATA files consist of one or more lines of input. The correistion of identification and counting data is order dependent, therefore, each file must maintain a line-for-line correspondence to the other so that data are paired properly when read by MASTERCALC. A line of input consists of multiple data fields; each field must be separated from the next by one or more blanks (any number of blanks is permissible). Fieldis designed to have an slphanumeric value may be composed of any characters that are legal under NOS. Integer fields must be composed of

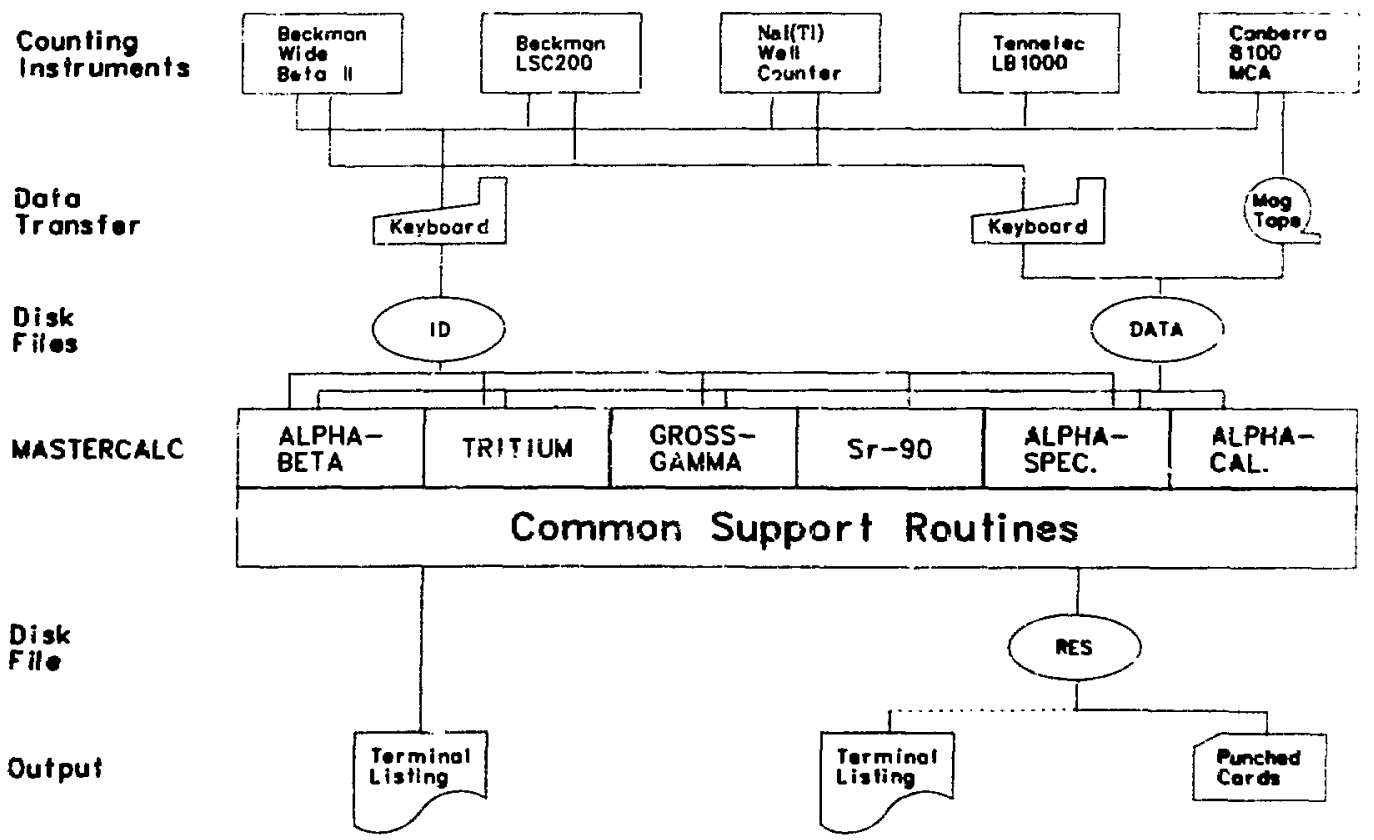

Fig. 1.

MASTERCALC-flnw of interaction. 
positive or negative whole numbers only (no decimal point). Fields that are for real numbers can be composed of any whole number (integer) or any whole number with decimal fraction (example $1,1 ., 1.5)$. Any real number of absolute value $<1$. nnust be expressed with the leading zero included ( 0.5 is correct, .5 is not).

Date specifications must be made in the form MM/DD/YY where MM is the month, DD the day, and YY the year. Leading zeros must be included where MM or DD is less than 10 (e.g., 02/09/79).

In many cases, fields may be duplicated from line to line. Where duplication is provided for, a " 0 " (zero) is used to duplicate all field types, except for date fields that are duplicated by the letter "X." Availability of the duplication option is noted in each of the module descriptions discussed in Section IV.

Analytical results are striped of insignificant digits before repcrting. To see the method employed by MASTERCALC, consider an analytical result in the form

$\sum_{\mathrm{j}} \mathrm{A}_{\mathrm{J}} \times 10^{\mathrm{j}} \pm \Sigma_{\mathrm{j}} \mathrm{E}_{\mathrm{J}} \times 10^{\mathrm{j}}$

where $A_{j}, E_{j}$ are nonnegative integers (digits) and $j$ is an integer. Equivalently then the result may be expressed in the form

$\ldots A_{2} A_{1} A_{0} . A_{-1} A_{-2} A_{-3} \ldots \pm E_{2} E_{1} E_{0} . E_{-3} E_{-2} E_{-3} \ldots$

Using this notation, the algorithm used to determine the number of significant digits in an analytical result is

1. Find the first nonzero digit of the error term and note the index $j$.

2. If the digit $E_{j}$ is a 1 , then round and report the answer and error tenns to the $j$-1st digit. Otherwise, round and report the answer and error terms to the $\mathrm{jth}$ digit.

Examples:

\begin{tabular}{|c|c|}
\hline Computed Value & Reported Value \\
\hline $5.1246 \pm 1.2516$ & $5.1 \pm 1.3$ \\
\hline $5.1246^{2} \pm 0.2516$ & $5.1 \pm 0.3$ \\
\hline $5.1245 \pm 2.4132$ & 5. \pm 2 \\
\hline $5.1246 \pm 24.1323$ & 10. \pm 20 \\
\hline $5.1246 \pm 0.0241$ & $5.12 \pm 0.02$ \\
\hline
\end{tabular}

Output from MASTERCALC is in two forms. A printer listing of raw and computed data is cutput to the user's terminal, and in addition, a local file is created under the name "RES" in which the analytical results are stored in System 2000 (a data base management system on NOS) compatible format. The listings are divided into 8.5 by 11 in. pages, with each page bounclary delineated by a dashed line. The user should retain these listings as a record of the sanple analyses. The "RES" file is generally translated into punched cards, which can later be loaded directly into the H-8 analytical data base (H8DATA).

The file names "ID," "DATA," and "RES," which have been used thus far and will appenr frequently in Section IV, must be adhered to in a generic sense only. The user may substitute any legal NOS file name of his choosing as long as the names are substituted consistently throughout the operational sequences and the file contents satisfy the requirements for that particular analysis module. 


\section{OPERATING INSTRUCTIONS}

This section contains step by step instruction in the use of the various computational modules of MASTERCALC. It is assumed that the user has a basic familiarity with NOS, a text editor, and computer terminals. For help with these types of problems, the user is referred to the following sources:

LASL Guide to NOS (PIM-4)"

NOS Version 1 Time Sharing User's Guide ${ }^{2}$

NOS Version 1 Reference Manual ${ }^{(3)}$

XEDIT (PIM-2)

C-DIV Consulting Office, Telephone No. 7-7547

An example of an actual terminal session is presented for each analysis module. To delineate the responses of the user from those of the computer, all text typed by the user is Bold Italic. Sometimes, non-printing control characters are part of a response; when this is the case they are noted by enclosing the control sequence in brackets [ ]. For example, [CTRL/C] indicates that the user is to press the "CTRL" and " $\mathrm{C}$ " keys of his terminal simultaneously. Responses, which will necessarily vary for different users, are enclosed in " $<>$ " and carry a generic meaning only. $A$ carriage return is always required to terminate a line of keyboard input. The reader must keep this in mind while following the operational sequences, as carriage returns are not noted.

\section{A. Gross Alpha and Beta Analyses}

1. Overview. The alpha/beta analysis procedure is used for reducing data from the Beckman Wide Beta Il proportional counter. Sample and counting information is entered into the $1 \mathrm{D}$ and DATA files via a terminal keyboard. Predetermined efficiency relations based on the sample matrix and mass loading of the planchet are internal to the program. The user must supply background counting rates appropriate for the data set being analyzed.

\section{Procedure}

(A) Sign on CCF machine $M$.

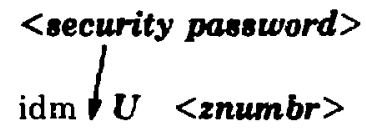

79/08/14. 14.45.08.

LASL $6600-00\left(2^{*}\right.$ ACTUAL CP TIME) NOS1.3-485C 790813

USER NUMBER: <warnbr,passwrd>

TERMINAL: 13 , TTY

RECOVER/SYSTEM:

(B) Create the ID and DATA files. Each file may have up to 60 entries.

The ID file may be entered as follows:

/NEW,ID

/TEXT

ENTER TEXT MODE. 


$\begin{array}{rrrrr}78.06020 & \text { JWO } & 0.5 & 0.067 & \text { LITER } \\ 78.06021 & \text { JWO } & 0 & 0.066 & \text { LITER } \\ 78.06022 & \text { JWO } & 0 & 0.064 & \text { LITER }\end{array}$

[CTRL $C] \longleftarrow$ Depress "CTRL" and "C" keys simultaneously. EXIT TEXT MODE

NOSORT

/PACK

PACK COMPLETE.

/REPLACE

where the fields (1) - (5) are

(1) Sample identification: alphanumeric, 10 characters or less.

(2) Sample owner: alphanumeric, 2 or 3 characters.

(3) Sample quantity: an integer or real number.

(4) Sample mass residue on the counting planchet: a real number expressed in grams.

(5) Sample unit quantity: the units in which field (3) is expressed. Legal units are LITER, GRAM, M..3 (for cubic meters) and SAMPLE.

Verify the contents of the ID file.

\section{$/ \mathrm{LNH}$}

$\left.\begin{array}{rrrrr}78.06020 & \text { JWO } & 0.5 & 0.067 & \text { LITER } \\ 78.06021 & \text { JWO } & 0 & 0.966 & \text { LITER } \\ 78.06022 & \text { JWO } & 0 & 0.064 & \text { LITER }\end{array}\right\}$ (Contents of file "ID")

If the file is not as desired, use a text editor to correct the file or return to the beginning of step (B).

The DATA file may be created as follows:

/NEW,DATA

/TEXT

ENTER TEXT MODE.

$\begin{array}{lcccc}(1) & (2) & (3) & (4) & (5) \\ 0 & 0 & 894 & 130 & 50 \\ 0 & 0 & 957 & 128 & 50\end{array}$

$[$ CTRL/C] — (Depress "CTRL" and "C" keys simultaneously)

EXIT TEXT MODE.

NOSORT

/PACK

PACK COMPLETE.

/REPLACE 
where fields (1) - (5) are

(1), (2) Dummy fields not currently used by the program. They are included for potential use of the apper tape cutput of the Beckman counter, but presently serve only as position holders. Any number will suffice for these fields.

(3) Total beta counts observed for the counting period: an integer rumber.

(4) Total alpha counts observed for the counting period: an integer number.

(5) The counting period: a real number expressed in minutes.

Verification of the DATA file may be accomplished via the LNH command in the same manner as for the ID file.

(C) Execute the alpha/beta analysis module by following the secuence below .

\section{/ATTACH,LGO/UN $=900027$}

/ATTACH,PASLIB/UN =LIBRARY

/RFL,50000

RFL, 50000.

/GET,ID,DATA

/LGO(, RES,ID,DATA)

PLACE AN X UNDER THE DESIRED ANALYSIS

$\begin{array}{lllllll} & \text { A } & \text { A } & \text { A } & \text { T } & \text { G } & \text { S } \\ \text { L } & \text { L } & \text { L } & \text { R } & \text { R } & \text { R } \\ \text { P } & \text { P } & \text { P } & \text { I } & \text { O } & - \\ & \text { H } & \text { H } & \text { H } & \text { T } & \text { S } & \mathbf{9} \\ \text { A } & \text { A } & \text { A } & \text { l } & \text { S } & \mathbf{0} \\ \text { S } & \text { B } & \text { C } & \text { U } & \text { G } & \\ \text { P } & \text { E } & \text { A } & \text { M } & \text { A } & \\ & \text { E } & \text { T } & \text { L } & & \text { M } & \\ & \text { C } & \text { A } & & & & \end{array}$

ENTER DATA COUNTED - EXAMPLE 12/01/76

?04/19/79

ALPHA BACKGROUND=

?30

BETA BACKGROUND

?468

BACKGROUND COUNTING TIME=

$? 50$

The backgrounds are derived from counting the appropriate blanks with the sample set.

Program output will commence here.

(D) Collect the output. The output generated from the example sequence diacusaed thus far is shown in Figs. 2 and 3 . By performing the sequence below, one obtains $a$ listing of the file RDS and also creates a deck of punched cards containing the same information. 
RAW DATA

\begin{tabular}{|c|c|c|c|c|c|c|}
\hline SAMPLE ID & OWNER & QUANTITY & $\begin{array}{l}\text { UNIT } \\
\text { QUAN }\end{array}$ & $\begin{array}{c}\text { COUNT } \\
\text { TIME }\end{array}$ & $\begin{array}{c}\text { ALPHA } \\
\text { COUNTS }\end{array}$ & $\begin{array}{l}\text { BETA } \\
\text { COUNTS }\end{array}$ \\
\hline 78.06020 & JWO & 0.50 & LITER & 50.00 & 130 & 894 \\
\hline 78.06021 & JWO & 0.50 & LITER & 50.00 & 128 & 957 \\
\hline 78.06022 & JWO & 0.50 & LITER & 50.00 & 135 & 893 \\
\hline
\end{tabular}

Fig. 2.

Alpha/beta procedure output - raw data.

DATE COUNTED $=04 / 19 / 79$

PAGE 2

\title{
CALCULATED RESULTS
}

$\begin{array}{cccc}\text { SAMPLE ID } & \text { OWNER } & \text { ALPHA PCL/LITER } & \text { BETA PCL/LTTER } \\ 78.06020 & \text { JWO } & 1.2+/-0.3 \times 10 \mathrm{E} 1 & 1.7+/-0.2 \times 10 \mathrm{E} 1 \\ 78.06021 & \text { JWO } & 1.1+/-0.3 \times 10 \mathrm{E} 1 & 1.9+/-0.2 \times 10 \mathrm{E} 1 \\ 78.06022 & \text { JWO } & 1.2+/-0.3 \times 10 \mathrm{E} 1 & 1.7+/-0.2 \times 10 \mathrm{E} 1\end{array}$

Fig. 3.

Alpha/beta procedure output - computed results

\begin{abstract}
PACK,RES
PACK COMPLETE.

/COPY,RES

*PUTAl 12.0000, 3.0000,PCI/L,04/19/79,78.06020,JWO,ALPHA);

* PUTAR $\quad 17.0000, \quad 2.0000$, PCI/L,04/19/79,78.06020,JWO,BETA);

* PLiTAR $11.0000, \quad 3.0000, P C 1 / L, 04 / 19 / 79,78.06021, J W 0, A L P H A) ;$

*PUTAR $12.0000, \quad 3.0000$, PCL/L,04/19/78.06022,JWO,ALPHA);

*PUTA( 17.0000, 2.0000,PCL/L,04/19/78.06022,JWO,BETA);
\end{abstract}

EOI ENCOUNTERED.

\section{/REWIND,RES}

SREWIND,RES.

/DISPOSE, RES $=P H$

$\mathrm{H} 8$

The punched card deck will be available on the "H8" shelf at the CCF approximately 30 minutes following program execution. If further sets of data are to be calculated, the user should retum to step B of this section; otherwise, proceed to step E. 
(E) Sign off.

$/ B Y E$

900027

900027

LOG OFF 11.24.19.

SRU 10.848 UNTS.

\section{B. Tritium Analysis}

1. Overview. The tritium analysis procedure is for reducing counting data from the Beckman LSC-200 liquid scintillation counter or other tritium counting instrument. Sample and counting information is entered into the ID and DATA files via a ternainal keyboard. All counting parameters must be supplied by the user at program execution time.

2. Proceduris

(A) Sign on CCF machine M.

<security passwrd>

idm $/ U<$ <numbr $>$

$79 / 08 / 14.14 .45 .08$.

LASL 6600 - 00 (2*ACTUAL CP TIME) NOS1.3-485C 790813

USER NUMBER: <usrnbr,passwrd>

TERMINAL: $\quad 13$, TTY

RECOVER/SYSTEM:

(B) Construct the input files ID and DATA. Data from up to 100 samples may be processed at once.

The ID file may be entered as follows:

/NEW,ID

/TEXT

ENTER TEXT MODE.

(1) (2) (3) (4) (5)

78.08482 TG 0.0052 .710 .0036

78.07483 TG 0.0052 .710 .0078

78.07484 TG 0.0052 .710 .0076

$|C T R L / C|$

EXIT TEXT MODE

NOSORT

/PACK

PACK COMPLETE.

/REPLACE 
where the fields (1) through (5) are defined as

(1) Sample identification: alphanumeric, 10 characters or less.

(2) Sample owner: alphanumeric, 2 or 3 characters.

(3) Sample quantity: a real number expressed in liters. Fields (4) and (5) are applicable only to tritium in air determinations. If the user is computing for a sample type other than tritium, these two fields should be omitted.

(4) Sample air volume: a real number expressed in cubic meters.

(5) Volume of water extracted from the sample air volume: a real number expressed in liters.

Verify the contents of the ID file.

\section{/LNH}

$\begin{array}{lllll}78.08482 & \text { TG } & 0.005 & 2.71 & 0.0036\end{array}$

$\begin{array}{lllll}78.07483 & \text { TG } & 0.005 & 2.71 & 0.0073\end{array}$

$\begin{array}{lllll}78.07484 & \text { TG } & 0.005 & 2.71 & 0.0076\end{array}$

If the contents are not as desired, use a text editor to correct the file or return to the beginning of step (B).

The Data file may be created as follows:

/NEW,DATA

/TEXT

(1) (2)

$\begin{array}{llll}50.0 & 1597 & 0.810\end{array}$

$\begin{array}{lll}50.0 & 1358 & 0.800\end{array}$

$\begin{array}{llll}50.0 & 1428 & 0.832\end{array}$

$[C T R L / C]$

EXIT TEXT MODE

NOSORT

/PACK

PACK COMPLETE.

/REPLACE

where the fields (1) through (3) are defined as

(1) counting time: a real number expressed in minutes.

(2) Total tritium counts: an integer number.

(3) "S-Factor:" A unitless real number. This field is included for use with the Beckman LSC200 or other counter which is able to produce an "external standard ratio." The external stanclard ratio is a measure of quenching in liquid scintillation samples. This field is included for information only, however, and it is not used in calculation of tritium activity. Therefore, any number is legal in this field but it is suggested that the user enter a 0 in this position if the value is not meaningful so that "dummy" values may be easily distinguished from actual external standard ratios. 
Verify the DA'TA file.

$/$ LNH

$\begin{array}{llll}50.0 & 1597 & 0.810\end{array}$

$50.0 \quad 1358 \quad 0.800$

$\begin{array}{llll}50.0 & 1428 & 0.832\end{array}$

If the contents of the DATA file are not as desired, use a text editor to correct the problem or return to middle of step $(B)$ and recreate the file.

(C) Execute the tritium analysis module by following the sequence below.

\section{/GET,ID,DATA}

/ATTACH,LGO/UN $=900027$

ATTACH,PASLIB/UN=LIBRARY

$/ R F L, 50000$

RFL, 50000 .

/LGO(,RES, ID,DATA)

PLACE AN X UNDER THE DESIRED ANALYSIS

$\begin{array}{llllll}\text { A } & \text { A } & \text { A } & \text { T } & \text { G } & \text { S } \\ \text { L } & \text { L } & \text { L } & \text { R } & \text { P } & \text { R } \\ \text { P } & \text { P } & \text { P } & \text { I } & \text { O } & - \\ \text { H } & \text { H } & \text { H } & \text { T } & \text { S } & \text { g } \\ \text { A } & \text { A } & \text { A } & \text { I } & \text { S } & 0 \\ \text { S } & \text { B } & \text { C } & \text { U } & \text { G } & \\ \text { P } & \text { E } & \text { A } & \text { M } & \text { A } & \\ \text { E } & \text { T } & \text { L } & & \text { M } & \\ \text { C } & \text { A } & & & & \end{array}$

ENTER DATE COUNTED - EXAMPLE 12/01/76

$? 08 / 23 / 79$

ENTER COJNTING EFFICIENCY (C/D)

$? 0.282$

ENTER RELATTVE STD OF COUNTING EFFICIENCY

$? 0.02$

ENTER TRITIUM BKG - TOTAL COUIVTS

?1066

ENTER BACKGROUND COUNTING TIME (MIN)

?50

IS THE CTDAT FILE IS LSC 200 PAPER TAPE FORMAT

?NO

Background and efficiency parameters should be derived from counting appropriare blank and standard samples with each sample set. Program output will commence at this point.

(D) Collect the outpit. The output generated from the example sequence discussed ir this section is shown in Figs. 4 and 5. By performing the sequence below, the user obtains a printer listing and a punched card deck of the file RFS. 


\begin{tabular}{|c|c|c|c|c|c|c|c|}
\hline $\begin{array}{c}\text { SAMPLE } \\
\text { ID } \\
\end{array}$ & OWNER & $\begin{array}{c}\text { SAMPLE } \\
(\mathrm{L}) \\
\end{array}$ & $\begin{array}{c}\text { WATER } \\
\text { (L) } \\
\end{array}$ & $\begin{array}{l}\text { AIR } \\
(\mathrm{M}) \\
\end{array}$ & $\begin{array}{c}\text { H-3 } \\
\text { COUNTS }\end{array}$ & $\begin{array}{c}\text { COUNT } \\
\text { TIME }\end{array}$ & SFACTOR \\
\hline 78.07482 & TG & 0.005 & 0.0036 & 2.71 & 1597 & 50.00 & 0.810 \\
\hline 78.07483 & TG & 0.005 & 0.0073 & 2.71 & 1358 & 50.00 & 0.800 \\
\hline 78.07484 & TG & 0.005 & 0.0076 & 2.71 & 1428 & 50.00 & 0.832 \\
\hline
\end{tabular}

Fig. 4.

Tritium procedure output-raw data.

TRITIUM RESUL'TS

DATE COUNTED $=08 / 23 / 79$

PAGE 2

\begin{tabular}{|c|c|c|}
\hline $\begin{array}{c}\text { SAMPLE } \\
\text { ID }\end{array}$ & OWNER & HTO CONCENTRATIO \\
\hline & & $\mathrm{I} / \mathrm{M}$ \\
\hline & TG & $5.0+1-1.2 \times 10 \mathrm{E}$ O PCI $\mathrm{M}$ \\
\hline 78.07484 & 'TG & $6.5+/-1.4 \times 10 \mathrm{E} 0 \mathrm{PCI} / \mathrm{M}$ \\
\hline
\end{tabular}

Fig. 5.

Tritium procedure output-computed results.

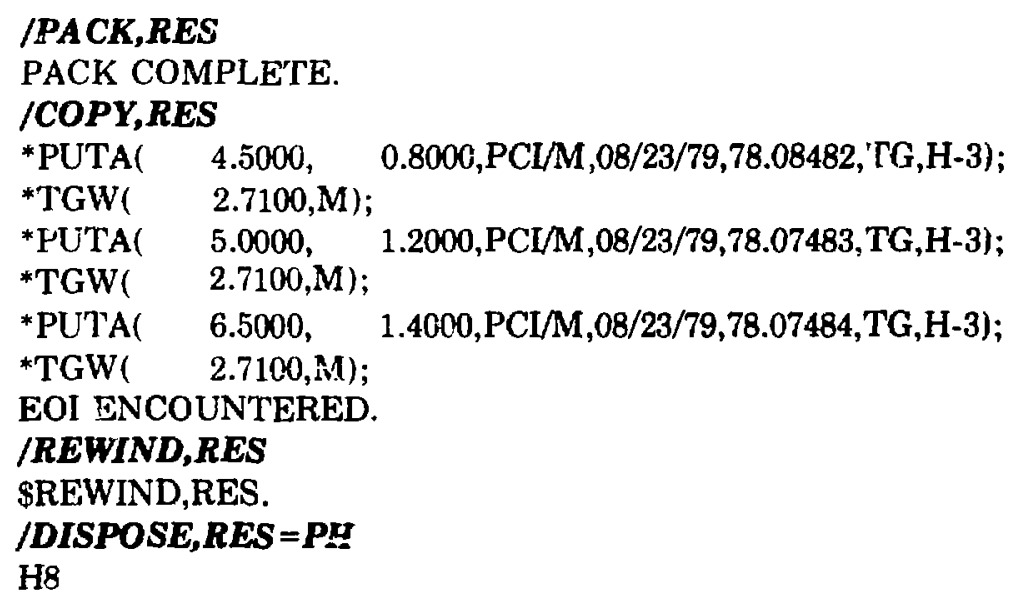

The punched card deck should be available at the CCF on the "H8" shelf approximately 30 minutes after execution. If further sets of data are to be calculated, the user should return to step (B) of this section; otherwise, proceed to step (E). 
(E) Sign off.

/BYE

$900027 \quad$ LOG OFF 15.50 .38 .

900027 SRU 2.827 UNTS.

\section{Gross Gamma Analysis}

1. Overview. The gross gamma procedure is designed to reduce data from the $\mathrm{NaI}$ (Tl) detector and single channel analyzer counting system. Sample information and counting data are entered into the ID and DATA files via a terminal keyboard. The background counting rate appropriate for the data set being calculated must be supplied at program execution time. Resuits are reported in terms of net counts per minute per unit quantity; therefore, counting efficiency parameters are not required.

\section{Procedure}

(A) Sign on CCF machine $M$.

<security passwrd>

idm $/ U<$ znumber $>$

79/08/14. 14.45 .08 .

LASL 6600 - $00\left(2^{*}\right.$ ACTUAL CP TIME) NOS1.3-485C 790813

USER NUMBER: <usrnbr,pasawrd>

TERMINAL: $13, \mathrm{~T} T Y$

RECOVER/SYSTEM:

(B) Create the ID and DATA files. The gross gamma procedure can process an unlimited number of sample entries at each execution.

The ID file may be created as follows:

/NEW,ID

/TEXT

ENTER TEXT MODE.

(1) (2) (3) (4)

$\begin{array}{llll}79.01234 & A S & 0.5 & L\end{array}$

79.01235 AS $0.5 \quad L$

$\begin{array}{llll}79.01236 & A S & 0.5 & L\end{array}$

79.01237 AS $0.5 \mathrm{E}$

79.01238 AS $0.5 \quad L$

79.01239 AS $0.5 \quad L$

[CTRL/C]

EXIT TEXT MODE

/NOSORT

/PACK

PACK COMPLETE.

/REPLACE 
where the fields (1) through (4) are

(1) Sample identification: alphanumeric, 10 characters or less.

(2) Sample owner: alphanumeric, 2 or 3 characters.

(3) Sample quantity: a real number expressed in the units supplied for field (4).

(4) Sample unit quantity: alphanumeric, one character.

Verify the ID file.

\section{/LNH}

79.01234 AS $0.5 \quad$ ¿

79.01235 AS $0.5 \quad \mathrm{~L}$

79.01236 AS $0.5 \quad \mathrm{~L}$

79.01237 AS $0.5 \quad \mathrm{~L}$

79.01238 AS $0.5 \mathrm{~L}$

79.01239 AS $0.5 \quad \mathrm{~L}$

If the contents of the ID file are not as desired, use a text editor to correct the error(s) or return to the beginning of step (B) and recreate the file.

The data file may be entered as follows:

\section{/NEW,DATA}

/TEXT

ENTER TEXT MODE.

(1) (2)

$37084 \quad 30$

$36653 \quad 30$

3661230

3649430

$36377 \quad 30$

$36274 \quad 30$

$[\mathrm{CTRL} / \mathrm{C}]$

EXIT TEXT MODE

NOSORT

IPACK

PACK COMPLETE.

/REPLACE

where the fields (1), (2) are defined as

(1) Total gamma counts detected: an integer number.

(2) Counting period: a real number expressed in minutes. 
Verify the contents of the DATA file.

\section{/LNH}

$37084 \quad 30$

$36653 \quad 30$

3661230

3649430

$36377 \quad 30$

3627430

If the contents of the DATA file are incorrect, use a text editor to correct the problem or return to the middle of step $(B)$ and recreate the file. Execute the gross gamma analysis module by following the sequence below.

/ATTACH,LGO/UN $=900027$

/ATTACH,PASLIB/UN =LIBRARY

/GET,ID,DATA

$/ R F L, 40000$

RFL, 40000 .

LGO(,,RES,ID,DATA)

PLACE AN X UNDFR THE DESIRED ANALYSIS

$\begin{array}{llllll}\text { A } & \text { A } & \text { A } & \text { T } & \text { G } & \text { S } \\ \text { L } & \text { L } & \text { L } & \text { R } & \text { R } & \text { R } \\ \text { P } & \text { P } & \text { P } & \text { I } & \text { O } & - \\ \text { H } & \text { H } & \text { H } & \text { T } & \text { S } & 9 \\ \text { A } & \text { A } & \text { A } & \text { I } & \text { S } & 0 \\ \text { S } & \text { B } & \text { C } & \text { U } & \text { G } & \\ \text { P } & \text { E } & \text { A } & \text { M } & \text { A } & \\ \text { E } & \text { T } & \text { L } & & \text { M } & \\ \text { C } & \text { A } & & & & \end{array}$

$? \quad \boldsymbol{X}$

ENTER DATE COUNTED - EXAMPLE 12/01/76

?08/28/79

ENTER GROSS GAMMA BKG - TOTAL COUNTS

$? 845011$

ENTER BKG COUNTING TIME - MNN

?700

Program output will commence at this point.

(D) Collect the output. The output generated from the example sequence is shown in Fig. 6. By performing the sequence below, the user obtains a printer listing and a punched card deck of the file RES.

/PACK,RES

PACK COMPLETE. 


\begin{tabular}{|c|c|c|c|c|c|}
\hline SAMPLE ID & OWNER & QUAN & COUNTS & TIME & GROSS GAMMA CONCENTRATION \\
\hline 79.01234 & AS & 0.50 & 37084 & 30.00 & $5.8+/-1.3 \times 10 \mathrm{E} 1 \mathrm{NCPM} / \mathrm{L}$ \\
\hline 79.0235 & AS & 0.50 & 36653 & 30.00 & $2.9+/-1.3 \times 10 \mathrm{E} 1 \mathrm{NCPM} / \mathrm{L}$ \\
\hline 79.01236 & AS & 0.50 & 36612 & 30.00 & $2.6+/-1.3 \times 10 \mathrm{E} 1 \mathrm{NCPM} / \mathrm{L}$ \\
\hline 79.01237 & AS & 0.50 & 36494 & 30.00 & $1.9+/-1.3 \times 10 \mathrm{E} 1 \mathrm{NCPM} / \mathrm{L}$ \\
\hline 79.01238 & AS & 0.50 & 36377 & 30.00 & $1.1+/-1.3 \times 10 \mathrm{E} 1 \mathrm{NCPM} / \mathrm{L}$ \\
\hline 79.01239 & AS & 0.50 & 36274 & 30.00 & $0.4+/-1.3 \times 10 \mathrm{E} 1 \mathrm{NCPM} / \mathrm{L}$ \\
\hline
\end{tabular}

Fig. 6.

Gross gamma procedure output.

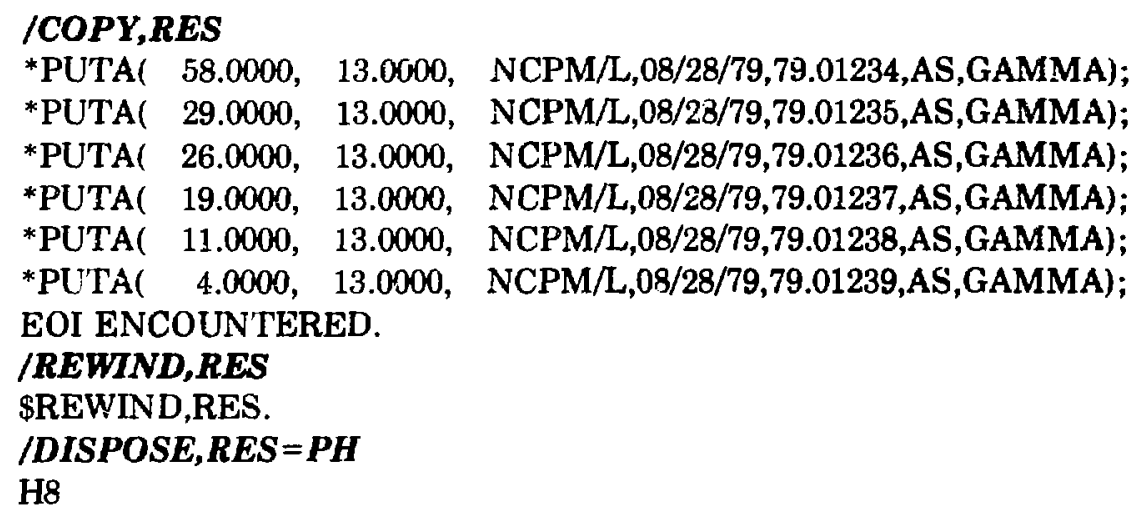

The punched card deck should be available at the CCF on $\mathrm{tr}$ "H8" shelf approximately 30 minutes after execution. If further sets of data are to be calculated, the user should return to step (B) of this section; otherwise, proceed to step (E).

(E) Sign off.

/BYE

900027 LOG OFF 09.27 .19 .

900027 SRU 2.921 UNTS.

\section{D. ${ }^{\circ 0} \mathrm{Sr}$ Analysis}

1. Overview. This procedure is for reducing data from low background proportional counting of samples having undergone previous chemical processing for ${ }^{\circ} \mathrm{Y}(6)$ isolation. Sample, counting, and pertinent chemistzy information is keyboard entered into the ID file. The DATA file is not required. Counter background and efficiency parameters must be supplied by the user at program execution time. 


\section{Procedure}

(A) Sign on CCF machine $M$.

<security passurd>

idm $U<$ Unumbr $>$

79/08/14. 14.45.08.

LASL $6600-00\left(2^{*}\right.$ ACTUAL CP TIME) NOS1.3-485C 790813

USER NUMBER: <usmbr,passwrd>

TERMINAL: 13 , TTY

RECOVER/SYSTEM:

(B) Create the ID file. Up to 49 sample entries may be processed at once. Duplication of fields is denoted by an "X" for date fields and a "0" (zero) for other field types as shown.

NEW,ID

/TEXT

ENTER TEXT MODE.

\begin{tabular}{|c|c|c|c|c|c|c|c|c|c|c|c|c|}
\hline (i) & $(2)$ & (3) & (4) & (5) & (6) & (7) & (8) & (9) & (110) & (11) & (12) & (13) \\
\hline T8.06for 1 & IWO & 1 & $s$ & 3453 & 300 & 25 & $16 . \overline{7}$ & $08 / 13 / 79$ & 8 & 34 & $08 / 13 / 79$ & 16 \\
\hline $78 .(6)(1) 2$ & $\theta$ & $\theta$ & 0 & 1958 & 300 & 0 & 11.4 & $\mathrm{x}$ & 0 & 0 & $08 / 14 / 79$ & 8 \\
\hline 78.06015 & 0 & 0.5 & L. & 526 & 297 & 0 & 15.8 & $\mathrm{x}$ & 0 & 0 & $08 / 15 / 79$ & 8 \\
\hline
\end{tabular}

[CTRL/C]

EXIT TEXT MODE

NOSORT

/PACK

PACK COMPLETE.

REPLACE

The fields (1) through (14) are defined as follows:

(1) Sample identification: alphanumeric, 10 characters or less.

(2) Sample owner: alphanumeric, 2 or 3 characters.

(3) Sample quantity: a real number expressed in the unita of field (4).

(4) Sample unit quantity: alphanumeric, one character.

(5) total beta counts: an integer number.

(6) Count duration: a real number expressed in minutes.

(7) Amount of $\mathrm{Y}$ carrier added to the sample: a real number expressed in milligrams.

(8) Amount of $\mathrm{Y}$ carrier recovered from the sample: a real number expressed in milligrams.

(9) Separation date. 
(10) Separation hour of the day: an integer number in 24 hour clock terms (leading zeros not required). ( $1 \leq$ separation hour $<24)$.

(11) Separation minute: an integer number (leading zeros not required). ( $1 \leq$ separation minute <60).

(12) Counting date.

(13) Counting hour of the day: an integer number (leading zeros not required). ( $1 \leq$ count hour $<24)$.

(14) Counting minute: an integer number (leading zeros not required). ( $1 \leq$ count minute $<60$ ).

Verify the contents of the ID file.

\section{$/ \mathbf{L N H}$}

\begin{tabular}{|c|c|c|c|c|c|c|c|c|c|c|c|c|}
\hline $78.066(1) !$ & .1100 & 1 & $\dot{s}$ & $345: 3$ & 300 & 25 & 16.7 & 0 & $\kappa$ & 34 & $08 / 13 / 79$ & 16 \\
\hline 78.0601122 & U & 0 & 0 & 1958 & 300 & 0 & 114 & $x$ & \& & 11 & $08 / 1+7 / 9$ & 8 \\
\hline 78.116015 & I) & 0.5 & 1. & 526 & 297 & 0 & 15.6 & $x$ & 0 & 11 & (1) $15 / 79$ & 8 \\
\hline
\end{tabular}

If the contents are not as desired, use a text editor to correct the error or return to the beginning of step (B) and reenter the file.

(C) Execute the ${ }^{80} \mathrm{Sr}$ analysis module by following the sequence below:

/GET,ID

/ATTACH,LGO/UN=900027

/ATTACH,PASLIB/UN = LIBRARY

/RFL, 40000

RFL, 40000 .

/LGO(, RES,ID)

PLACE AN X UNDER THE DESIRED ANALYSIS

$\begin{array}{llllll}\text { A } & \text { A } & \text { A } & \text { T } & \text { G } & \text { S } \\ \text { L } & \text { L } & \text { L } & \text { R } & \text { R } & \text { R } \\ \text { P } & \text { P } & \text { P } & \text { I } & \text { O } & - \\ \text { H } & \text { H } & \text { H } & \text { T } & \text { S } & 9 \\ \text { A } & \text { A } & \text { A } & \text { I } & \text { S } & 0 \\ \text { S } & \text { B } & \text { C } & \text { U } & \text { G } & \\ \text { P } & \text { E } & \text { A } & \text { M } & \text { A } & \\ \text { E } & \text { T } & \text { L } & & \text { M } & \\ \text { C } & \text { A } & & & & \end{array}$

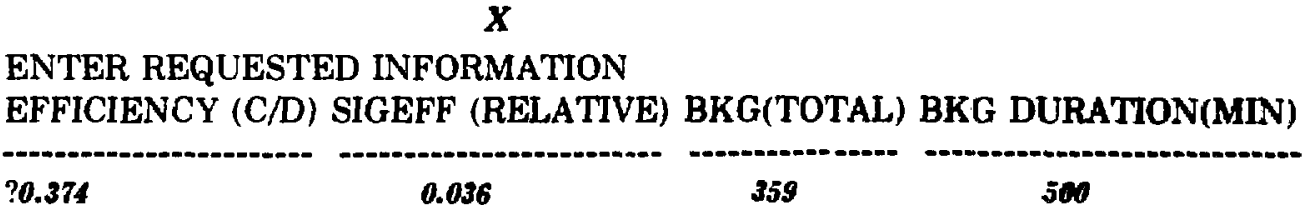


The background and efficiency parameters should be derived from the performance log maintained on the low background beta counting system (LA Notebook Y.91). Program output will commence at this point.

(D) Collect the output. The output generated fror: the example sequence is shown in Figs. 7, 7a, and 8 . By performing the sequence below, the user will obtain a printer listing and a punched card deck of the result file RES.

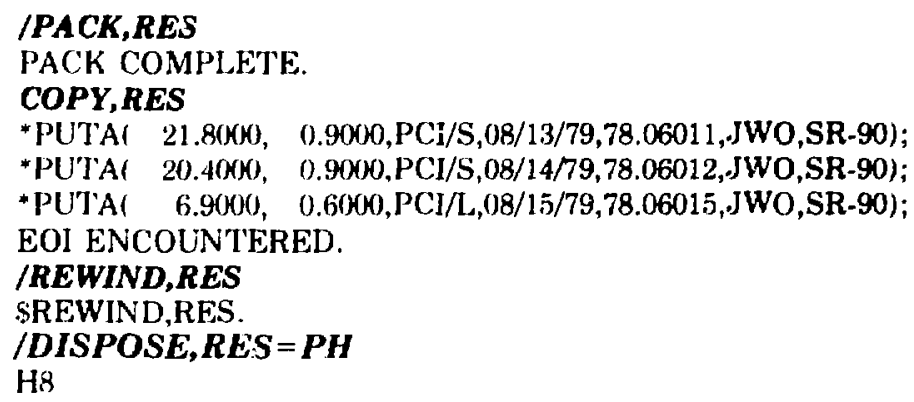

The punched cards should be available on the "H8" sł.elf approximately 30 rninutes after execution. If further sets of data are to be calculated, the user should return to step (B) of this section; otherwise proceed to step (E).

(E) Sign off.

\section{/BYE}

900027 LOG OFF 15.28.58.

900027 SRU 1.748 UNTS.

PAGE 1

\begin{tabular}{|c|c|c|c|c|c|}
\hline $\begin{array}{l}\text { SAMPLE } \\
\text { ID }\end{array}$ & OWNER & QUAN & $\begin{array}{c}\text { UNIT } \\
\text { QUAN }\end{array}$ & COUNTS & $\begin{array}{l}\text { CNT } \\
\text { MIN }\end{array}$ \\
\hline & JWO & 1.00 & $\mathbf{S}$ & 3453 & 300.00 \\
\hline 78.06012 & JWO & 1.00 & $\mathbf{S}$ & 1958 & 300.00 \\
\hline 78.06015 & JWO & 0.50 & $L$ & 526 & 297.00 \\
\hline
\end{tabular}

Fig. 7.

SR-90 Procedure output-raw data.

SR-90 ANALYSES

PAGE 2

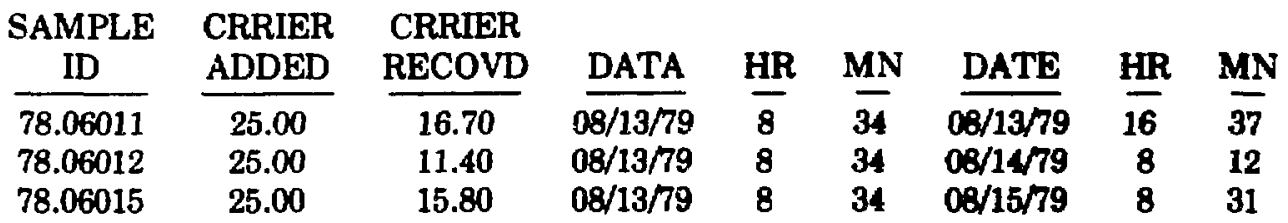

Fig. $7 A$.

$S R-90$ procedure output-raw data. 


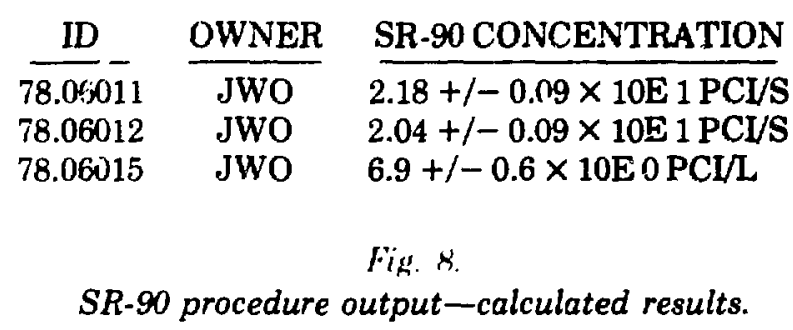

\section{E. Alpha Spectral Analysis}

The alpha spectral analysis software consists of a procedure to reduce the spectral data and two supporting routines to keep necessary detector dependent parameters available $\leqslant$ the analysis program. The alpha spectral analysis procedure is described in section $E$. 1 . The alpha calibration procedure inaintains a file of calibration information, which is used by the spectral analysis program and is described in Section E.2. Program BKGD2, although not an integral part of MASTERCALC, maintains the necessary detector background information for the analysis code. and because of its kinship to MASTE?CALC, it is described in Section E.3.

It is imperative that the person in charge of alpha spectral analyses keep the calibration and background information current via the two utilities mentioned above. When this is the case, alpha spectral daia reduction may be handled relatively easily by using the alpha spectral analysis procedure of MASTERCALC as described in the next section.

\section{Alpha Spectral Analysis Procedure}

a. Overview. The alpha spectroscopy procedure of MASTERCALC is designed to provide an automated means of interpreting and reducing spectral information obtained from solid state counting of previously prepared electrodeposited plates resultant of specific radiochemistry. ${ }^{6}$ Sample information and pertinent radiochemical parameters are entered via a keyboard terminal into the ID file. A cassette tape containing the counting data from a Canberra 8100 multichannel analyzer is read into the DATA file from a Texas Instruments (TI-733) data terminal. Program execution echos the ID file information and produces spectral data listings and a final isotopic concentration summary for the data set under consideration. As in all other MASTERCALC analysis modules, a System 2000 data base (H8DATA) compatible result file is also produced.

The analysis procedure is applicable to any alpha spectral data after appropriate internal program tables have been loaded with the necessary information. Currently, analysis for ${ }^{236} \mathbf{P u}$, ${ }^{238} \mathrm{Pu},{ }^{238} \mathrm{Pu},{ }^{241} \mathrm{Am},{ }^{243} \mathrm{Am},{ }^{208} \mathrm{Po},{ }^{210} \mathrm{Po}$ is provided for, where one isotope is designated as the tracer and up to three isotopes of the same element are specified as analytes. The necessary tasks of peak location, peak integration, background subtraction, interference correction for tracer impurities, peak fitting, and correction for poorly resolved peaks are all provided for in the analysis code.

\section{b. Procedure}

(A) Sign on CCF machine $M$. 
<security passwrd>

idm $f U<$ inumbr $>$

79/08/14. 14.45 .08 .

LASL $6600-00 \quad\left(2^{*}\right.$ ACTUAL CP TIME) NOS1.3-485C 790813

USER NUMBER: <usrnbr,passwrd>

TERMINAL: 13 , TTY

RECOVER/SYSTEM:

(B) Construct the ID and DATA files. Up to 32 samples may be processed at once. Value duplication is provided for by the use of a " 0 " (zero) as shown. The ID file may be created as follows:

/NEW,ID

/TEXT

ENTER TEXT MODE.

(I)

NO-SAMPLE

79.01395

79.01396

NO-SAMPLE

NO-SAMPLE

79.01398

79.01399

79.01400

79.01401

79.01402

79.01403

NO-SAMPLE

79.02144

79.02145

79.00501
(2)

WP PU238,PU239

00,0

(3)

WP$$
\text { O }
$$

o

$\theta \quad 0,0$

$0 \quad 0,0$

o 0,0
TH PU238,PU239
0,0
0,0
TG $\quad 0,0$

(4)

PU242
0

(5)

(6)

(i)

(8)

(9) 
(2) Sample owner: alphanumeric, 2 or 3 characters.

(3) Analysis isotopes: alphanumeric, 5 characters. This field consists of one to three isotopes of the same element, separated by a comma(s).

(4) Tracer isotope: alphanumeric 5 characters.

(5) Tracer activity: a real number expressed in disintegrations per minute of the tracer isotope added to the sample.

(6) Sample quantity: a real number expressed in the units specified by field (8).

(7) Aliquot fraction: a real number specifying the portion of the total sample which was used for the analysis.

(8) Sample unit quantity: alphanumeric, 1 character.

(9) Separation date (optional): a date in the form MM/DD/YY. This field is included only for use with ${ }^{210} \mathrm{Pu}$ analyses so that the concentrations may be decay corrected back to the separation date. The field is left blank for all other analyses. The duplication character for this field is "X."

Verify the contents of the ID file.

$/ \mathrm{LNH}$

$\begin{array}{lccccccc}\text { NO-SAMPLE } & & & & & & \\ 79.01395 & \text { WP } & \text { PU238,PU239 } & \text { PU242 } & 11.8 & 10 & 1 & \text { G } \\ 79.01396 & 0 & 0,0 & 0 & 0 & 0 & 0 & 0 \\ \text { NO-SAMPLE } & & & & & & & \\ \text { NO-SAMPLE } & & & & & & & \\ 79.01398 & \text { WP } & \text { PU238,PU239 } & \text { PU242 } & 11.8 & 10 & 1 & \text { G } \\ 79.01399 & 0 & 0,0 & 0 & 0 & 0 & 0 & 0 \\ 79.01400 & 0 & 0,0 & 0 & 0 & 0 & 0 & 0 \\ 79.01401 & 0 & 0,0 & 0 & 0 & 0 & 0 & 0 \\ 79.01402 & 0 & 0,0 & 0 & 0 & 0 & 0 & 0 \\ 79.01403 & 0 & 0,0 & 0 & 0 & 0 & 0 & 0 \\ \text { NO-SAMPLE } & & & & & & & \\ 79.02144 & \text { TH } & \text { PU238,PU239 } & \text { PU242 } & 11.8 & 1 & 1 & \text { S } \\ 79.02145 & 0 & 0,0 & 0 & 0 & 0 & 0 & 0 \\ 79.00501 & \text { TG } & 0,0 & 0 & 0 & 0 & 0 & 0\end{array}$

If the contents of the ID file are not as desired, use a text editor to correct the error or return to the beginning of step (B) and recreate the file.

Read the cassette tape containing the alpha spectral counting data into the DATA file. The DATA file may be created by following the steps below.

(a) With the PLAYBACK and PRINTER switches in LOCAL mode (see Fig. 9)," use the REWIND, FF (fast forward) and BLOCK FWD controls to position the cassette tape at the beginning of the counting data for the sample set of interest.

(b) Return the PLAYBACK and PRINTER switches to LINE mode and execute the following sequence. 


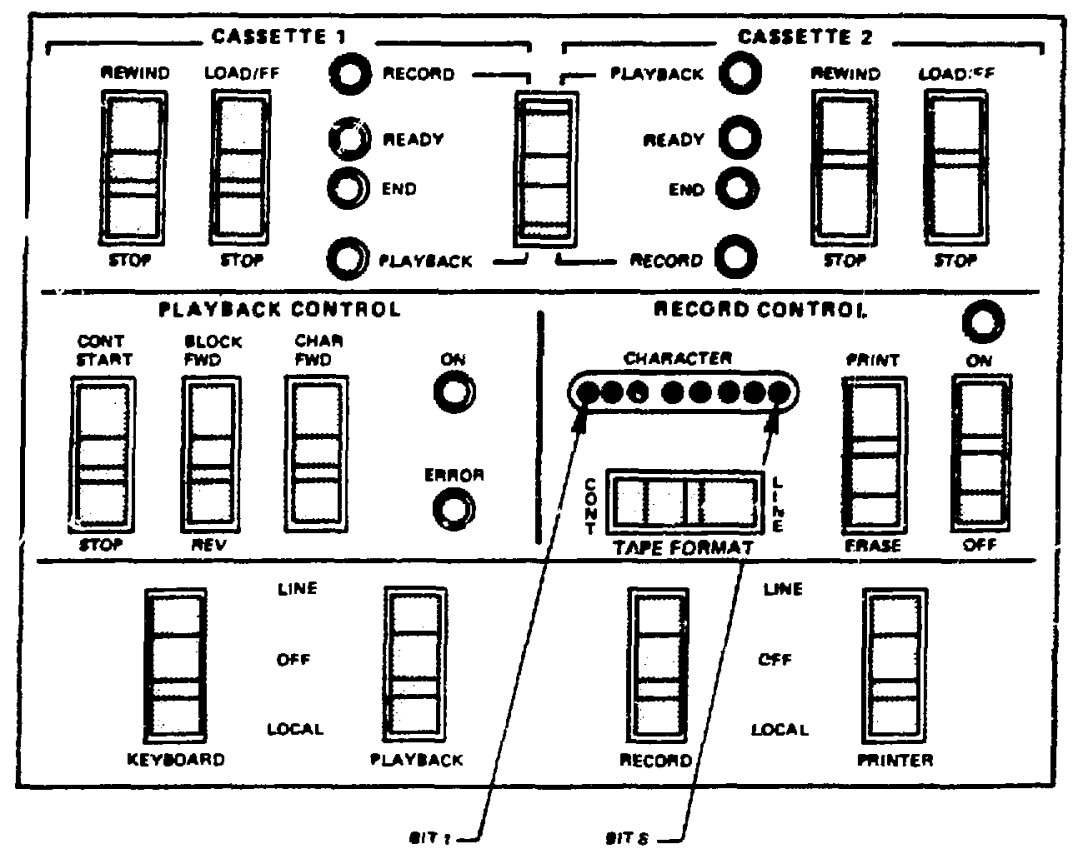

Fig. 9.

TI733 switch panel.

\section{/NEW,DATA}

\section{TAPE}

TEXT

ENTER TEXT MODE.

[PRESS CONT START ON PLAYBACK CONTROL]

07/02/79 ALPHA SPEC 79.01395 (1)

$080000(2)$

$0001(3)$

000000

000001

000000

000000

$000000 \quad 000000$

$000000 \quad 000000$

$000000 \quad 000002$

$000000 \quad 000002$

000000

000001

000000

$000001 \quad 000001$

$000001 \quad 000001$

000000

000000

000000

000000

$000000 \quad 000000$

000000

000000

000000

000000

000000 :

000000

000001

$000000 \quad 000000$

000000

000000

000000

000000

000000

000001

000000

000002

000002

000001

000000

$000000 \quad 000000$

$000001 \quad 000000$

000000

000000

000000

000000

000000

00000

$000000 \quad 000000$

000000

000000

00000

000000

000000

00000

00000

000000

000000

000000

000000

000000

000000

000000

000000

000000

000000

000000

000000

000000

000000

$000000 \quad 000000$

000000

000000

000001

000000

0101 (3)

000000

000000

$000000 \quad 000000$

$000000 \quad 000000$

000000

000001

000000

$000000>(4)$

000000

000000

000000

000000

000000

000000

000000

000000

000000

000000

000000

000000

000000

000000

$000000 \quad 000000$

000000

000000

$000000 \quad 000000$

000000

000000

000000

$000000\}$ (4)

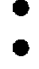




\begin{tabular}{|c|c|c|c|c|c|c|c|c|c|}
\hline 000000 & 000000 & 000000 & 000000 & 006900 & 000000 & 000000 & 000000 & 0000 & \\
\hline 000000 & 000000 & 000000 & 000000 & 000010 & 000000 & 000000 & 000000 & 000000 & \\
\hline 000000 & 000000 & 000000 & 000000 & 000000 & 000000 & 000000 & 000000 & 000 & \\
\hline \multicolumn{10}{|l|}{4001} \\
\hline 000000 & 000000 & 000000 & 000000 & 000000 & 000000 & 000000 & 000000 & 000000 & 000000 \\
\hline 000000 & 000000 & 000000 & 000000 & 000000 & & & & & \\
\hline 000000 & 000000 & 000000 & 000000 & 000000 & 000000 & 000000 & 000000 & & 000 \\
\hline 000000 & 000000 & 000000 & 000000 & 000000 & 000000 & 000000 & 005000 & 000000 & \\
\hline 000000 & 000000 & 000000 & 000000 & 000000 & 000000 & 000000 & 000000 & 000000 & 000000 \\
\hline 000000 & 000000 & 000000 & 000000 & 000000 & 000000 & 000000 & 000000 & 000000 & 000 \\
\hline 000000 & 000000 & 000000 & 000000 & 000000 & 000000 & 000000 & 000000 & 000000 & \\
\hline 000000 & 000000 & 000000 & 000000 & 000000 & 000000 & 000000 & 000000 & 000000 & 00000 \\
\hline 000000 & 000000 & 000000 & 000000 & 000000 & 000000 & 000000 & 000020 & 000000 & 00000 \\
\hline
\end{tabular}

[Turn playback control "OFF"][CR/LF]

$[C T R L / C]$

NOSORT

NORMAL

/PACK

PACK COMPLETE.

/REPLACE

The elements (1) through (4) are

(1) Spectrum identifier: A line of text up to 80 characters to positively identify data that immediately follows it. It is used for informational purposes only and is not used by the analysis program.

(2) Time channel: counting time in seconds.

(3) Ch 1 inel marker: channel number of the next data value following. Channel markers are recorded onto the tape every 100 channels from 1 to 4001 .

(4) Data block: The data data blocks contain the alpha spectral data. Each data block contains 100 channels, with the exception of the last block, which contains 95 channels. There should be 41 data blocks in each spectrum, yielding a total of 4095 channels.

The data file is so long that it is not practical to list the entire file for verification. A text editor may be used to proof the file in an abbreviated form, however, by checking for the most commonly occurring errors, as shown in the following errors as shown in the followings example.

\section{/XEDIT,DATA}

XEDIT VER.8.1 REVISED 78/08/25. 08.08.06.

DATA IS EDIT FILE

?PRINT (check identifier line)

07/02/79 ALPHA SPEC 79.0135

$>$ ?BOTTOM (find the last line of the file)

$000000 \quad 000000 \quad 000000 \quad 000000 \quad 000000$

$>$ ?WHERE

453 (file length)

$>$ ?END

DATA IS A LOCAL FILE

I 
If the DATA file has been entered properly, it should consist of the identification line and 452 lines of data, for a total file length of 453 lines. It frequently happens (because of improper termination of the cassette tape readback) that the last line of data will not be included in the file. This condition is allowed for in the analysis program, however, and should not affect its execution. If for any other reason, the file is less than 453 lines long or if it is greater than 453 lines long, the DATA file should be considered unreliable and it should be reentered in its entirety.

(C) Execute the alpha spectral analysis procedure by following the sequence beiow:

/GET,ID,DATA,BKGDFL,DETDATA

/ATTACH,LGO/UN=900027

/ATTACH,PASLIB/UN =LIBRARY

$/ R F L, 130000$

RFL, 130000 .

/LGO(,OUTPUT,RES,ID,DATA)

\section{PLACE AN X UNDER THE DESIRED ANALYSIS}

$\begin{array}{lllllll} & \text { A } & \text { A } & \text { A } & \text { T } & \text { G } & \text { S } \\ & \text { L } & \text { L } & \text { L } & \text { R } & \text { R } & \text { R } \\ & \text { P } & \text { P } & \text { P } & \text { I } & \text { O } & - \\ & \text { H } & \text { H } & \text { H } & \text { T } & \text { S } & 9 \\ & \text { A } & \text { A } & \text { A } & \text { I } & \text { S } & \text { 0 } \\ \text { S } & \text { B } & \text { C } & \text { U } & \text { G } & \\ & \text { P } & \text { E } & \text { A } & \text { M } & \text { A } & \\ & \text { E } & \text { T } & \text { L } & & \text { M } & \\ & \text { C } & \text { A } & & & & \\ \text { ? } & \text { X } & & & & & \end{array}$

ENTER DATE COUNTED - EXAMPLE 12/01/76

?08/31/79

All necessary counting parameters are obtained from internal program tables or from the supporting files DETDATA and BKGDFL; thus only the counting date is requested. Program output commences at this point. Because of the volume of output that may be generated by the analysis program, it may be desirable to reroute the output to a device other than the user's terminal. Refer to Appendix A for details.

(D) Collect the output. The output generated from the example sequence discussed in this section is shown in Figs. 10 through 14.

Figure 10 is an echo of the information passed to the program througt the ID file.

Figure 11 contains the isotopic activity concentrations for the sample set. Note that for sample 79.02145 there are entries under the "FIT COEFF" column indicating that the alpha peaks were poorly resolved and a least squares fit was attempted on the data. The fit coefficients are the square root of the correlation coefficients obtained from the regression cilculations ${ }^{\mathrm{s}}$ on each alpha peak. The fit coefficients are a measure of the closeness of fit of the calculated model $Y=$ $\mathrm{Ae}^{\mathrm{BX}}$ ( $\mathrm{A}$ and $\mathrm{B}$ determined by regression) to the counting data. A correlatic $\mathrm{I}$ coefficient of 1 indicates a perfect fit; decreasing values indicate decreasingly suitable tits. The "EXTRAP COUNT" entry for sample 79.02145 indicates that the fitted peaks predicted that 35 counts under the ${ }^{242} \mathrm{Pu}$ energy interval were caused by interference from the ${ }^{230} \mathrm{Pu}$ and/or ${ }^{230} \mathrm{Pu}$ peaks. All other peaks were found cleanly resolvable and no fitting was attempted. 


\begin{tabular}{|c|c|c|c|c|c|c|c|c|}
\hline DET & ID & ANALYSES & TRACER & $\underset{\text { TRAC }}{\text { ACT }}$ & QUAN & $\begin{array}{l}\text { ALQT } \\
\text { FRAC }\end{array}$ & UNITS & $\begin{array}{c}\text { SEP } \\
\text { DATE }\end{array}$ \\
\hline 1 & NO-SAMPLE & & ::::: & 0 & 0 & 0 & $:$ & \\
\hline 2 & 79.01395 & PU238 PU239 & PU242 & 11.8 & 10.000 & $1: 000$ & $\mathbf{G}$ & \\
\hline 3 & 79.01396 & PU238 PU239 & PU242 & 11.8 & 10.000 & $1: 000$ & $\mathbf{G}$ & \\
\hline 4 & NO-SAMPLE & & ::::: & 0 & 0 & 0 & : & \\
\hline 5 & NO-SAMPLE & & ::::: & 0 & 0 & : & & \\
\hline 6 & 79.01398 & PU238 PU239 & PU242 & 11.8 & 10.000 & $1: 000$ & $\mathbf{G}$ & \\
\hline 7 & 79.01398 & PU238 PU239 & PU242 & 11.8 & 10.000 & $1: 000$ & $\mathbf{G}$ & \\
\hline 8 & 79.01400 & PU238 PU239 & PU242 & 11.8 & 10.000 & $1: 000$ & $\mathbf{G}$ & \\
\hline 9 & 79.01401 & PU238 PU239 & PU242 & 11.8 & 10.000 & $1: 000$ & $\mathbf{G}$ & \\
\hline 10 & 79.01402 & PU238 PU239 & PU242 & 11.8 & 10.000 & $1: 000$ & $\mathbf{G}$ & \\
\hline 11 & 79.01403 & PU238 PU239 & PU242 & 11.8 & 10.000 & $1: 000$ & $\mathbf{G}$ & \\
\hline 12 & NO-SAMPLE & & ::::: & 0 & 0 & 0 & : & \\
\hline 13 & 79.02144 & PU238 PU239 & PU242 & 11.8 & 1.000 & $1: 000$ & $\mathbf{S}$ & \\
\hline 14 & 79.02145 & PU2 88 PU239 & PU242 & 11.8 & 1.000 & $1: 000$ & $\mathbf{S}$ & \\
\hline 15 & 79.00501 & PU238 PU239 & PU242 & 11.8 & 1.000 & $1: 000$ & $\mathbf{S}$ & \\
\hline
\end{tabular}

Column definitions:

$\mathrm{DET}=$ detector number

ID = sample identification

ANALYSES : isotopes for which the analyses were performed

TRACER = tracer isotope

ACT TRAC $=$ activity of the tracer in disintegrations per minute

QUAN = sample quantity

ALQT FRAC = aliquot fraction, or the fraction of the sample used in this analysis

UNITS - unit quantity in which QUAN was expressed

SEP DATE = separation date

Fig. 10.

Alpha spectroscspy procedure output-raw data. 


\begin{tabular}{|c|c|c|c|c|c|c|c|}
\hline \multicolumn{8}{|c|}{ AL.PHA SPECTRA ANALYSES } \\
\hline \multicolumn{3}{|c|}{ DATE COLNTED $=08 / 31 / 79$} & \multicolumn{5}{|c|}{ COLNTING TIME $=80000$ SECONDS } \\
\hline DET & $\begin{array}{c}\text { SAMPLE } \\
\text { ID }\end{array}$ & ISOTOPE & $\begin{array}{l}\text { GROSS } \\
\text { COUNT }\end{array}$ & $\begin{array}{l}\text { BKGD } \\
\text { COUNT }\end{array}$ & $\begin{array}{l}\text { EXTRAP } \\
\text { COUNT }\end{array}$ & $\begin{array}{c}\text { FIT } \\
\text { COEFF }\end{array}$ & SAMPLE ACTTVITY \\
\hline \multirow[t]{3}{*}{2} & 79.01395 & PU242 & 1834 & 5.00 & 0 & $\cdots$ & ...................... \\
\hline & & PU238 & 1 & 4.00 & 0 & $\ldots$ & $-10.7+/-7.0 \times 10 \mathrm{E}-4 \mathrm{PCL}$ \\
\hline & & PU239 & 3 & 5,00 & 0 & .... & $-6 .+1-9 . \times 10 \mathrm{E}-4 \mathrm{PCL} / \mathrm{g}$ \\
\hline \multirow[t]{3}{*}{3} & 79.01396 & PU242 & 646 & 8.00 & $\mathbf{0}$ & $\ldots$ & - \\
\hline & & PU238 & 5 & 11.00 & 0 & $\ldots$ & $-5 .+1-4 . \times 10 \mathrm{E}-3 \mathrm{PCI} / \mathrm{G}$ \\
\hline & & PL239 & 11 & 6.00 & 0 & $\cdots$ & 4. $+/-4 . \times 10 \mathrm{E}-3 \mathrm{PCL} / \mathrm{G}$ \\
\hline \multirow[t]{3}{*}{6} & 79.01398 & PU242 & 933 & 10.00 & 0 & $\cdots$ & (n) \\
\hline & & PU238 & 6 & 4.00 & $\mathbf{0}$ & $\ldots$ & i. $+/-2 . \times 10 \mathrm{E}-3 \mathrm{PCL} / \mathrm{G}$ \\
\hline & & PU239 & 62 & 7.00 & 0 & $\cdots$ & $3.2+/-0.5 \times 10 \mathrm{E}-2 \mathrm{PCL} / \mathrm{G}$ \\
\hline \multirow[t]{3}{*}{7} & 79.01399 & PU242 & 725 & 9.00 & 0 & $\cdots$ & (n) \\
\hline & & PU238 & 0 & 6.00 & $\mathbf{0}$ & $\cdots$ & $-5 .+1-2 . \times 10 \mathrm{E}-3 \mathrm{PCL} / \mathrm{G}$ \\
\hline & & PU239 & 17 & 16.00 & 0 & $\cdots$ & 1. $+/-5 . \times 10 \mathrm{E}-3 \mathrm{PCV} / \mathrm{G}$ \\
\hline \multirow[t]{3}{*}{8} & 79.01400 & PU242 & 1011 & 5.00 & 0 & -... & n...................... \\
\hline & & PU238 & 3 & 4.00 & 0 & $\cdots$ & $-0.7+/-1.8 \times 10 \mathrm{E}-3 \mathrm{PCL} / \mathrm{G}$ \\
\hline & & PU239 & 2 & 5.00 & 0 & $\ldots$ & $-1.6+/-1.7 \times 10 \mathrm{E}-3 \mathrm{PCL} / \mathrm{G}$ \\
\hline \multirow[t]{3}{*}{9} & 79.01401 & PU242 & 1449 & 10.00 & 0 & $\cdots$ & (n) \\
\hline & & PU238 & 2 & 8.00 & 0 & $\ldots$ & $-2.4+/-1.2 \times 10 \mathrm{E}-3 \mathrm{PCL} / \mathrm{G}$ \\
\hline & & PU239 & 3 & 9.00 & 0 & $\ldots$ & $-2.3+/-1 .+\times 10 \mathrm{E}-3 \mathrm{PCL} / \mathrm{G}$ \\
\hline \multirow[t]{3}{*}{10} & $79.014 i s 2$ & PL1242 & 1263 & 9.00 & $\mathbf{0}$ & $\cdots$ & (-..................... \\
\hline & & PU238 & 6 & 2.00 & 0 & $\cdots$ & $1.6+/-1.5 \times 10 \mathrm{E}-3 \mathrm{PCI} / \mathrm{G}$ \\
\hline & & PU239 & 6 & 3.00 & $\mathbf{0}$ & $\cdots$ & $1.2+/-1.6 \times 10 \mathrm{E}-3 \mathrm{PCV} / \mathrm{G}$ \\
\hline \multirow[t]{3}{*}{11} & 79.01403 & PU242 & 1182 & 9.00 & 0 & $\cdots$ & - \\
\hline & & PU238 & 4 & 3.00 & 0 & $\cdots$ & $0.3+/-1.4 \times 10 \mathrm{E}-3 \mathrm{PC} / \mathrm{G}$ \\
\hline & & PU239 & 3 & 2.00 & 0 & $\cdots$ & $0.4+i-1.3 \times 10 E-3$ PCI/G \\
\hline \multirow[t]{3}{*}{13} & 79.02144 & PU242 & 869 & 8.00 & 0 & $\ldots$ & c....................... \\
\hline & & PU238 & 8 & 2.00 & 0 & $\cdots$ & 4. $+/-2 . \times 10 \mathrm{E}-2 \mathrm{PCI} / \mathrm{S}$ \\
\hline & & PU239 & 40 & 4.00 & 0 & $\cdots$ & $2.2+/-0.4 \times 10 \mathrm{E}-1 \mathrm{PCW} / \mathrm{S}$ \\
\hline \multirow[t]{3}{*}{14} & 79.02145 & PU242 & 1265 & 6.00 & 35 & 0.97 & 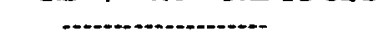 \\
\hline & & PU238 & 11 & 3.00 & 0 & 0.02 & $3.3+/-1.8 \times 10 \mathrm{E}-2 \mathrm{PCL} / \mathrm{S}$ \\
\hline & & PU239 & 1075 & 7.00 & 0 & 0.93 & $4.6+/-3.2 \times 10 \mathrm{E} 0 \mathrm{PCW} / \mathrm{S}$ \\
\hline \multirow[t]{3}{*}{15} & $79.0050 i$ & PU242 & 1529 & 20.00 & 0 & $\ldots$ & - \\
\hline & & PU238 & 2 & 5.00 & $\mathbf{0}$ & $\cdots$ & $-1.2+/-0.9 \times 10 \mathrm{E}-2 \mathrm{PCL} / \mathrm{S}$ \\
\hline & & PU239 & 8 & 4.00 & $\mathbf{0}$ & $\ldots$ & $1.4+/-1.5 \times 10 \mathrm{E}-2 \mathrm{PCI} / \mathrm{S}$ \\
\hline
\end{tabular}

Column definitions:

DET - detector number

SAMPLE ID = sample identification

ISOTOPE - isotope for which the analysis was performed

GROSS COUNT = gross total counts under the alpha peak for the given isotope

EX'TRAP COUNT = total extrapolated counts under the alpha peak from isotopes other than the analysis isotope

FIT COEFF = fit coefficient (refer to the discussion in this section)

SAMPLE ACTIVITY = concentration of the analysis isotope in pCi/unit quantity

Fig. 11.

Alpha spectroscopy procedure output-computed results. 


\begin{tabular}{|c|c|c|c|c|c|c|c|c|}
\hline $\begin{array}{l}\text { CHAN } \\
\text { NO. }\end{array}$ & $\stackrel{2}{2}$ & $\begin{array}{c}3 \\
\text { PRMRY }\end{array}$ & $\begin{array}{c}6 \\
\text { PRMRY }\end{array}$ & $\stackrel{7}{7}{ }^{\text {PRRY }}$ & $\begin{array}{c}8 \\
\text { PRMRY }\end{array}$ & $\stackrel{9}{9}$ & $\begin{array}{c}10 \\
\text { PRMRY }\end{array}$ & $\begin{array}{c}11 \\
\text { PRMRY }\end{array}$ \\
\hline 5 & 1 & 0 & 2 & 6 & 1 & 4 & 12 & 1 \\
\hline 6 & 10 & 0 & 1 & 7 & 7 & 2 & 10 & 1 \\
\hline 7 & 12 & 2 & 1 & 7 & $\mathbf{9}$ & 7 & 20 & 2 \\
\hline 8 & 25 & 2 & 1 & 7 & 12 & 7 & 25 & 11 \\
\hline 9 & 35 & 6 & 7 & 16 & 19 & 5 & 25 & 14 \\
\hline 10 & 33 & 13 & 7 & 12 & 10 & 6 & 26 & 8 \\
\hline 11 & 51 & 9 & 9 & 18 & 13 & 11 & 35 & 23 \\
\hline 12 & 70 & 11 & 9 & 31 & 27 & 9 & 46 & 21 \\
\hline 13 & $62 \mathrm{~T}$ & $22 \mathrm{~T}$ & $19 \mathrm{~T}$ & $31 \mathrm{~T}$ & 23 & 15 & $52 \mathrm{~T}$ & 22 \\
\hline 14 & 101 & 21 & 24 & 42 & 24 & 30 & 61 & $34 \mathrm{~T}$ \\
\hline 15 & 154 & 27 & 57 & 51 & $22 \mathrm{~T}$ & $49 \mathrm{~T}$ & 93 & 58 \\
\hline 16 & 236 & 49 & 71 & 60 & 72 & 62 & 115 & 96 \\
\hline 17 & 264 & 48 & 88 & 67 & 79 & 107 & 135 & 127 \\
\hline 18 & 241 & 81 & 133 & 99 & 97 & 166 & 170 & 153 \\
\hline 19 & 313 & 110 & 169 & 125 & 124 & 211 & 186 & 195 \\
\hline 20 & 258 & 89 & 154 & 96 & 123 & 268 & 179 & 223 \\
\hline 21 & 147 & 109 & 111 & 85 & 155 & 286 & 161 & 189 \\
\hline 22 & $58 \mathrm{~T}$ & $90 \mathrm{~T}$ & $107 \mathrm{~T}$ & $6 y \mathrm{~T}$ & 132 & 203 & $111 \mathrm{~T}$ & 81 \\
\hline 23 & 24 & 73 & 39 & 31 & 120 & 68 & 86 & $26 \mathrm{~T}$ \\
\hline 24 & 4 & 34 & 15 & 7 & $87 \mathrm{~T}$ & $29 \mathrm{~T}$ & 34 & 4 \\
\hline 25 & 0 & 15 & 2 & 1 & 39 & 5 & 16 & 0 \\
\hline 26 & 0 & 0 & 1 & 1 & 13 & 0 & 2 & 0 \\
\hline 27 & 0 & 0 & 0 & 1 & 4 & 0 & 3 & 0 \\
\hline 28 & 0 & 0 & 0 & 0 & 0 & 0 & 0 & 0 \\
\hline 29 & 0 & 0 & 0 & 2 & 0 & 0 & 1 & 0 \\
\hline 30 & 0 & 1 & $2 \mathrm{~B}$ & 0 & 0 & 0 & 0 & 0 \\
\hline 31 & 0 & 1 & 1 & 2 & 0 & 1 & 0 & 0 \\
\hline 32 & 0 & IB & 8 & OB & 0 & 0 & OB & O B \\
\hline 33 & $\mathrm{OB}$ & 1 & 3 & 4 & $\mathbf{O B}$ & $O B$ & 0 & 0 \\
\hline 34 & 1 & 2 & 9 & 3 & 1 & 0 & 1 & 0 \\
\hline 35 & 1 & 1 & 7 & 2 & 1 & 1 & 1 & 0 \\
\hline 36 & 0 & 1 & 14 & 4 & 0 & 1 & 2 & 0 \\
\hline 37 & 0 & 2 & 6 & 0 & 1 & 0 & 0 & \\
\hline 38 & 1 & 1 & 7 & 1 & 0 & o & 1 & 1 \\
\hline 39 & 0 & 2 & $5 B$ & 0 & 0 & 0 & 0 & 1 \\
\hline 40 & 0 & 0 & 2 & 2 & 0 & o & 0 & 0 \\
\hline 41 & 0 & $\mathbf{O B}$ & 2 & $1 \mathrm{~B}$ & 0 & 0 & $1 \mathrm{~B}$ & $\mathbf{O B}$ \\
\hline 42 & $\mathrm{OB}$ & 0 & 0 & 0 & $\mathbf{O B}$ & $\mathrm{OB}$ & 0 & 0 \\
\hline 43 & 0 & 0 & 1 & 0 & 1 & 0 & 0 & 1 \\
\hline 44 & 0 & C & 0 & 0 & 0 & 0 & 0 & 0 \\
\hline 45 & 0 & 0 & 0 & 0 & 0 & 1 & 0 & 1 \\
\hline 46 & 1 & 0 & 2 & 0 & 0 & 0 & 0 & 0 \\
\hline 47 & 0 & 0 & 0 & 0 & 0 & 0 & 0 & 0 \\
\hline 48 & 0 & 1 & 0 & 0 & 0 & 0 & 0 & 0 \\
\hline 49 & 0 & 0 & 0 & 0 & 0 & 0 & 0 & 0 \\
\hline 50 & 0 & 0 & 0 & 0 & 0 & 0 & 0 & 0 \\
\hline 51 & 0 & 1 & 0 & 0 & 1 & 0 & 0 & 0 \\
\hline 52 & 0 & 0 & 0 & 1 & 10 & 0 & 0 & 0 \\
\hline 53 & 0 & $0 \mathrm{~A}$ & 0 & OA & 0 & 0 & OA & OA \\
\hline 54 & 0 & 0 & 0 & 0 & 0 & 0 & 1 & 0 \\
\hline 55 & 0 & 0 & 1 & 0 & 1 & 0 & 1 & 0 \\
\hline
\end{tabular}

Fig. 12.

Alpha spectroscopy procedure output-spectrum listing. 


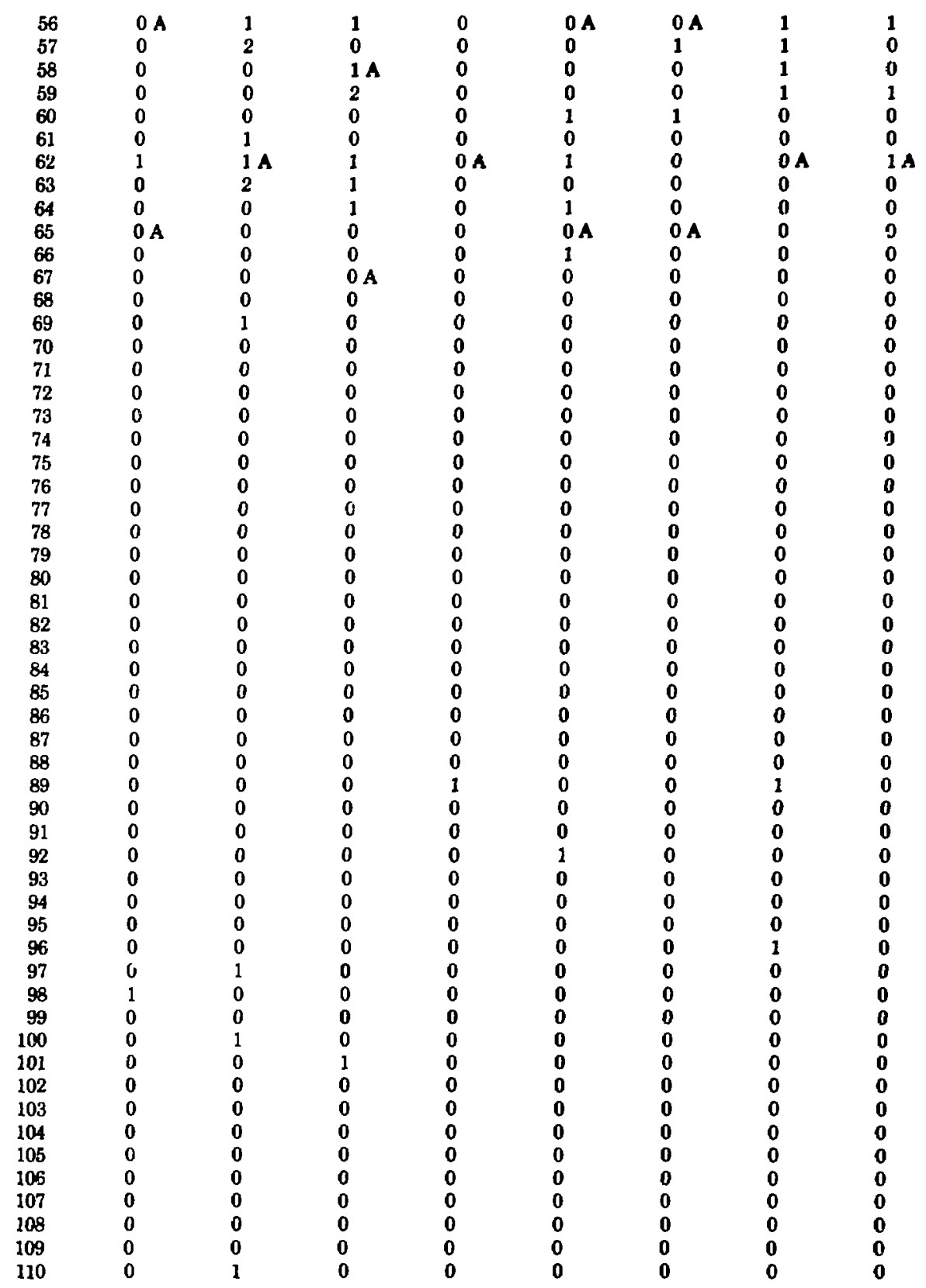

Fig. 12 (cont). 


\section{SPECTRUM}

\begin{tabular}{|c|c|c|c|c|c|}
\hline $\begin{array}{c}\text { CHAN } \\
\text { NO }\end{array}$ & $\begin{array}{c}13 \\
\text { PRMRY }\end{array}$ & $\begin{array}{c}14 \\
\text { PRMRY }\end{array}$ & $\begin{array}{c}14 \\
\text { PU239 }\end{array}$ & $\begin{array}{c}14 \\
\text { PU242 }\end{array}$ & $\begin{array}{c}15 \\
\text { PRMRY }\end{array}$ \\
\hline 5 & 8 & 9 & 0 & 8 & 14 \\
\hline 6 & 13 & 8 & 0 & 10 & 10 \\
\hline 7 & 13 & 8 & 0 & 12 & 22 \\
\hline 8 & 17 & 15 & 0 & 15 & 21 \\
\hline 9 & 22 & 16 & 0 & 19 & 32 \\
\hline 10 & 15 & 17 & 0 & 24 & 18 \\
\hline 11 & 32 & 28 & 0 & 30 & 53 \\
\hline 12 & 29 & 35 & 0 & 38 & $86 \mathrm{~T}$ \\
\hline 13 & 49 & 56 & 0 & 47 & 105 \\
\hline 14 & $56 \mathrm{~T}$ & $51 \mathrm{~T}$ & $0 \mathrm{~T}$ & $0 \mathrm{~T}$ & 113 \\
\hline 15 & 77 & 83 & 1 & G & 134 \\
\hline 16 & 103 & 93 & 2 & 0 & 183 \\
\hline 17 & 111 & 135 & 2 & 0 & 206 \\
\hline 18 & 121 & 151 & 3 & 0 & 210 \\
\hline 19 & 122 & 190 & 3 & 0 & 182 \\
\hline 20 & 131 & 196 & 4 & 0 & 183 \\
\hline 21 & 83 & 169 & 5 & 0 & $127 \mathrm{~T}$ \\
\hline 22 & 47 & 134 & 7 & 0 & 80 \\
\hline 23 & $18 \mathrm{~T}$ & $63 \mathrm{~T}$ & $8 \mathrm{~T}$ & $0 \mathrm{~T}$ & 32 \\
\hline 24 & 5 & 35 & 11 & 0 & 13 \\
\hline 25 & 1 & 33 & 13 & 0 & 1 \\
\hline 26 & 0 & 19 & 17 & 0 & 0 \\
\hline 27 & 0 & 20 & 21 & 0 & 0 \\
\hline 28 & 2 & 21 & 27 & 0 & 2 \\
\hline 29 & $0 \mathrm{~B}$ & 27 & 34 & 0 & 1 \\
\hline 30 & 1 & 52 & 43 & 0 & 1 \\
\hline 31 & 1 & $67 \mathrm{~B}$ & $0 \mathrm{~B}$ & O B & 0 \\
\hline 32 & 5 & 79 & 0 & 0 & 2 \\
\hline 33 & 3 & 95 & 0 & 0 & $5 \mathrm{~B}$ \\
\hline 34 & 9 & 123 & 0 & 0 & 1 \\
\hline 35 & 10 & 140 & 0 & C & 0 \\
\hline 36 & 8 & 164 & 0 & 0 & 2 \\
\hline 37 & 3 & 168 & 0 & 0 & 0 \\
\hline 38 & $0 \mathrm{~B}$ & 124 & 0 & 0 & 0 \\
\hline 39 & 2 & 65 & 0 & 0 & 0 \\
\hline 40 & 1 & $50 \mathrm{~B}$ & $0 \mathrm{~B}$ & $0 \mathrm{~B}$ & 0 \\
\hline 41 & 1 & 17 & 0 & 0 & 0 \\
\hline 42 & 1 & 3 & 0 & 0 & OB \\
\hline 43 & 0 & 0 & 0 & 0 & 0 \\
\hline 44 & 0 & 0 & 0 & 0 & 0 \\
\hline 45 & 0 & 0 & 0 & 0 & 0 \\
\hline 46 & 0 & 0 & 0 & 0 & 0 \\
\hline 47 & 1 & 2 & 0 & 0 & 0 \\
\hline 48 & i? & 0 & 0 & 0 & 0 \\
\hline 49 & 0 & 0 & 0 & 0 & 0 \\
\hline 50 & 0 & 0 & 0 & 0 & 0 \\
\hline 51 & 0 & 0 & 0 & 0 & 0 \\
\hline 52 & 0 & 0 & 0 & 0 & 0 \\
\hline 53 & $0 \mathrm{~A}$ & $0 \mathrm{~A}$ & $0 \mathrm{~A}$ & $O A$ & 0 \\
\hline 54 & 0 & 2 & 0 & 0 & $0 A$ \\
\hline
\end{tabular}

Fig. 13.

Alpha spectroscopy procedure output-spectrum listing. 


\begin{tabular}{|c|c|c|c|c|c|}
\hline 55 & 3 & 2 & 0 & 0 & 1 \\
\hline 56 & 1 & 3 & 0 & 0 & 0 \\
\hline 57 & 2 & 0 & 0 & 0 & 0 \\
\hline 58 & 1 & 1 & 0 & 0 & 0 \\
\hline 59 & 0 & 0 & 0 & 0 & 0 \\
\hline 60 & 1 & 1 & 0 & 0 & 1 \\
\hline 61 & 0 & 1 & 0 & 0 & 0 \\
\hline 62 & $0 \mathrm{~A}$ & I A & $\mathbf{O A}$ & $0 \mathrm{~A}$ & 0 \\
\hline 63 & 0 & 0 & 0 & 0 & $0 \mathrm{~A}$ \\
\hline 64 & 0 & 0 & 0 & 0 & 0 \\
\hline 65 & 0 & 0 & 0 & 0 & 0 \\
\hline 66 & 0 & 0 & 0 & 0 & 0 \\
\hline 67 & 0 & 0 & $u$ & 0 & 0 \\
\hline 68 & 0 & 0 & 0 & 0 & 0 \\
\hline 69 & 0 & 0 & 0 & 0 & 0 \\
\hline 70 & 0 & 0 & 0 & 0 & 0 \\
\hline 71 & 0 & 0 & 0 & 0 & 0 \\
\hline 72 & 0 & 0 & 0 & 0 & 0 \\
\hline 73 & 0 & 0 & 0 & 0 & 0 \\
\hline 74 & 0 & 0 & 0 & 0 & 0 \\
\hline 75 & 0 & 0 & 0 & 0 & 0 \\
\hline 76 & 0 & 0 & 0 & 0 & 0 \\
\hline 77 & 0 & 0 & 0 & 0 & 0 \\
\hline 78 & 0 & 0 & 0 & 0 & 0 \\
\hline 79 & 0 & 0 & 0 & 0 & 0 \\
\hline 80 & 0 & 0 & 0 & 0 & 0 \\
\hline 81 & 0 & 0 & 0 & 0 & 0 \\
\hline 82 & 0 & 0 & 0 & 0 & 0 \\
\hline 83 & 0 & 0 & 0 & 0 & 0 \\
\hline 84 & 0 & 0 & 0 & 0 & 0 \\
\hline 85 & 0 & 0 & 0 & 0 & 0 \\
\hline 86 & 0 & 0 & 0 & 0 & 0 \\
\hline 87 & 0 & 0 & 0 & 0 & 0 \\
\hline 88 & 0 & 0 & 0 & 0 & 0 \\
\hline 89 & 0 & 0 & 0 & 0 & 1 \\
\hline 90 & 0 & 1 & 0 & 0 & 0 \\
\hline 91 & 0 & 0 & 0 & 0 & 0 \\
\hline 92 & 0 & 0 & 0 & 0 & 0 \\
\hline 93 & 0 & 0 & 0 & 0 & 0 \\
\hline 94 & 0 & 0 & 0 & 0 & 0 \\
\hline 95 & 0 & 0 & 0 & 0 & 1 \\
\hline 96 & 2 & 0 & 0 & 0 & 0 \\
\hline 97 & 0 & 0 & 0 & 0 & 0 \\
\hline 98 & 0 & 0 & 0 & 0 & 0 \\
\hline 99 & 0 & 0 & 0 & 0 & 1 \\
\hline 100 & 0 & 0 & 0 & 0 & 0 \\
\hline 101 & 0 & 0 & 0 & 0 & 0 \\
\hline 102 & 0 & 0 & 0 & 0 & 0 \\
\hline 103 & 0 & 0 & 0 & 0 & 0 \\
\hline 104 & 0 & 0 & 0 & 0 & 0 \\
\hline 105 & 0 & 0 & 0 & 0 & 0 \\
\hline 106 & 0 & 0 & 0 & 0 & 0 \\
\hline 107 & 0 & 0 & 0 & 0 & 0 \\
\hline 108 & 0 & 0 & 0 & 0 & 0 \\
\hline 109 & 0 & 0 & 0 & 0 & 0 \\
\hline 110 & 0 & 0 & 0 & 0 & 0 \\
\hline
\end{tabular}

Fig. 13 (cont). 


\begin{tabular}{|c|c|c|c|}
\hline DET & $\begin{array}{l}\text { SAMPLE } \\
\text { ID }\end{array}$ & $\begin{array}{c}\% \\
\text { RECOVERY }\end{array}$ & $\begin{array}{l}\text { FWHM(KEV) } \\
\text { RESOLUTION }\end{array}$ \\
\hline 2 & 79.01395 & 77 & 89 \\
\hline 3 & 79.01396 & 24 & 100 \\
\hline 6 & 79.01398 & 36 & 79 \\
\hline 7 & 79.01399 & 27 & 93 \\
\hline 8 & 79.01400 & 43 & 112 \\
\hline 9 & 79.01401 & 53 & 73 \\
\hline 10 & 79.01402 & 48 & 124 \\
\hline 11 & 79.01403 & 44 & 83 \\
\hline 13 & 79.02144 & 31 & 113 \\
\hline 14 & 79.02145 & 56 & 102 \\
\hline 15 & 79.00501 & 61 & 135 \\
\hline
\end{tabular}

Fig. 14.

Alpha spectroscopy procedure output-diagnostic summary.

Figures 12 and 13 are spectral representations of the counting data. The spectra are labeled according to detector number and spectrum type. The label "PMRY" designates the data is the primary or unmodified counting data for that detector. The other possible labels for data from a given detector would reflect the extrapolated data from an exponential fit on the alpha peak from the labeled isotope. Detector 14 of Fig. 13, for example, has spectral data listed for the primary spectrum and also extrapolations from peak fitting on the ${ }^{239} \mathrm{Pu}$ and ${ }^{242} \mathrm{Pu}$ isotopes. The markers T. 1 , and $B$ delineate the integration limits for the peaks of the tracer, analyte $A$ and analyte $B$, respectively. The order of the analytes $A, B$ (and possibly $C$ ) are defined by the order in which they are listed in the ID file; $A$ first, $C$ last.

Figure 14 contains calculated recovery and resolution values, which are of some use in gauging effectiveness of the chemical processing for each sample. Resolution values of 0 (zero) indicate that the analysis program was unable to compute a meaningful ${ }^{242} \mathrm{Pu}$ alpha resolution for that sample.

As in all other MASTERCALC analysis modules, a data base (H8DATA) compatible record of the computed results is produced. By performing the sequence below, the user will obtain a printer listing and a punched card deck of the file RES.

- LOAD FL 025024

/PACK, RES

PACK COMPLETE.

/COPY,RES

\begin{tabular}{|c|c|c|}
\hline *PUTA( & -0.0010 & 0.0007,PCI/G,08/31/79,79.01395,WP,PU-238); \\
\hline & -0.006 & 0.009,PCL/G,08/31/79,79.01395,WP,PU-239) \\
\hline & -0.0050 & 0.0040,PCI/G,08/31/79,79.01396,WP,I \\
\hline PU & 0.0040 & $0.0040, \mathrm{PCL} / \mathrm{G}, 08 / 31 / 79,79.01396, \mathrm{WP}$ \\
\hline *PUT & 0.0010 & 0.0020,PCL/G,08/31/79,79.01398,WP,PU-23 \\
\hline *PUT & 0.0320 & 0.0050,PCL/G,08/31/79,79.01398,WP,PU-2 \\
\hline *PUT & -0.0050 & $0.0020, P C L / G, 08 / 31 / 79,79.01399, W$ \\
\hline DIT & 0.0010 & $0.0050, \mathrm{PCL} / \mathrm{G}, 08 / 31 / 79,79.01399, \mathrm{~W}$ \\
\hline
\end{tabular}




\begin{tabular}{|c|c|c|}
\hline PUTA & -0.0007 & $0.0018, \mathrm{PCI} / \mathrm{G}, 08 / 31 / 79,79.01400,1$ \\
\hline & -0.0016 & $0.0017, \mathrm{PCH} / \mathrm{G}, 08 / 31 / 79,79.01400, \mathrm{~W}$ \\
\hline PUTA & -0.0024 & $0.0012, \mathrm{PCI} / \mathrm{G}, 08 / 31 / 79,79.01401, \mathrm{WP}$, \\
\hline *PUTA( & -0.0023 & $0.0013, \mathrm{PCI} / \mathrm{G}, 08 / 31 / 79,79.01401, \mathrm{WP}, \mathrm{P}$ \\
\hline *PUTA( & 0.0016 & 0.0015,PCI/G,08/31/79,79.01402,WP,PU-238 \\
\hline *PUTA & 0.0012 & 0.0016,PCI/G,08/31/79,79.01402,WP,PU-239 \\
\hline *PUTA & 0.0003 & $0.0014, \mathrm{PCI} / \mathrm{G}, 08 / 31 / 79,79.01403, \mathrm{WP}, \mathrm{PU}-238$ \\
\hline PUTA & 0.0004 & 0.0013,PCI/G,08/31/79,79.01403,WP,PU-239 \\
\hline "PUT & 0.0400 & 0.0200,PCL/S,08/31/79,79.02144,TH,PU-238 \\
\hline PUT & 0.2200 & $0.0400, \mathrm{PCI} / \mathrm{S}, 08 / 31 / 79,79.02144, \mathrm{TH}, \mathrm{PU}-239$ \\
\hline${ }^{*}$ PUT & 0.0330 & $0.0180, \mathrm{PCl} / \mathrm{S}, 08 / 31 / 79,79.02145, \mathrm{TH}, \mathrm{PU}-238)$ \\
\hline *PU1 & 4.6000 & $0.2000, \mathrm{PCI} / \mathrm{S}, 08 / 31 / 79,79.02145, \mathrm{TH}, \mathrm{PU}-239)$ \\
\hline $\begin{array}{l}\text { *PUTA } \\
{ }^{*} \text { TGW }\end{array}$ & $\begin{array}{l}-0.0120 \\
1.0000, \mathrm{~S})\end{array}$ & $0.0090, \mathrm{PCI} / \mathrm{S}, 08 / 31 / 79,79.00501, \mathrm{TG}, \mathrm{PU}-238$ \\
\hline${ }^{*}$ PUTA & $\begin{array}{l}0.0140 \\
1.0000, \mathrm{~S})\end{array}$ & $0.0150, \mathrm{PCI} / \mathrm{S}, 08 / 31 / 79,79.00501, \mathrm{TG}$ \\
\hline
\end{tabular}

EOI ENCG JNTERED.

/REWIND,RES

\$REWIND,RES

IDISPOSE, RES $=P H$

$\mathrm{H} 8$

The punched card deck should be available at the CCF on the "H8" shelf approximately 30 minutes after execution. If fur:her sets of data are to be calculated, the user should return to step (B) of this section; otherwise, proceed to step (E).

(E) Sign off.

$/ B Y E$

900027 LOG OFF 15.39 .19 .

900027 SRU 162.806 UNTS.

\section{Alpha Spectrometer Calibration}

a. Overview. The alpha calibration procedure is designed to analyze calibration data from the $\mathrm{H}-8$ alpha spectroscopy system. Calibration data are generated by counting known amounts of ${ }^{242} \mathrm{Pu}$, ${ }^{238} \mathrm{Pu}$, and ${ }^{24} \mathrm{Am}$ with each detector. The data are transferred to the DATA file via a cassette tape. The alpha calibration procedure then uses this information to determine a counting efficiency, resolutior, and energy scale for each detector. A hard copy record of the calibration data is produced and a summary of the individual detector performance characteristics is loaded into the file DETDATA for later use by the alpha spectral analysis program.

b. Procedure

(A) Sign on CCF machine $M$. 
<security passurd $>$
idm $/ U<2$ numbr $>$

79/08/14. 14.45.08.

LASL $6600-00\left(2^{*}\right.$ ACTUAL CP TIME) NOS1.3-485C 790813

USER NUMBER: <uarnbr,pasowrd>

TERMINAL: 13 , TTY

RECOVER/SYSTEM:

Because this procedure not only reads but also writes files that are used by MASTERCALC, 900027 must be entered in the <USRNBR> position. Contact the person in charge of program MASTERCAL to obtain the current <PASSWRD>.

(B) Read the cassette tape containing the calibration counting data into the DATA file. The DATA file may be created by following the steps below.

(a) With the terminal in LOCAL mode, position the cassette tape at the beginning of the calibration data.

(b) Return the terminal to LINE mode and execute the following sequence.

\section{/NEW,DATA}

\section{ITAPE}

TEXT

ENTER TEXT MODE.

[Press cont start on playback control]

ALPHASPEC 08/17/79 1-32 STDS

0ín400

0001

$000000 \quad 000000$

000005

000389

000002

000002000003

000006

$000912 \quad 000255$

000003

000000

$000001 \quad 000003$

$\begin{array}{llllll}000016 & 000011 & 000026 & 000061 & 000168 & 000290\end{array}$

000096

000009000015

000028

000001

000001

000001

000001000006

000000

000008

$000001 \quad 000002$

000031

000074

000131

000275

000505

000356

000385

$000001 \quad 000004$

$000001 \quad 000001$

000001

000001

000000

000002

000000

000274

$000121 \quad 000066$

000009

000011

000035

000057

000083

000226

$000000 \quad 000000$

000027

000005

000000

000000

000000

000000

$000000 \quad 000000$

$000000 \quad 000000$

000000

000000

000000

000000

000000

000000

000000

000000

000000

000000

000000

000000

000000

000000

000000

0101

000000

000000

000000

000000

000000

000000

000000

000000

000000

000000

000000

000000

000000

000000

000000

000000

000000

000000

000000

000000

000000

$000000 \quad 000000$

000000

000000

000000

000000

$000000 \quad 000000$

000000000000

000000

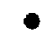

$\bullet$

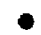

$000000 \quad 000000 \quad 000000 \quad 000000 \quad 000000$

$000000 \quad 000000 \quad 000000$

$000000 \quad 000000 \quad 000000$

$000000 \quad 000000 \quad 000000$

000000

000000

000000

000000

000000

000000

000000

$000000 \quad 000000$

000000000000

000000

000000

000000

000000

000000

000000

000000

000000

000000

000000

000000 


\begin{tabular}{|c|c|c|c|c|c|c|c|c|c|}
\hline 1 & $m$ & 000000 & 000000 & 000000 & 000000 & 000000 & 100000 & 000000 & 000001 \\
\hline 000000 & 000000 & 000000 & 000000 & 000000 & 000000 & 000000 & 000000 & 000000 & 000000 \\
\hline 000000 & 000000 & 000000 & 000000 & 000000 & 000000 & 000000 & 000000 & 000000 & 100001 \\
\hline 000001 & 000000 & 000000 & 0000 & 0000 & 000 & & 000 & 000000 & 000000 \\
\hline 000000 & 000000 & 000000 & 000000 & & 0000 & 000 & 000 & 000 & 000000 \\
\hline 000000 & 000000 & 000000 & 000000 & 000001 & 000000 & 000 & 000 & 000 & 000000 \\
\hline 000000 & 000000 & 00000 & 000000 & 0000 & 000 & & 000 & 000 & 000000 \\
\hline 000000 & 000000 & 000000 & 000000 & 000000 & 0000 & & 000000 & 0000 & 000000 \\
\hline 000000 & 000000 & 000000 & 000000 & 000000 & 000000 & 000000 & 000000 & 000000 & 000000 \\
\hline 000000 & 000000 & 000000 & 000000 & 000000 & & & & & \\
\hline
\end{tabular}

[Turn playback control off; press $C T R L / C$ ]

EXIT TEXT MODE

NOSORT

PACK

PACK COMPLETE.

NORMAL

/REPLACE

The structure of the data file is defined in detail in section E.1.a. Refer to page 19 for its description.

Use a text editor to verify the data file, as shown in the following example.

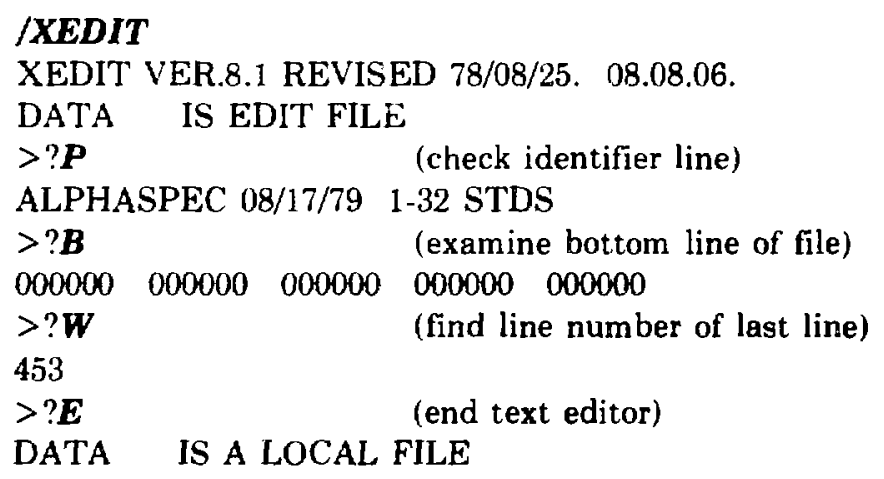

The data file should consist of an identification line, followed by 452 lines of data, for a total file length of 453 lines. The last data line may be omitted without adverse effects on the program's execution. If the file is less than 453 lines for any other reason, or if it is greater than 453 lines, the DATA file should be considered unreliable and it should be reentered in its entirety.

(C) Execute the alpha spectrometer calibration procedure by following the sequence below.

/RFL, 600000

RFL, 60000 .

/ATTACH,LGO

/ATTACH,PASLIB/UN=LIBRARY

IGET,DATA,DETDATA

/LGO(,X, Y,DATA,DETDATA) 
PLACE AN X UNDER THE DESIRIBD ANALYSIS

$\begin{array}{llllll}\text { A } & \text { A } & \text { A } & \text { T } & \text { G } & \text { S } \\ \text { L } & \text { L } & \text { L } & \text { R } & \text { R } & \text { R } \\ \text { P } & \text { P } & \text { P } & \text { I } & \text { O } & - \\ \text { H } & \text { H } & \text { H } & \text { T } & \text { S } & 9 \\ \text { A } & \text { A } & \text { S } & \text { I } & \text { S } & \text { O } \\ \text { S } & \text { B } & \text { C } & \text { U } & \text { G } & \\ \text { P } & \text { E } & \text { A } & \text { M } & \text { A } & \\ \text { E } & \text { T } & \text { L } & & \text { M } & \\ \text { C } & \text { A } & & & & \end{array}$

$? \stackrel{X}{\text { COUNTDATE }=}$
$? 08 / 17 / 79$
PEAK IDENTIFICATION PRO

\section{PEAK IDENTIFICATION PROBLEM AT DETECTOR 5}

PEAK IDENTIFICATION PROBLEM AT DETECTOR 16

PEAK IDENTIFICATION PROBLEM AT DETECTOR 32

All necessary counting parameters are obtained from internal program tables or from the supporting files DETDATA and BKGDFL; thus only the counting date is requested. Program output will commence at this pcint.

Any diagnostics output by the program will immediately follow the "COUNTDATE" query. In the example case, the procedure was unable to construct valid calibration parameters for detectors $4,5,16.32$, so the warnings "PEAK IDENTIFICATION PROBLEM AT DETECTOR - . -" were issued. Referring to the spectrai listings (Figs. 15 through 18), the reader will notice that the alpha peaks from detector 4 were poorly resolved and no counting data were collected for detectors 5,16 , and 32 .

(D) Collect the output. The output generated from the exaniple sequence discussed in this section is shown in Figs. 15 through 19.

Figures 15 through 18 are listings of the calibration counting data. The data are listed in columns by detector number. Three alpha peaks should be visible for each functioning detector; from page top to page bottom they are ${ }^{212} \mathrm{Pu},{ }^{230} \mathrm{Pu}$ and ${ }^{241} \mathrm{Am}$, respectively. Note that for detectors 5,16 , and 32 , there are no calibration data listed. This indicates "dead" detectors and consequently no calibration information will be entered in the DETDATA file for these positions.

Figure 19 is a summary of the calibration information that was derived from the $D$. iTA file. The "OLD DATA" column gives a true/false indicator as to whether or not the detector parameters were copied over from a previous calibration run. Under some circumstances the calibration procedure will conclude that the data from the current run ere inconsistent and it will retain the previous calibration parameters in the DETDATA file with the OLD DATA flag set to true. The "RESOLUTION" column gives the full width at half maximum (FWHM) alpha resolution in $\mathrm{keV}$ for each detector as measured at the ${ }^{242} \mathrm{Pu}$ alpha energy. The "EFFICIENCY" column lists the alpha detection efficiency in counts/disintegration based on the ${ }^{202} \mathrm{Pu}$ alpha measurement. "KEV/CH" refers to the energy scale for each detector in terms of keV per channel. The table of laading edge channels is a listing of the peak leading edges determined for the three isotopes in the calibration standards, and an extrapolation to predict the leading edge channels for the other isotopes of interest. 


\begin{tabular}{|c|c|c|c|c|c|c|c|c|c|c|}
\hline \multirow[b]{2}{*}{$\mathrm{CH}$} & \multicolumn{9}{|c|}{ DETECTOR NUMBER } & \multirow{2}{*}{$\begin{array}{c}\text { DA? } \\
10\end{array}$} \\
\hline & 1 & 2 & 3 & 4 & 5 & 6 & 7 & 8 & 9 & \\
\hline 10 & 3 & 2 & 0 & 38 & 0 & 0 & 2 & 7 & 2 & \\
\hline 11 & 5 & 1 & 1 & 65 & 0 & 3 & 5 & 4 & 1 & \\
\hline 12 & 2 & 1 & 2 & 71 & 0 & 1 & 4 & 4 & 1 & \\
\hline 13 & 2 & 3 & 2 & 80 & 0 & 3 & 12 & 5 & 1 & \\
\hline 14 & 3 & 10 & 2 & 77 & 0 & 5 & 14 & 6 & 1 & \\
\hline 15 & 16 & 9 & 3 & 91 & 0 & 2 & 42 & 8 & 5 & 14 \\
\hline 16 & 11 & 20 & 7 & 115 & 0 & 5 & 121 & 27 & 5 & 42 \\
\hline 17 & 26 & 44 & 9 & 179 & 0 & 22 & 225 & 69 & 11 & 73 \\
\hline 18 & 61 & 128 & 18 & 254 & 0 & 30 & 408 & 176 & 19 & 189 \\
\hline 19 & 168 & 271 & 77 & 291 & 0 & 97 & 700 & 310 & 19 & 345 \\
\hline 20 & 290 & 439 & 318 & 470 & 0 & 251 & 1003 & 567 & 203 & 732 \\
\hline 21 & 389 & 775 & 455 & 550 & 0 & 381 & 961 & 861 & 274 & 983 \\
\hline 22 & 896 & 1007 & 802 & 260 & 0 & 712 & 484 & 1022 & 489 & 988 \\
\hline 23 & 912 & 529 & 1644 & 130 & 0 & 1080 & 219 & 551 & 1020 & 558 \\
\hline 24 & 255 & 149 & 948 & 117 & 0 & 717 & 68 & 190 & 805 & 224 \\
\hline 25 & 28 & 28 & 97 & 94 & 0 & 160 & 14 & 42 & 100 & 35 \\
\hline 26 & 1 & 5 & 3 & 117 & 0 & 7 & 2 & 3 & 2 & 4 \\
\hline 27 & 1 & 1 & 1 & 93 & 0 & 0 & 1 & 0 & 0 & 3 \\
\hline 28 & 1 & 2 & 0 & 83 & 0 & 0 & 3 & 0 & 1 & 1 \\
\hline 29 & 1 & 1 & 0 & 78 & 0 & 1 & 2 & 0 & 1 & 1 \\
\hline 30 & 6 & 2 & 0 & 77 & 0 & 0 & 5 & 2 & 1 & 5 \\
\hline 31 & 6 & 4 & 2 & 89 & 0 & 2 & 13 & 5 & 3 & 6 \\
\hline 32 & 5 & 4 & 2 & 79 & 0 & 4 & 41 & 5 & 3 & 11 \\
\hline 33 & 9 & 13 & 7 & 120 & 0 & 3 & 90 & 10 & 4 & 49 \\
\hline 34 & 15 & 40 & 13 & 164 & 0 & 5 & 184 & 41 & 7 & 117 \\
\hline 35 & 31 & 90 & 39 & 219 & 0 & 26 & 256 & 106 & 13 & 216 \\
\hline 36 & 74 & 153 & 84 & 321 & 0 & 52 & 459 & 164 & 52 & 396 \\
\hline 37 & 131 & 319 & 158 & 242 & 0 & 94 & 541 & 335 & 98 & 485 \\
\hline 38 & 275 & 534 & 319 & 128 & 0 & 128 & 352 & 483 & 203 & 401 \\
\hline 39 & 505 & 372 & 806 & 88 & 0 & 363 & 160 & 474 & 474 & 192 \\
\hline 40 & 356 & 151 & 519 & 79 & 0 & 532 & 55 & 197 & 469 & 52 \\
\hline 41 & 96 & 37 & 72 & 77 & 0 & 343 & 20 & 69 & 112 & 11 \\
\hline 42 & 8 & $B$ & 1 & 66 & 0 & 74 & 1 & 28 & 6 & 1 \\
\hline 43 & 1 & 0 & 0 & 67 & 0 & 8 & 0 & 2 & 0 & : \\
\hline 44 & 2 & 0 & 0 & 46 & 0 & 0 & 9 & 1 & 0 & 1 \\
\hline 45 & 1 & 1 & 0 & 61 & 0 & 0 & 0 & 1 & 0 & 0 \\
\hline 46 & 1 & 0 & 0 & 42 & 0 & 0 & 0 & 1 & 1 & 3 \\
\hline 47 & 1 & 0 & 0 & 54 & 0 & 0 & 0 & 0 & 2 & 1 \\
\hline 48 & 1 & 3 & 0 & 55 & 0 & 0 & 0 & 2 & 0 & 2 \\
\hline 49 & 0 & 0 & 1 & 51 & 0 & 1 & 1 & 0 & 0 & 2 \\
\hline 50 & 2 & 1 & 0 & 60 & 0 & 0 & 2 & 0 & 1 & 3 \\
\hline 51 & 0 & 2 & 1 & 54 & 0 & 0 & 5 & 2 & 1 & 4 \\
\hline 52 & 2 & 3 & 2 & 64 & 0 & 0 & 8 & 1 & 3 & 18 \\
\hline 53 & 1 & 4 & $\theta$ & 66 & 0 & 1 & 17 & 4 & 2 & 36 \\
\hline 54 & 4 & 10 & 10 & 75 & 0 & 1 & 30 & 10 & 3 & 45 \\
\hline 55 & 9 & 14 & 11 & 110 & 0 & 6 & 75 & 12 & 4 & 133 \\
\hline 56 & 11 & 37 & 16 & 167 & 0 & 6 & 160 & 31 & 16 & 268 \\
\hline 57 & 35 & 69 & 61 & 182 & 0 & $\mathbf{q}$ & 251 & 66 & 39 & 331 \\
\hline 58 & 57 & 139 & 125 & 150 & 0 & 33 & 391 & 167 & 67 & 404 \\
\hline 59 & 83 & 289 & 261 & 82 & 0 & 58 & 345 & 274 & 100 & 240 \\
\hline 60 & 226 & 336 & 549 & 54 & 0 & 122 & 238 & 434 & 299 & 157 \\
\hline 61 & 385 & 202 & 388 & 52 & 0 & 261 & 134 & 353 & 375 & 67 \\
\hline 62 & 274 & 107 & 158 & 33 & 0 & 396 & 64 & 170 & 176 & 31 \\
\hline 63 & 121 & 54 & 90 & 29 & 0 & 275 & 24 & 109 & 85 & 5 \\
\hline 64 & 66 & 18 & 38 & 26 & 0 & 130 & 10 & 42 & 53 & C \\
\hline 65 & 27 & 8 & 6 & 22 & 0 & 65 & 3 & 7 & 6 & 0 \\
\hline 66 & 5 & 2 & 0 & 13 & 0 & 32 & 0 & 7 & 0 & 0 \\
\hline 67 & 0 & 0 & 0 & 22 & 0 & 7 & 0 & 1 & 0 & 0 \\
\hline 68 & 0 & 0 & 0 & 12 & 0 & 1 & 0 & 0 & 0 & 0 \\
\hline 69 & 0 & 0 & 0 & 18 & 0 & 0 & 0 & 0 & 0 & 0 \\
\hline 70 & 0 & 0 & 0 & 14 & 0 & 0 & 0 & 0 & 0 & 0 \\
\hline
\end{tabular}

Fig. 15.

Alpha spectrometer calibration procedure output-spectrum listing. 


\begin{tabular}{|c|c|c|c|c|c|c|c|c|c|c|c|}
\hline \multirow[b]{2}{*}{$\mathrm{CH}$} & \multicolumn{9}{|c|}{ DETECTOR NUMBER } & \multicolumn{2}{|c|}{ DATE $=08 / 17 / 79$} \\
\hline & 11 & 12 & 13 & 14 & 15 & 16 & 17 & 18 & 19 & 20 & \\
\hline 10 & 3 & 2 & 2 & $\mathbf{5}$ & 4 & 0 & 0 & 1 & 2 & o & \\
\hline 11 & 2 & 0 & 2 & 4 & 1 & 0 & 3 & 2 & 0 & 0 & \\
\hline 12 & 4 & 3 & 6 & 7 & 4 & 0 & 5 & 1 & 2 & 2 & \\
\hline 13 & 2 & 5 & 5 & 11 & 3 & 0 & 5 & 1 & 3 & 3 & \\
\hline 14 & 2 & 5 & 8 & 9 & 3 & 0 & 8 & 2 & 2 & 4 & \\
\hline 15 & 6 & 7 & 12 & 18 & B & 0 & 9 & 5 & 2 & 9 & \\
\hline 16 & $\epsilon$ & 22 & 17 & 22 & 18 & 0 & 19 & 6 & 12 & 22 & \\
\hline 17 & 8 & 67 & 42 & 61 & 30 & 0 & 22 & 29 & 11 & 59 & \\
\hline 18 & 25 & I55 & 130 & 135 & 55 & 0 & 69 & 65 & 40 & 179 & \\
\hline 19 & 90 & 295 & 254 & 209 & 134 & 0 & 169 & 233 & 143 & 348 & \\
\hline 20 & 247 & 527 & 478 & 360 & 222 & 0 & 320 & 377 & 391 & 548 & \\
\hline 21 & 462 & 900 & 789 & 699 & 415 & 0 & 533 & 640 & 559 & 1042 & \\
\hline 22 & 814 & 902 & 980 & 826 & 580 & 0 & 906 & 1211 & 1273 & 1361 & \\
\hline 23 & 1586 & 497 & 577 & 592 & 501 & 0 & 909 & 1242 & 1744 & 691 & \\
\hline 24 & 964 & 171 & 173 & 195 & 240 & 0 & 479 & 467 & 627 & 172 & \\
\hline 25 & 109 & 20 & 13 & 22 & 49 & 0 & 105 & 60 & 49 & 19 & \\
\hline 26 & 3 & 5 & 1 & 2 & 6 & 0 & 11 & 1 & 2 & 1 & \\
\hline 27 & 0 & 0 & 3 & 4 & 1 & 0 & 1 & 0 & 0 & 5 & \\
\hline 28 & 0 & I & 5 & 7 & 0 & 0 & 3 & 0 & 1 & 3 & . \\
\hline 29 & 0 & 1 & 2 & 10 & 0 & 0 & 2 & 3 & 3 & 1 & \\
\hline 30 & 6 & 1 & 7 & 8 & 7 & 0 & 4 & 1 & 3 & 0 & \\
\hline 31 & 1 & 7 & 0 & 9 & 2 & 0 & 4 & 2 & 2 & 4 & \\
\hline 32 & 4 & 4 & 4 & 16 & 7 & 0 & 5 & 5 & 2 & 7 & \\
\hline 33 & 6 & 17 & 19 & 33 & 5 & 0 & 18 & 8 & $B$ & 15 & \\
\hline 34 & 11 & 36 & 38 & 56 & 18 & 0 & 37 & 19 & 16 & 41 & \\
\hline 35 & 46 & 81 & 88 & 139 & 34 & 0 & 78 & 43 & 78 & 88 & \\
\hline 36 & 104 & 149 & 191 & 253 & 71 & 0 & 143 & 87 & 115 & 194 & \\
\hline 37 & 148 & 338 & 369 & 502 & 147 & 0 & 301 & 187 & 255 & 402 & \\
\hline 38 & 473 & 453 & 506 & 853 & 300 & 0 & 482 & 420 & 600 & 661 & \\
\hline 39 & 826 & 415 & 332 & 853 & 294 & 0 & 460 & 728 & 853 & 512 & \\
\hline 40 & 453 & 206 & 100 & 430 & 167 & 0 & 194 & 486 & 411 & 200 & \\
\hline 41 & 51 & 66 & 14 & 88 & 47 & 0 & 40 & 156 & 39 & 42 & \\
\hline 42 & 5 & 6 & 0 & 8 & 3 & 0 & 2 & 22 & 0 & 1 & \\
\hline 43 & 1 & 0 & 2 & 3 & 2 & 0 & 0 & 2 & 0 & 1 & \\
\hline 44 & 1 & 0 & 0 & 0 & 1 & 0 & 0 & 1 & 0 & 1 & \\
\hline 45 & 0 & 0 & 0 & 1 & 0 & 0 & 1 & 1 & 0 & 2 & \\
\hline 46 & 0 & 0 & 3 & 2 & 1 & 0 & 1 & 2 & 0 & 0 & \\
\hline 47 & 1 & 0 & 2 & 3 & 0 & 0 & 1 & 0 & 0 & 1 & \\
\hline 48 & 1 & 0 & 3 & 0 & 0 & 0 & 1 & 1 & 0 & 0 & \\
\hline 49 & 1 & 1 & 1 & 4 & 0 & 0 & 0 & 0 & 2 & 1 & \\
\hline 50 & 0 & 2 & 5 & 4 & 0 & 0 & 3 & 1 & 0 & 2 & \\
\hline 51 & 5 & 1 & 5 & 4 & 0 & 0 & 4 & 2 & 1 & 3 & \\
\hline 52 & 3 & 5 & 6 & 6 & 1 & 0 & 7 & 0 & 4 & 1 & \\
\hline 53 & 7 & 5 & 12 & 10 & 6 & 0 & 6 & 3 & 4 & 6 & \\
\hline 54 & 15 & 7 & 16 & 16 & 4 & 0 & 23 & 3 & 8 & 9 & \\
\hline 55 & 13 & 16 & 29 & 27 & 9 & 0 & 29 & 9 & 13 & 14 & \\
\hline 56 & 40 & 24 & 61 & 27 & 19 & 0 & 54 & 16 & 30 & 40 & \\
\hline 57 & 94 & 58 & 140 & 72 & 32 & 0 & 121 & 29 & B3 & 87 & \\
\hline 58 & 145 & 128 & 284 & 140 & 81 & 0 & 285 & 63 & 151 & 192 & \\
\hline 59 & 431 & 250 & 394 & 238 & 151 & 0 & 376 & $12 B$ & 404 & 365 & \\
\hline 60 & 550 & 347 & 325 & 362 & 202 & 0 & 321 & 298 & 558 & 520 & \\
\hline 61 & 334 & 342 & 153 & 300 & 169 & 0 & 154 & 452 & 331 & 320 & \\
\hline 62 & 130 & 174 & 61 & 179 & 90 & 0 & 56 & 337 & 170 & 150 & \\
\hline 63 & 68 & 95 & 28 & 77 & 34 & 0 & 34 & 165 & 78 & 84 & \\
\hline 64 & 17 & 47 & 7 & 25 & 21 & 0 & 7 & 100 & 20 & 30 & \\
\hline 65 & 2 & 17 & 0 & 11 & 6 & 0 & 3 & 32 & 1 & 7 & \\
\hline 66 & 0 & 6 & 0 & 2 & 0 & 0 & 0 & 8 & 0 & 0 & \\
\hline 67 & 0 & 1 & 0 & 0 & 0 & 0 & 0 & 0 & 0 & 0 & \\
\hline 68 & 0 & 0 & 0 & 0 & 0 & 0 & 0 & 0 & 0 & 0 & \\
\hline 69 & 0 & 0 & 0 & 0 & 0 & 0 & 0 & 0 & 0 & 1 & \\
\hline 70 & 0 & 0 & 0 & 0 & 0 & 0 & 0 & 0 & 0 & 0 & \\
\hline
\end{tabular}

Fig. 16.

Alpho spectrometer calibration procedure output-spectrum listing. 


\begin{tabular}{|c|c|c|c|c|c|c|c|c|c|c|}
\hline \multirow[b]{2}{*}{$\mathrm{CH}$} & \multicolumn{8}{|c|}{ DETECTOR NUMBER } & \multicolumn{2}{|r|}{ DATE $=08 / 17 / 79$} \\
\hline & 21 & 22 & 23 & 24 & 25 & 26 & 27 & 28 & 29 & 30 \\
\hline 10 & 1 & 0 & 0 & 2 & 1 & 1 & 1 & 3 & 6 & 2 \\
\hline 11 & 1 & 4 & 0 & 2 & 2 & 2 & 2 & 2 & 3 & 2 \\
\hline 12 & 1 & 3 & 0 & 5 & 2 & 2 & 0 & 1 & 6 & 5 \\
\hline 13 & 1 & 8 & 0 & 3 & 4 & 3 & 2 & 2 & 4 & 2 \\
\hline 14 & 5 & 3 & 7 & 6 & 3 & 5 & 1 & 2 & 6 & 14 \\
\hline 15 & 2 & 8 & 5 & 9 & 7 & 7 & 5 & 2 & 8 & 12 \\
\hline 16 & 6 & 18 & 2 & 10 & 12 & 11 & 5 & 5 & 7 & 25 \\
\hline 17 & 10 & 8 & 3 & 27 & 4 & 8 & 12 & 6 & 15 & 44 \\
\hline 18 & 19 & 33 & 29 & 98 & 14 & 39 & 33 & 28 & 45 & 95 \\
\hline 19 & 58 & 73 & 104 & 230 & 73 & 146 & 111 & 116 & 160 & 188 \\
\hline 20 & 297 & 176 & 292 & 395 & 232 & 313 & 289 & 308 & 312 & 335 \\
\hline 21 & 345 & 295 & 502 & 591 & 330 & 467 & 449 & 493 & 558 & 547 \\
\hline 22 & 627 & 439 & 820 & 1090 & 619 & 883 & 879 & 1075 & 997 & 880 \\
\hline 23 & 1248 & 938 & 1534 & 1166 & 1061 & 1629 & 1381 & 1227 & 1164 & 826 \\
\hline 24 & 935 & 732 & 1010 & 465 & 494 & 1169 & 963 & 380 & 352 & 351 \\
\hline 25 & 237 & 101 & 179 & 73 & 33 & 285 & 198 & 23 & 33 & 96 \\
\hline 26 & 16 & 3 & 14 & 5 & 1 & 22 & 11 & 0 & 1 & 8 \\
\hline 27 & 1 & 0 & 1 & 1 & 3 & 0 & 1 & 2 & 5 & 4 \\
\hline 28 & 0 & 1 & 2 & 2 & 1 & 1 & 0 & 1 & 4 & 4 \\
\hline 29 & 0 & 5 & 2 & 1 & 0 & 0 & 1 & 2 & 1 & 6 \\
\hline 30 & 2 & 5 & 2 & 3 & 2 & 2 & 1 & 1 & 5 & 9 \\
\hline 31 & 3 & 4 & 2 & 1 & 2 & 3 & 3 & 1 & 3 & 12 \\
\hline 32 & 2 & 7 & 7 & 3 & 2 & 1 & 4 & 5 & 6 & 17 \\
\hline 33 & 6 & 5 & 3 & 3 & 2 & 5 & 5 & 9 & 12 & 30 \\
\hline 34 & 11 & 12 & 5 & 10 & 10 & 7 & 9 & 30 & 51 & 74 \\
\hline 35 & 49 & 29 & 24 & 37 & 26 & 8 & 34 & 74 & 89 & 139 \\
\hline 36 & 113 & 71 & 79 & 81 & 74 & 32 & 78 & 125 & 163 & 307 \\
\hline 37 & 188 & 99 & 126 & 126 & 141 & 82 & 169 & 293 & 415 & 564 \\
\hline 38 & 440 & 243 & 305 & 263 & 241 & 149 & 387 & 611 & 639 & 864 \\
\hline 39 & 635 & 465 & 668 & 541 & 578 & 314 & 692 & 510 & 306 & 895 \\
\hline 40 & 333 & 364 & 712 & 571 & 383 & 655 & 561 & 129 & 46 & 451 \\
\hline 41 & 74 & 68 & 223 & 335 & 74 & 759 & $\mathbf{3 7 2}$ & 6 & 2 & 116 \\
\hline 42 & 7 & 0 & 32 & 73 & 1 & 316 & 17 & 2 & 2 & 18 \\
\hline 43 & 0 & 0 & 3 & 7 & 0 & 30 & 2 & 0 & 2 & 1 \\
\hline 44 & 0 & 0 & 1 & 0 & 0 & 3 & 0 & 0 & 0 & 1 \\
\hline 45 & 0 & 1 & 1 & 1 & 1 & 1 & 0 & 1 & 0 & 1 \\
\hline 46 & 1 & 0 & 0 & 1 & 1 & 0 & 0 & 1 & 0 & 2 \\
\hline 47 & 0 & 2 & 2 & 1 & 0 & 1 & 0 & 1 & 0 & 1 \\
\hline 48 & 1 & 0 & 1 & 0 & 0 & 0 & 2 & 1 & 0 & 2 \\
\hline 49 & 1 & 2 & 0 & 1 & 1 & 0 & 1 & 1 & 4 & 2 \\
\hline 50 & 2 & 1 & 0 & 1 & 2 & 1 & 0 & 1 & 4 & 0 \\
\hline 51 & 1 & 3 & 2 & 1 & 1 & 2 & 1 & 2 & 3 & 5 \\
\hline 52 & 1 & 11 & 1 & 1 & 1 & 3 & 4 & 5 & 12 & 6 \\
\hline 53 & 9 & 4 & 2 & 3 & 1 & 2 & 6 & 6 & 14 & 11 \\
\hline 54 & 4 & 7 & 10 & 6 & 3 & 2 & 6 & 9 & 28 & 20 \\
\hline 55 & 19 & 10 & 8 & 4 & 5 & 5 & 15 & 19 & 49 & 29 \\
\hline 56 & 46 & 31 & 19 & 8 & 11 & 7 & 17 & 64 & 116 & 60 \\
\hline 57 & $10^{7}$ & 52 & 32 & 11 & 29 & 9 & 58 & 102 & 288 & 106 \\
\hline 58 & 231 & 100 & 78 & 30 & 65 & 19 & 101 & 276 & 475 & 213 \\
\hline 59 & 456 & 201 & 168 & 74 & 145 & 32 & 230 & 513 & 358 & 370 \\
\hline 60 & 371 & 384 & 342 & $\mathbf{1 1 6}$ & 353 & ติ & 505 & 327 & 129 & 365 \\
\hline 61 & 169 & 244 & 553 & 257 & 394 & 131 & 512 & 130 & 56 & 270 \\
\hline 62 & 84 & 119 & 351 & 474 & 191 & 257 & 246 & 81 & 30 & 117 \\
\hline 63 & 43 & 51 & 151 & 415 & 76 & 586 & 108 & 23 & 6 & 56 \\
\hline 64 & 6 & 19 & 82 & 195 & 33 & 508 & 38 & 2 & 0 & 26 \\
\hline 65 & 1 & 2 & 28 & 90 & 13 & 227 & 18 & 0 & 0 & 4 \\
\hline 66 & 0 & 0 & 2 & 37 & 2 & 117 & 2 & 0 & 0 & 1 \\
\hline 67 & 0 & 0 & 0 & 12 & 0 & 74 & 1 & 0 & 0 & 0 \\
\hline 68 & 0 & 0 & 0 & 4 & 0 & 21 & 0 & 0 & 1 & 0 \\
\hline 69 & 0 & 0 & 0 & 0 & 0 & 3 & 0 & 0 & 0 & 0 \\
\hline $7 r$ & 0 & 0 & 0 & 1 & 0 & 0 & 0 & 0 & 0 & 0 \\
\hline
\end{tabular}

Fig. 17.

Alpha spectrometer calibration procedure output-spectrum listing. 


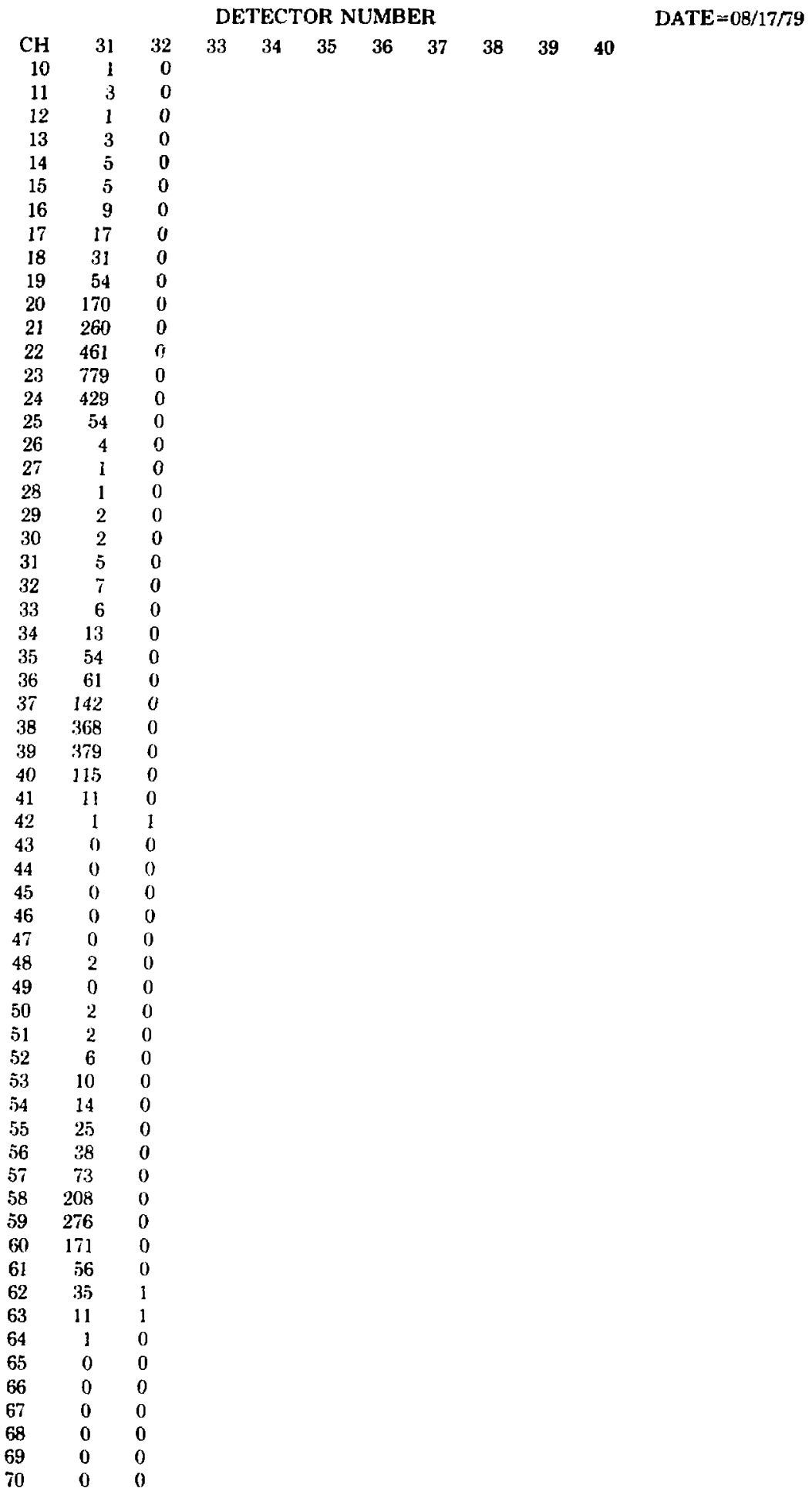

Fig. 18.

Alpha spectrometer calibretion procedure output-spectrum ïsting. 


\begin{tabular}{|c|c|c|c|c|c|c|c|c|c|c|c|c|}
\hline $\begin{array}{l}\text { DET } \\
\text { NO. }\end{array}$ & $\begin{array}{c}\text { OLD } \\
\text { DATA }\end{array}$ & $\begin{array}{l}\text { RESOL } \\
\text { UTION }\end{array}$ & $\begin{array}{l}\text { EFFIC } \\
\text { IENCY }\end{array}$ & $\begin{array}{c}\mathrm{KEV} \\
\mathrm{CH}\end{array}$ & PU242 & PU239 & PIj238 & PU236 & AM243 & AM241 & PO210 & P0208 \\
\hline 1 & FALSE & 38.6 & 0.155 & 15.06 & 26 & 43 & 66 & 84 & 51 & 66 & 53 & 40 \\
\hline 2 & FALSE & 43.3 & 0.151 & 15.06 & 26 & 43 & 66 & 84 & 51 & 66 & $\mathbf{5 3}$ & 40 \\
\hline 3 & FALSE & 34.0 & 0.167 & 16.00 & 26 & 42 & 63 & 80 & 50 & 63 & 51 & 39 \\
\hline 4 & FALSE & 0 & 0 & 0 & 0 & 0 & 0 & 0 & 0 & 0 & 0 & 0 \\
\hline 5 & FALSE & 0 & 0 & 0 & 0 & 0 & 0 & 0 & 0 & 0 & 0 & 0 \\
\hline 6 & FALSE & $4(1.4$ & 0.163 & 14.22 & 26 & 44 & 68 & 87 & 53 & 68 & 54 & 41 \\
\hline 7 & FALSE & 58.1 & 0.171 & 16.00 & 26 & 42 & 63 & 80 & 50 & 63 & 51 & 39 \\
\hline 8 & FALSE & 50.1 & 0.149 & 15.06 & 26 & 43 & 66 & 84 & 51 & 66 & $5 ;$ & 40 \\
\hline 9 & FALSE: & 35.8 & 0.174 & 15.06 & 26 & 43 & 66 & 84 & 51 & 66 & 5.3 & 40 \\
\hline 10) & FAISSE: & 60.9 & 0.167 & 16.00 & 26 & 42 & 63 & 80 & 50 & 63 & 51 & 39 \\
\hline 11 & FALSE & 36.2 & 0.171 & 16.00 & 26 & 42 & 63 & 80 & 50 & 63 & 51 & 39 \\
\hline 12 & FALSE & 52.2 & 0.168 & 15.06 & 26 & 48 & 66 & 84 & 51 & 66 & 53 & 40 \\
\hline 13 & FALSE & 50.8 & 0.177 & 16.00 & 26 & 42 & 63 & 80 & 50 & 63 & 51 & 39 \\
\hline 14 & FALSE; & 52.7 & 0.138 & 16.00 & 26 & 42 & 63 & 80 & 50 & 63 & 51 & 39 \\
\hline 15 & FALSE: & 55.3 & 0.156 & 16.00 & 27 & 43 & 64 & 81 & 51 & 64 & 52 & 40 \\
\hline 16 & FALSE & 0 & 0 & 0 & 0 & 0 & 0 & 1 & 0 & 0 & 0 & 0 \\
\hline 17 & FALSE & 58.6 & 0.180 & 17.07 & 27 & 42 & 62 & 78 & 49 & 62 & 51 & 39 \\
\hline 18 & FALSE & $4: 3.4$ & 0.192 & 15.06 & 26 & 43 & 66 & 84 & 51 & 66 & 53 & 40 \\
\hline 19 & FAI_SE & 37.5 & 0.185 & 16.00 & 26 & 42 & 63 & 80 & 50 & 63 & 51 & 39 \\
\hline 20 & FALSE & 44.0 & 0.173 & 16.00 & 26 & 42 & 63 & 80 & 50 & 63 & 51 & 39 \\
\hline 21 & FALSE: & 39.3 & 0.229 & 16.00 & 27 & 43 & 64 & 81 & 51 & 64 & 52 & 40 \\
\hline 22 & FALSE & 37.7 & 0.132 & 16.00 & 26 & 42 & 63 & 80 & 50 & 63 & 5i & 39 \\
\hline 23 & FALSE & 37.0 & 0.180 & 15.06 & 26 & 43 & 66 & 84 & 51 & 66 & 53 & 40 \\
\hline 24 & FALSE & 40.9 & 0.162 & 14.22 & 26 & 44 & 68 & $B 7$ & 53 & 68 & 54 & 41 \\
\hline 25 & FALSE & 35.9 & 0.167 & 16.00 & 26 & 42 & 63 & 80 & 50 & 63 & 51 & 39 \\
\hline 26 & FALSE & $: 38.6$ & 0.198 & 15.06 & 27 & 44 & 67 & 85 & 52 & 67 & 54 & 41 \\
\hline $2 \pi$ & FALSE & 42.1 & 0.172 & 15.06 & 26 & 43 & 66 & 84 & 51 & 66 & 53 & 40 \\
\hline 28 & FALSE & 40.3 & 0.171 & 16.00 & 26 & 42 & 63 & 80 & 50 & 63 & 51 & 39 \\
\hline 29 & FALSE & 45.4 & 0.186 & 17.07 & 26 & 41 & 61 & 77 & 48 & 61 & 50 & 38 \\
\hline 30 & FALSE & 50.0 & 0.149 & 15.06 & 26 & 43 & 66 & 84 & 51 & 66 & 5.3 & 40 \\
\hline $3 \mathrm{i}$ & EALSE & 39.4 & 0.157 & 16.00 & 26 & 42 & 63 & 80 & 50 & 63 & 51 & 39 \\
\hline is 2 & FALSE & $\theta$ & 0 & 0 & 0 & 0 & 0 & 0 & 0 & 0 & 0 & 0 \\
\hline
\end{tabular}

Fig. 19.

Alpha spectrometer calibration procedure output-detector performance summary.

Note that " 0 " (zero) entries are present for those detectors $(4,5,16$, and 32) where the calibration data suggested that it was unfit for routine use.

(E) Sign off.

/BYE

900027 LOG OFF 11.27.21.

900027 SRU 89.465 UNTS.

\section{Alpha Spectrometer Background Analysis Program}

a. Overview. Program BKGD2 is an adaptation of the alpha spectrometer background program written by Stewart Lombard in 1973. It is written in FORTRAN and was converted in 1975 by W. E. Goode to run interactively. 
Background counting data are generated by counting a set of "blank" samples in the alpha spectroscopy system. The counting data are then transferred via a cassette tape to the file CTDAT.* The background analysis program reads the CTDAT file and combines it with the data entered for the previous three BKGD2 runs to arrive at an average background for each channel of the 4095 channel spectrum over the four run period. The averaged spectrum is then written to the file BKGDFL for subsequent use by the alpha spectral analysis procedure of MASTERCALC.

\section{b. Procedure}

(A) Sign on CCF machine $\mathrm{M}$.

<security passwrd>

idm $U<$ znumbr $>$

79/08/14. 14.45 .08 .

LASL $6600-00$ (2*ACTUAL CP TIME) NOS1.3-485C 790813

USER NUMBER: <usrnbr,pasewrd>

TERMINAL: 13 , TTY

RECOVER/SYSTEM:

Because the background analyses program both reads and writes files that are used by MASTERCALC, 900027 must be entered in the USRNBR position. Contact the person in charge of program MASTERCALC to obtain the current PASSWRD.

(B) Read the cassette tape containing the alpha spectral counting data into the DATA file. The DATA file may be created by following the steps:

(a) With the terminal in LOCAL mode, position the cassette tape at the beginning of the background counting data.

(b) Return the terminal to LINE mode and execute the following sequence.

NEW,CTDAT

/TAPE

TEXT

FNTER TEXT MODE.

[Turn playback control on]

ALPHì SPEC BACKGROUND 08/22/79

*Unlike file names used with MASTERCALC procedures, this file name is fixed and must be used explicitly. 


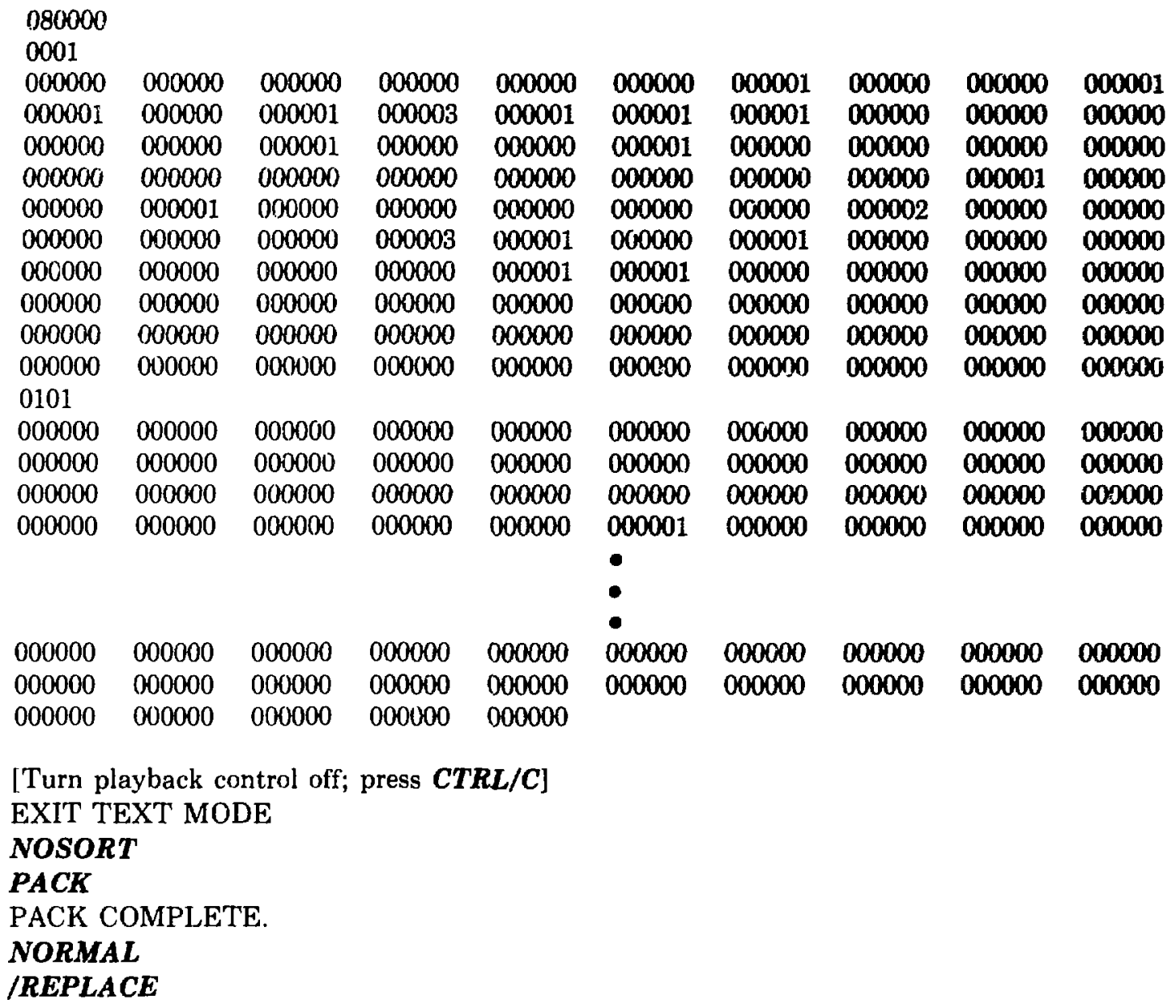

The structure of the counting data file is discussed in detail in section E.1.a. The reader may refer to page 19 for its description.

Use a text editor to examine the CTDAT file for obvious errors as shown in the following example.

\section{/XEDIT,CTDAT}

XEDIT VER.8.1 REVISED 78/08/25. 08.08.06.

CTDAT IS EDIT FILE

$>$ ?P

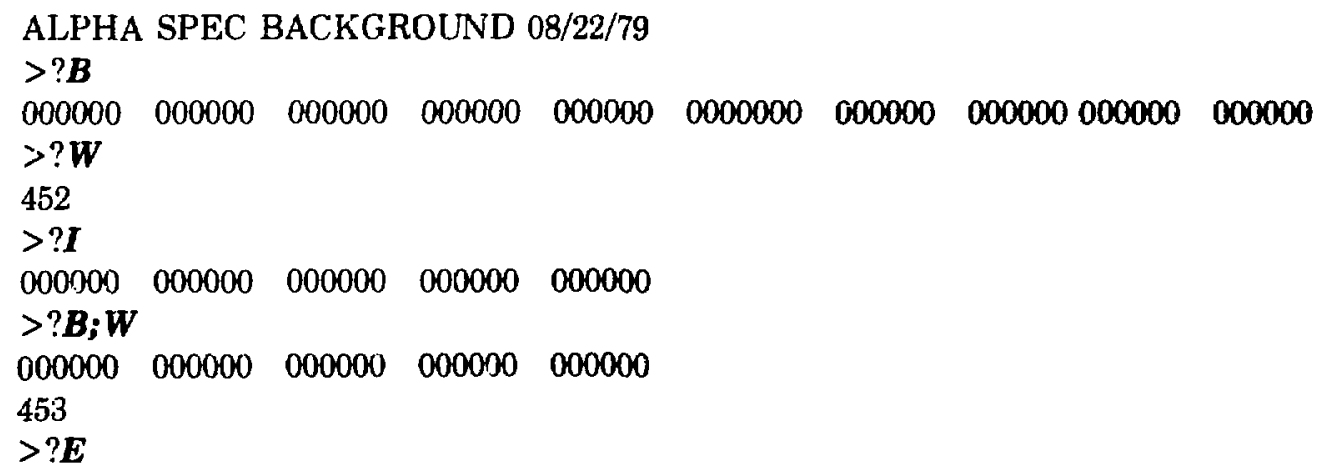


If the CTDA' file contains less than 453 lines for any reason other than the missing last line, or if the file is greater than 453 lines, it should be considered unreliable and should be reentered in its entirety.

(C) Execute the background analyses program by following the sequence below:

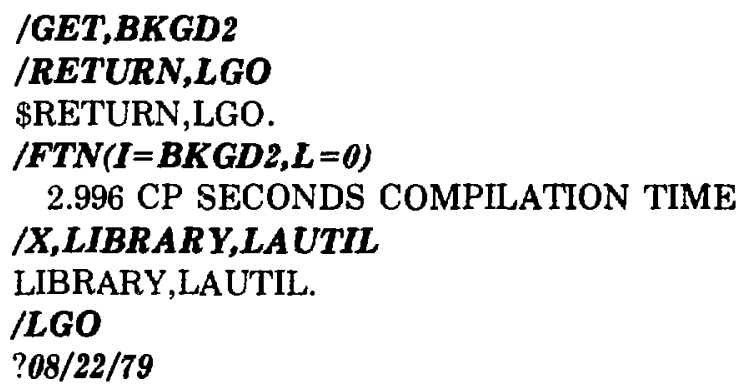

The only variable parameter supplied at execution time is the counting date. All other counting parameters are obtained automatically by the program. Program output will commence at this poin:.

(D) Collect the output.

A sample of the spectral listings from the background analysis program is shown in Figs. 20 and 21. The data are listed in terms of total count per channel for each alpha detector.

Figure 22 contains the background summary generated from the example sequence discussed thus far. The summary includes four weeks of background counting data; week 1 is the oldest, week 4 the most recent. Within each week, the estimated ${ }^{238} \mathrm{Pu},{ }^{238} \mathrm{Pu}$ and gross total (channels 1 to 128) background is computed for an 80000 second counting period. The "GRAND TOTAL" entry at the bottom of the table is the summation of all individual detector totals (or the total number of counts in 4095 channels). The user should find this information useful in assessing the contamination level of each detector, and, hence, it should provide some basis for scheduling detector usage and cleaning.

(E) Sign off. 


\begin{tabular}{|c|c|c|c|c|c|c|c|c|}
\hline \multirow[b]{2}{*}{$\mathrm{CH}$} & \multicolumn{8}{|c|}{ DETECTOR NUMBER } \\
\hline & 1 & 2 & 3 & 4 & $\mathbf{5}$ & 6 & & 8 \\
\hline 5 & 0 & 0 & 0 & 0 & 0 & 1 & 1 & 0 \\
\hline 6 & 0 & 0 & 0 & 0 & 0 & d] & & 1 \\
\hline 7 & 1 & 0 & 0 & 0 & 0 & 0 & 0 & 0 \\
\hline B & 0 & 1 & 0 & 0 & 0 & 1 & & 0 \\
\hline 9 & 0 & 0 & 1 & 0 & 0 & 0 & 1 & 1 \\
\hline 10 & 1 & 0 & 2 & 0 & 0 & 0 & & 0 \\
\hline 11 & 1 & 0 & 0 & 0 & 0 & I & 1 & $i$ \\
\hline 12 & 0 & 0 & 1 & 0 & 0 & 2 & 1 & 0 \\
\hline 13 & 1 & 0 & 0 & 0 & 0 & 0 & 1 & 1 \\
\hline 14 & 3 & 0 & 0 & 0 & 0 & 1 & 1 & 1 \\
\hline 15 & 1 & 0 & 0 & 0 & 0 & 0 & 0 & 0 \\
\hline 16 & 1 & 0 & 0 & 0 & 0 & i & 1 & 0 \\
\hline 17 & 1 & C & 0 & 1 & 0 & 1 & 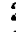 & 0 \\
\hline 18 & 0 & 0 & 1 & 1 & 0 & 1 & 0 & 0 \\
\hline 19 & 0 & 1 & 1 & 0 & 0 & 1 & 0 & 2 \\
\hline 20 & 0 & 0 & 0 & 0 & 0 & 1 & 0 & 0 \\
\hline 21 & 0 & 2 & 1 & 0 & 0 & 2 & 0 & 1 \\
\hline 22 & 0 & 0 & 1 & 0 & 0 & 0 & 1 & 0 \\
\hline 23 & 1 & 0 & 1 & 0 & 0 & 0 & 0 & 1 \\
\hline 24 & 0 & 0 & 0 & 1 & 0 & 0 & 0 & 0 \\
\hline 25 & 0 & 0 & 0 & 0 & 0 & 0 & 3 & 2 \\
\hline 26 & 1 & 0 & 0 & 0 & 0 & 0 & 3 & 0 \\
\hline 27 & 0 & 0 & 0 & 0 & 0 & 0 & 2 & 0 \\
\hline 28 & 0 & 2 & 0 & 0 & 0 & 0 & 1 & 0 \\
\hline 29 & 0 & 0 & 0 & 0 & 0 & 0 & 0 & 0 \\
\hline 30 & 0 & 0 & 0 & 1 & 0 & 0 & 0 & 0 \\
\hline 31 & 0 & 0 & 0 & 0 & 0 & 0 & 2 & 0 \\
\hline 32 & 0 & 0 & 0 & 0 & 0 & 1 & I & 0 \\
\hline 33 & 0 & 0 & 0 & 0 & 0 & 1 & 1 & 1 \\
\hline 34 & 0 & 0 & 0 & 0 & 0 & 0 & 1 & 0 \\
\hline 35 & 0 & 0 & 1 & 0 & 0 & 1 & 0 & 1 \\
\hline 36 & 0 & 1 & 1 & 0 & 0 & 1 & 0 & 1 \\
\hline 37 & 0 & 0 & 0 & 0 & 0 & 1 & 1 & 0 \\
\hline 38 & 0 & 0 & 0 & 1 & 0 & 0 & 0 & 1 \\
\hline 39 & 1 & 0 & 0 & 1 & 0 & 1 & 0 & 0 \\
\hline 40 & 0 & 0 & 0 & 0 & 0 & 0 & 1 & 0 \\
\hline 41 & 0 & 0 & 0 & 1 & 0 & 1 & 0 & 0 \\
\hline 42 & 1 & 0 & 0 & 2 & 0 & 1 & 0 & 0 \\
\hline 43 & 0 & 0 & 0 & 1 & 0 & 0 & 0 & 0 \\
\hline 44 & 0 & 0 & 0 & 0 & 0 & 0 & 0 & 0 \\
\hline 45 & 0 & 0 & 0 & 1 & 0 & 0 & 0 & 0 \\
\hline 46 & 0 & 0 & 1 & 1 & 0 & 0 & 1 & 0 \\
\hline 47 & 0 & 0 & 0 & 0 & 0 & 0 & 1 & 1 \\
\hline 48 & 2 & 0 & 0 & 0 & 0 & 0 & 0 & 0 \\
\hline 49 & 0 & 0 & 0 & 0 & 0 & 0 & 1 & 0 \\
\hline 50 & 0 & 0 & 0 & 0 & 0 & 0 & 0 & 0 \\
\hline 51 & 0 & 0 & 0 & 0 & 0 & 0 & 0 & 0 \\
\hline 52 & 0 & 0 & 0 & 0 & 0 & 1 & 2 & 0 \\
\hline 53 & 0 & 0 & 0 & 0 & 0 & 0 & 0 & 0 \\
\hline 54 & 3 & 1 & 0 & 0 & 0 & 0 & 0 & 0 \\
\hline 55 & 1 & 0 & 1 & 1 & 0 & 0 & 1 & 0 \\
\hline 56 & 0 & 0 & 0 & 0 & 1 & 1 & 0 & 1 \\
\hline 57 & 1 & 0 & 3 & 0 & 0 & 0 & 0 & 0 \\
\hline 58 & 0 & 0 & 1 & 0 & 0 & 0 & 0 & 2 \\
\hline 59 & 0 & 0 & 2 & 0 & 0 & 1 & 1 & 0 \\
\hline 60 & 0 & 0 & 0 & 1 & 0 & 0 & 0 & 0 \\
\hline G1 & 0 & 0 & 0 & 0 & 0 & 0 & 0 & 1 \\
\hline 62 & 0 & 0 & 0 & 0 & 0 & 0 & 0 & 0 \\
\hline 63 & 0 & 0 & 0 & 0 & 0 & 0 & 0 & 0 \\
\hline 64 & 0 & 0 & 0 & $n$ & 0 & 0 & 0 & 0 \\
\hline 65 & 1 & 1 & 0 & 1 & 0 & 0 & 0 & 0 \\
\hline
\end{tabular}

Fig. 20.

Background analysis program output-spectrum listing for Channels J-65. 
DETECTOR NUMBER

\begin{tabular}{|c|c|c|c|c|c|c|c|c|}
\hline $\mathrm{CH}$ & 1 & 2 & 3 & 4 & 5 & 6 & 7 & \\
\hline 65 & 1 & 2 & 0 & 1 & 0 & 0 & 0 & \\
\hline 66 & 1 & 0 & 0 & 0 & 0 & 0 & 0 & \\
\hline 67 & 0 & 0 & 0 & 0 & 0 & 0 & 0 & \\
\hline 68 & 0 & 0 & 1 & 0 & 0 & 0 & 0 & \\
\hline 69 & 0 & 0 & 0 & 0 & 0 & 0 & 0 & \\
\hline 70 & 0 & 0 & 0 & 0 & 0 & 0 & 1 & \\
\hline 71 & 0 & 0 & 0 & 1 & 0 & 0 & 0 & \\
\hline 72 & 0 & 0 & 0 & 0 & 0 & 0 & 0 & \\
\hline 73 & 0 & 0 & 0 & 0 & 0 & 0 & 0 & \\
\hline 74 & 0 & 0 & 0 & 0 & 0 & 0 & 0 & \\
\hline 75 & 0 & 0 & 1 & 0 & 0 & 0 & 0 & \\
\hline 76 & 0 & 0 & 0 & 0 & 0 & 0 & 0 & \\
\hline 77 & 0 & 0 & 0 & 0 & 0 & 0 & 0 & \\
\hline 78 & 0 & 0 & 0 & 0 & 0 & 0 & 0 & \\
\hline 79 & 0 & 0 & 0 & 0 & 0 & 0 & 0 & \\
\hline 80 & 0 & 0 & 0 & 0 & 0 & 1 & 0 & \\
\hline 81 & 0 & 0 & 0 & 0 & 0 & 0 & 0 & \\
\hline 82 & 0 & 0 & 0 & 0 & 0 & 0 & 0 & \\
\hline 83 & 0 & 0 & 0 & 0 & 0 & 0 & 0 & \\
\hline 84 & 0 & 0 & 0 & 0 & 0 & 0 & 0 & \\
\hline 85 & 0 & 0 & 0 & 0 & 0 & 0 & 0 & \\
\hline 86 & 0 & 0 & 0 & 0 & 0 & 0 & 0 & \\
\hline 87 & () & 0 & 0 & 0 & 0 & 0 & 0 & \\
\hline 88 & 0 & 0 & 0 & 0 & 0 & 0 & 0 & \\
\hline 89 & 0 & 0 & 0 & 0 & 0 & 0 & 0 & \\
\hline 90 & 0 & 0 & 0 & 0 & 0 & 0 & 0 & \\
\hline 91 & 0 & 0 & 0 & 0 & 0 & 0 & 0 & \\
\hline 92 & 0 & 0 & 0 & 0 & 0 & 0 & 0 & 1 \\
\hline 93 & 0 & 0 & 0 & 0 & 0 & 0 & 0 & 0 \\
\hline 94 & 0 & 0 & 0 & 0 & 0 & 0 & 0 & 0 \\
\hline 95 & 0 & 0 & 1 & 0 & 0 & 0 & 0 & 0 \\
\hline 96 & 0 & 0 & 0 & 0 & 0 & 0 & 0 & ) \\
\hline 97 & 0 & 0 & 0 & 0 & 0 & 0 & 0 & 0 \\
\hline 98 & 0 & () & 0 & 0 & 0 & 0 & 0 & 0 \\
\hline 99 & 0 & 0 & 0 & 0 & 0 & 1 & 0 & 0 \\
\hline 100 & 0 & 0 & 0 & 0 & 0 & 0 & 0 & 0 \\
\hline 101 & 0 & 0 & 0 & 1 & 0 & 0 & 0 & 0 \\
\hline 102 & 0 & 0 & 0 & 0 & 0 & 0 & 0 & 0 \\
\hline 103 & 0 & 0 & 0 & 0 & 0 & 0 & 0 & 0 \\
\hline 104 & 0 & 0 & 0 & 0 & 0 & 0 & 0 & 0 \\
\hline 105 & 0 & 0 & 0 & 1 & 0 & 0 & 0 & 0 \\
\hline 106 & 0 & 0 & 1 & 0 & 0 & 0 & 0 & 0 \\
\hline 107 & 0 & 0 & 0 & 0 & 0 & 0 & 0 & 0 \\
\hline 108 & 0 & 0 & 0 & 0 & 0 & 0 & 0 & 0 \\
\hline 109 & 0 & 0 & 0 & 0 & 0 & 0 & 0 & 0 \\
\hline 110 & 0 & 0 & 0 & 0 & 0 & 0 & 0 & 0 \\
\hline 111 & 0 & 0 & 0 & 0 & 0 & 0 & 0 & 0 \\
\hline 112 & 0 & 0 & 0 & 0 & 0 & 1 & 0 & 0 \\
\hline 113 & 0 & 0 & 0 & 0 & 0 & 0 & 0 & 0 \\
\hline 114 & 0 & 0 & 0 & 0 & 0 & 0 & 0 & 0 \\
\hline 115 & 0 & 0 & 0 & 0 & 0 & 0 & 0 & 0 \\
\hline 116 & 0 & 0 & 0 & 0 & 0 & 0 & 0 & 0 \\
\hline 117 & 0 & 0 & 0 & 0 & 0 & 0 & 0 & 0 \\
\hline 118 & 0 & 0 & 0 & 0 & 0 & 0 & 0 & 0 \\
\hline 119 & 0 & 0 & 0 & 0 & 0 & 0 & 0 & 0 \\
\hline 120 & 0 & 0 & 0 & 0 & 0 & 0 & 0 & 0 \\
\hline 121 & 0 & 0 & 0 & 0 & 0 & 0 & 0 & 0 \\
\hline 122 & 0 & 0 & 0 & 1 & 0 & 1 & 0 & 0 \\
\hline 123 & 0 & 0 & 0 & 0 & 0 & 0 & 0 & 0 \\
\hline 124 & 0 & 0 & 0 & 0 & 0 & 0 & 0 & 0 \\
\hline 125 & 0 & 0 & 0 & 0 & 0 & 0 & 0 & 0 \\
\hline
\end{tabular}

Fig. 21.

Background analysis program output-spectrum listing for channels 65-125. 


\section{BACKGROUND SUMMARY}

\begin{tabular}{|c|c|c|c|c|c|c|c|c|c|c|c|c|}
\hline & & 1 & & & 2 & & & 3 & & & 4 & \\
\hline DET & 238 & 239 & TOT & 238 & 239 & TOT & 238 & 239 & TOT & 238 & 239 & TOT \\
\hline 1 & 4 & 2 & 29 & 4 & 1 & 27 & 5 & 2 & 23 & 5 & 2 & 23 \\
\hline 2 & 2 & 7 & 19 & 2 & 4 & 15 & 1 & 1 & 9 & 1 & 1 & 9 \\
\hline 3 & 12 & 4 & 32 & 8 & 6 & 25 & 7 & 2 & 23 & 7 & 2 & 23 \\
\hline 4 & 1 & 5 & 25 & 4 & 3 & 17 & 2 & 5 & 19 & 2 & 5 & 19 \\
\hline 5 & 0 & 0 & 0 & 0 & 0 & 0 & 0 & 1 & 0 & 2 & 1 & 0 \\
\hline 6 & 7 & 2 & 29 & 3 & 3 & 27 & 2 & 8 & 28 & 2 & 8 & 28 \\
\hline 7 & 2 & 19 & 50 & 7 & 16 & 42 & 2 & 5 & 35 & 2 & 5 & 35 \\
\hline 8 & 3 & 4 & 19 & 0 & 2 & 13 & 4 & 4 & 22 & 4 & 4 & 22 \\
\hline 9 & 5 & 7 & 30 & 10 & 6 & 36 & 3 & 7 & 23 & 3 & 7 & 23 \\
\hline 10 & 4 & 3 & 19 & 2 & 4 & 23 & 2 & 3 & 13 & 2 & 3 & 13 \\
\hline 11 & 1 & 2 & 19 & 4 & 1 & 13 & 2 & 3 & 12 & 2 & 3 & 12 \\
\hline 12 & 2 & 4 & 17 & 2 & 0 & 9 & 0 & 2 & 12 & 0 & 2 & 12 \\
\hline 13 & 5 & 5 & 30 & 0 & 3 & 14 & 2 & 3 & 16 & 2 & 3 & 16 \\
\hline 14 & 1 & 7 & 20 & 1 & 8 & 19 & 5 & 5 & 27 & 5 & 5 & 27 \\
\hline 15 & 2 & 5 & 32 & 4 & 1 & 29 & 5 & 5 & 29 & 5 & 5 & 29 \\
\hline 16 & 0 & 0 & 0 & 0 & 0 & 0 & 0 & 0 & 0 & 0 & 0 & 0 \\
\hline 17 & 4 & 0 & 10 & 4 & 2 & 13 & 3 & 1 & 11 & 3 & 1 & 11 \\
\hline 18 & 2 & 4 & 14 & 1 & 3 & 20 & 3 & 0 & 15 & 3 & 0 & 15 \\
\hline 19 & 6 & 6 & 20 & 7 & 4 & 22 & 4 & 5 & 31 & 4 & 5 & 31 \\
\hline 20 & 1 & 2 & 14 & 2 & 3 & 21 & 1 & 4 & 12 & 1 & 4 & 12 \\
\hline 21 & 1 & 4 & 14 & 0 & 1 & 11 & 0 & 1 & 10 & 0 & 1 & 10 \\
\hline 22 & 10 & 2 & 25 & 3 & 2 & 23 & 4 & 4 & 20 & 4 & 4 & 20 \\
\hline 23 & 3 & 3 & 19 & 4 & 7 & 21 & 5 & 2 & 17 & 5 & 2 & 17 \\
\hline 24 & 1 & 4 & 13 & 1 & 3 & 14 & 0 & 1 & 15 & 0 & 1 & 15 \\
\hline 25 & 3 & 3 & 16 & 5 & 2 & 19 & 5 & 2 & 19 & 5 & 2 & 19 \\
\hline 26 & 0 & 0 & 12 & 0 & 1 & 9 & 1 & 3 & 11 & 1 & 3 & 11 \\
\hline 27 & 5 & 0 & 18 & 2 & 1 & 11 & 3 & 1 & 10 & 3 & 1 & 10 \\
\hline 28 & 1 & 1 & 14 & 2 & 1 & 16 & 2 & 2 & 19 & 2 & 2 & 19 \\
\hline 29 & 5 & 2 & 26 & 9 & 2 & 26 & 5 & 5 & 17 & 5 & 5 & 17 \\
\hline 30 & 4 & 15 & 31 & 3 & 20 & 38 & 3 & 15 & 37 & 3 & 15 & 37 \\
\hline 31 & 4 & 105 & 137 & 2 & 95 & 120 & 6 & 85 & 135 & 6 & 85 & 135 \\
\hline 32 & 0 & $\begin{array}{r}0 \\
753\end{array}$ & 0 & 0 & $\begin{array}{r}0 \\
693\end{array}$ & 0 & 0 & $\begin{array}{r}0 \\
672\end{array}$ & 0 & 0 & $\begin{array}{r}0 \\
67 \%\end{array}$ & 0 \\
\hline
\end{tabular}

Fig. 22.

Background analysis program output-four week background summary. 


\section{REFERENCES}

1. Software Documentation, Group C-2, Los Alamos Scientific Laboratory, "Programmer's Information Manual," Vol. 4, August 1978, LA-5525-M, Los Alamos, New Mexico.

2. Control Data Corp., "NOS Version 1 Time Sharing User's Guide," CDC Publication 60436400, July 1977, 4201 N. Lexington Ave., St. Paul, Minn.

3. Control Data Corp., "NOS Version 1 Reference Manual," Vol. 1, CDC Publication 60435400, May 1978, 4201 N. Lexington Ave., St. Paul, Minn.

4. Frank, B., "XEDIT," Program Library Write-up P201, May 1978, Los Alamos Scientific Laboratory, Los Alamos, New Mexico.

5. Goode, W. and Curtis D., "A Guide to the Environmental Surveillance Data Base 'H8DATA,'" (in preparation).

6. Peters, R. J., Knab, D. K., Gladney, E., Goode, W., Burns, C., Eberhardt, W., and Schweitzer, W., "Environmental Radiochemical Procedures" (in preparation).

7. Model 733 ASR/KSR Operating Instructions Manual No. 959227-9701, Revision C, April 1978, Texas Instruments Inc., P. O. Box 1444, Houston Texas.

8. Neter J. and Wasserman, W., Applied Linear Statistical Models, Richard D. Irwin Inc., 1974, Homewood, Ill.

\section{APPENDIX A \\ REROUTING PROGRAM OUTPUT}

Conventions of NOS make it relatively easy to reroute program input and output (1/O) from one file or device to another.

In the beader statement of a program, one finds the general form

$$
\text { PROGNAME(FILE } \left., \text { FILE }_{2}, \ldots . \text { FlLE }\right)
$$

Where PROGNAME is the program name and FILE $n$ are the I/O file arguments for the program. The "load and execute" call to the operating system is of the form

$$
\text { PROGBINARY(FILE } \left.\text { FILE }_{2}, \ldots . \text { FILE }_{n}\right)
$$

where PROGBINARY is the executable file formed from compilation of the source file and FILE is the same as in the program header statement.

Assume the executable code has been written to the file LGO. File name substitutions may be made at any position in the LGO statement to reroute $1 / 0$ from the file declared in the program 
header to the file named in the LGO statement. In the timesharing environment, the files INPUT and OUTPUT are connected to the user's terminal by default. Therefore, given the program header statement

PROG(INPUT,OUTPUT,file, ,file $e_{2}, \ldots .$. file $_{n}$ )

which was compiled into the executable file LGO, one could defer the output from the terminal to the file OUT by entering

\section{LGO(,OUT)}

Thus, all output normally received at the terminal would be written to the local file OUT instead.

OUT could then later be sent to a high speed line printer by the command sequence

REWIND,OUT

COPYSBF(OUT,OUT1)

REWIND,OUT1

DISPOSE, OUT $1=$ PR

This output rerouting procedure can be very useful in handling large amounts of printed out put, which would take long periods of time to print at a terminal.

\section{APPENDIX B}

\section{PROGRAM LISTINGS}

This appendix contains source listings for the routines described in the body of this report.

Program MASTERCALC, which is written in PASCAL, occupies the first 39 pages of this section. The reader should note the 6 digit octal number immediately to the left of each line of code. This number gives the approximate relative address of each code segment at execution time and it will be referenced in any error messages reported by the PASCAL runtime system. Thus, in at tempting to trace program execution errors, one may relate the error address to the source listing to locate the approximate point at which the program stopped.

Program BKGD2, which is written in FORTRAN, follows program MASTERCALC. Error diagnostics from the FTN system should be related to statement sequence numbers (not statement labels) for rather straightforward interpretation. 


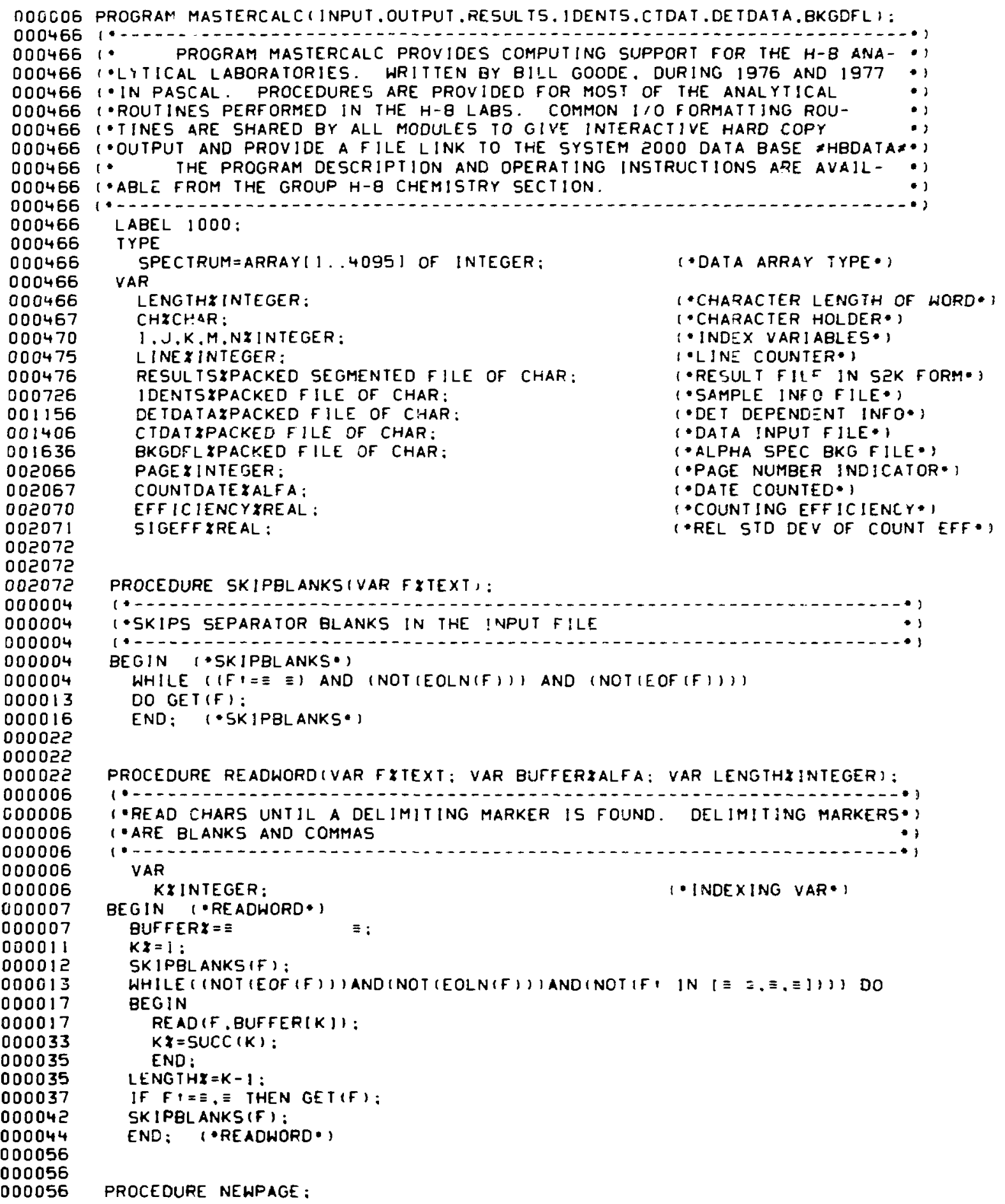


000003

000003

000003

000003

000003

000014

000020

000020

000020

000003

000003

000003

000003

000003

000013

000021

000036

000036

000036

000036

000003

000003

000003

000003

000003

000007

000013

000013

000013

000003

000003

000003

000003

000003

000004

000004

000014

000025

000025

000022

000011

000011

030011

000011

000011

000011

000011

000011

000011

000012

000013

000014

000015

000016

000017

000020

00002 !

000022

000023

000024

000024

000024

000005

000005

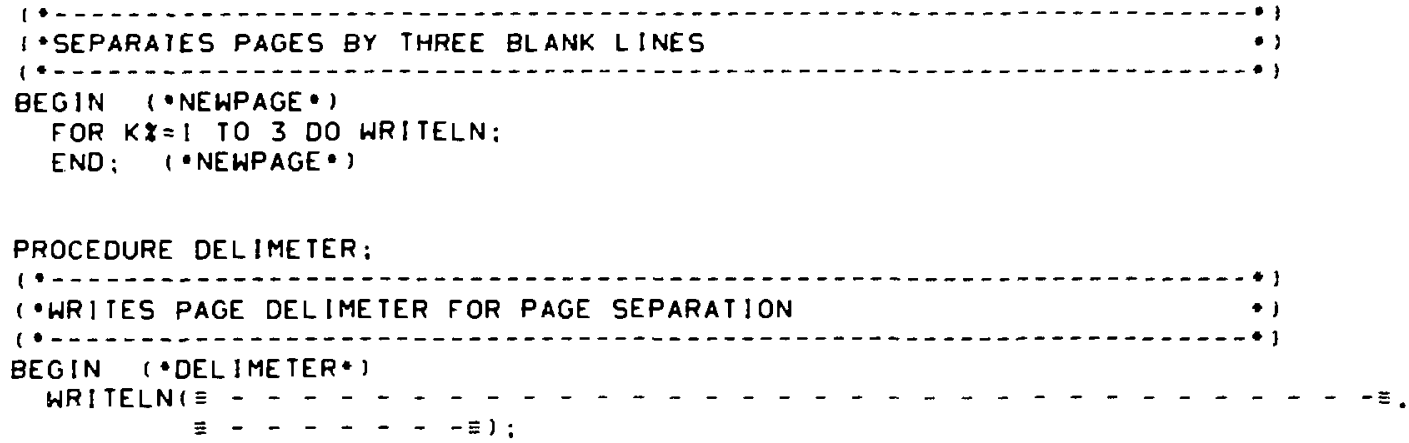

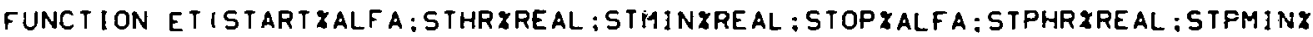
REAL I YREAL :

(- COMPUTES THE ELAPSED TIME IN DAYS BETHEEN THE START AND STOP OATES:)

FUNCTION TOTOAYSISTRTMI STARTMONTH*),STPMI STOPMONTH I*INTEGERIIINTEGER: (०COMPUTES THE ELAPSED TIME IN DAYS BETHEEN TWO DATES 


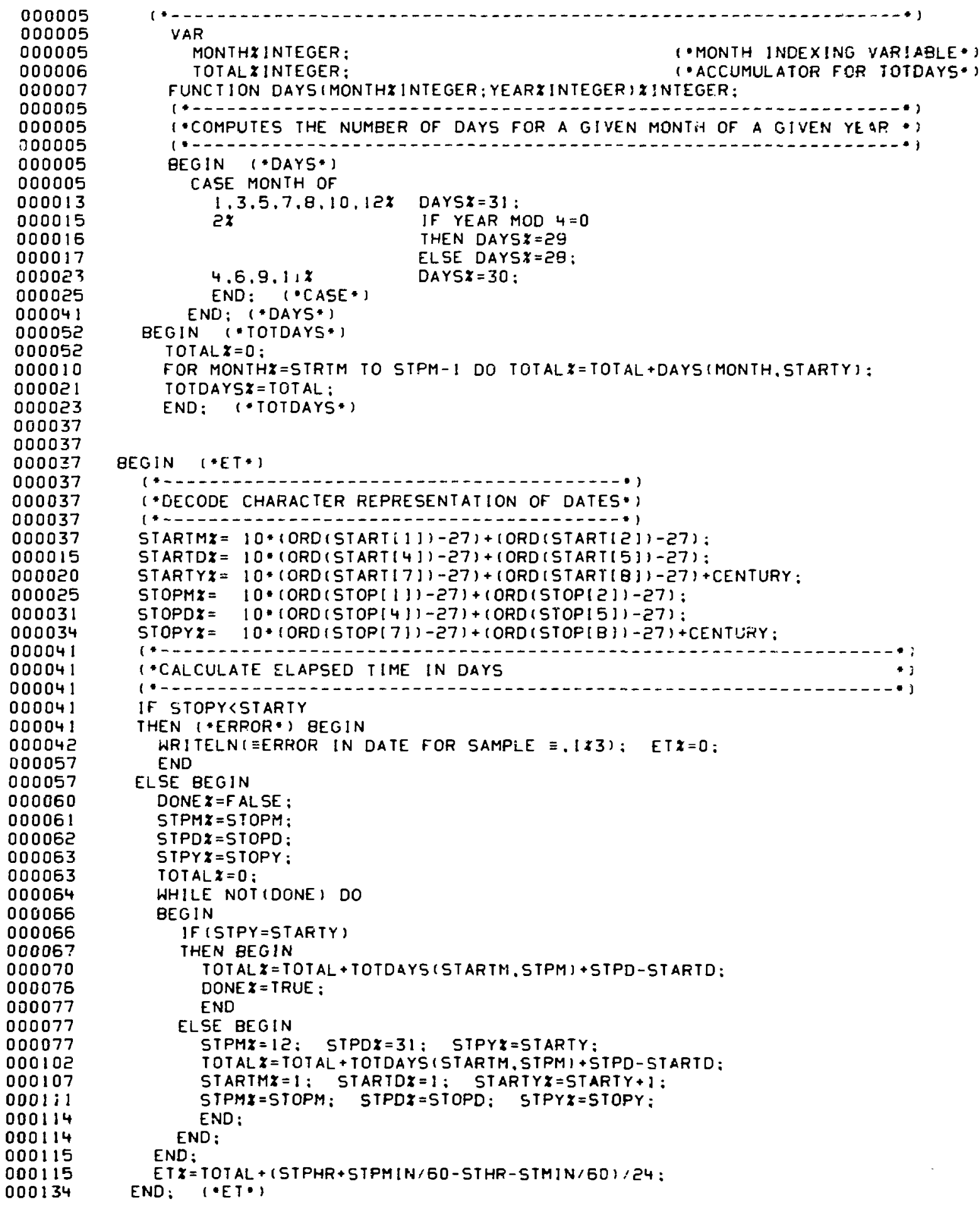

000005 000005 000005 000006 000007 000005 000005 000005 000005 000005 000013 000015 000016 000017 000023 000025 00004 ! 000052 000052 000010 000021 000023 000037 000037 $0000 \leq 7$ 000037 000037 000037 000037 000015 000020 000025 000031 000034 000041 00004 ! 00004 ! 000041 00004 ! 000042 000057 000057 000060 000061 000062 000063 000063 000064 000066 000066 00006 ? 000070 000076 000077 000077 000077 000102 000107 $0001: 1$ 000114 000114 000115 000115 000134 


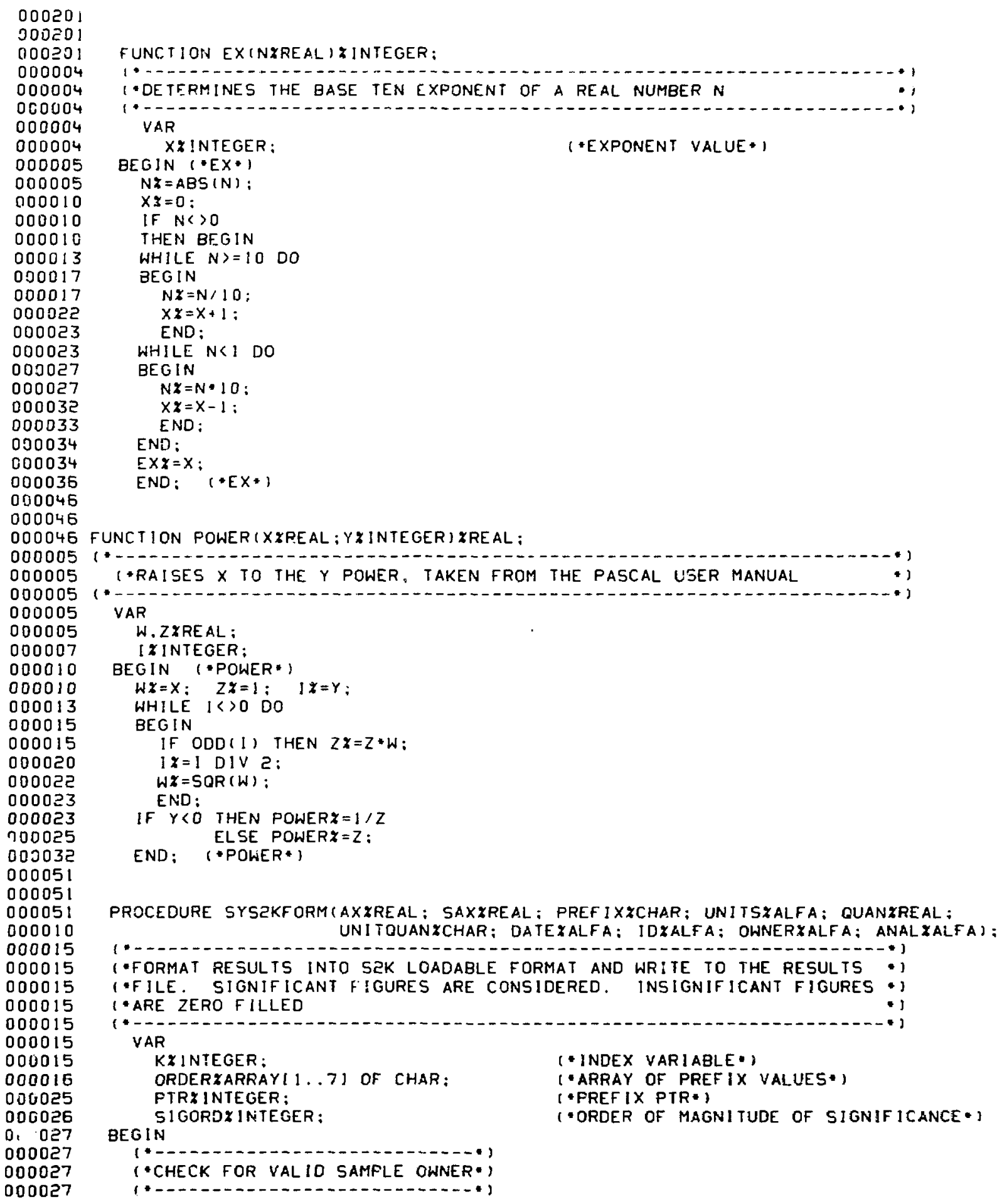

PROCEDURE SYSZKFORM (AXXREAL: SAXXREAL: PREF IXXCHAR; UNITSZALFA: OUANZREAL: UNITOUANXCHAR; DATEXALFA: IDXALFA; OWNERXALFA; ANALXALFA]; 


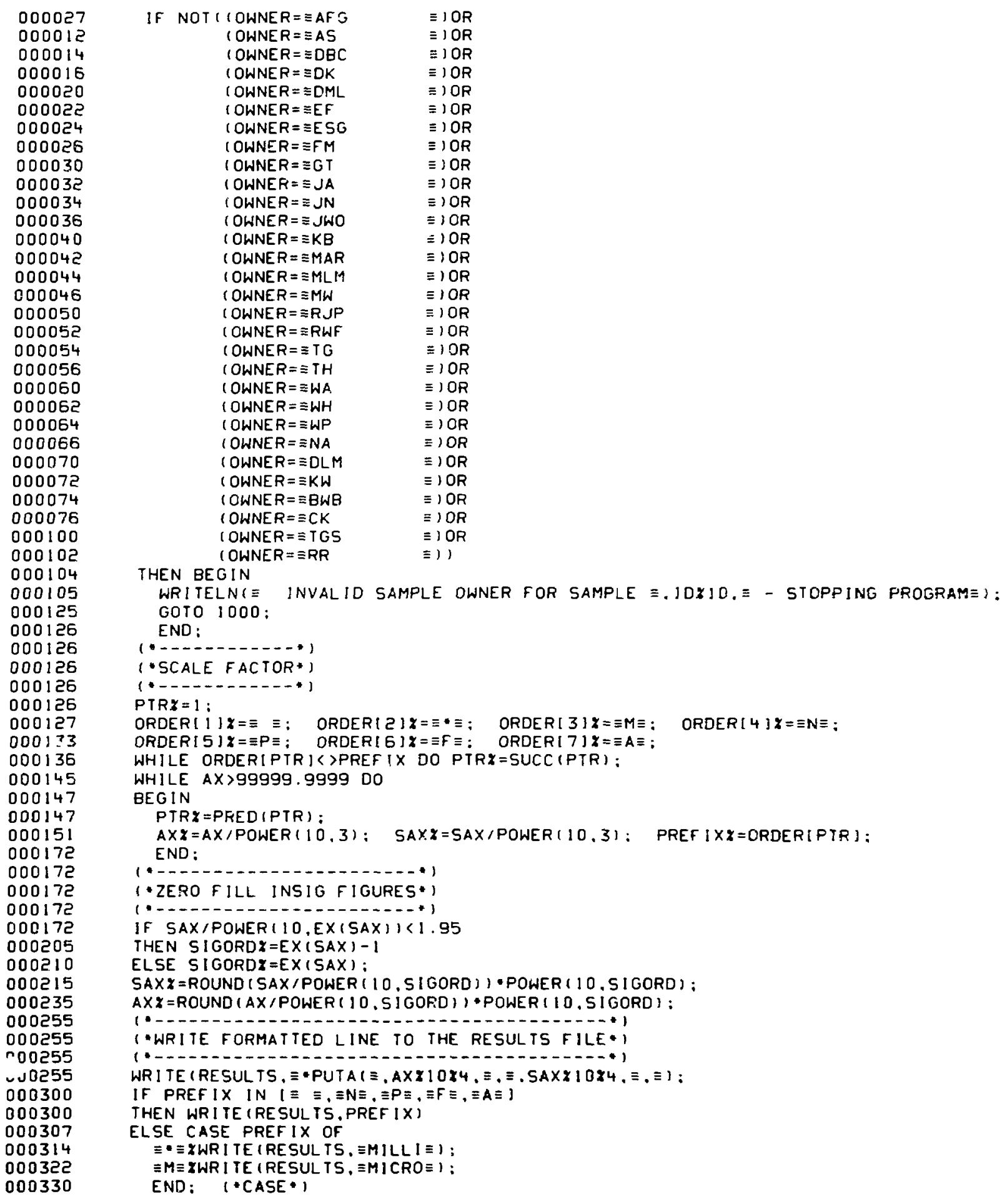




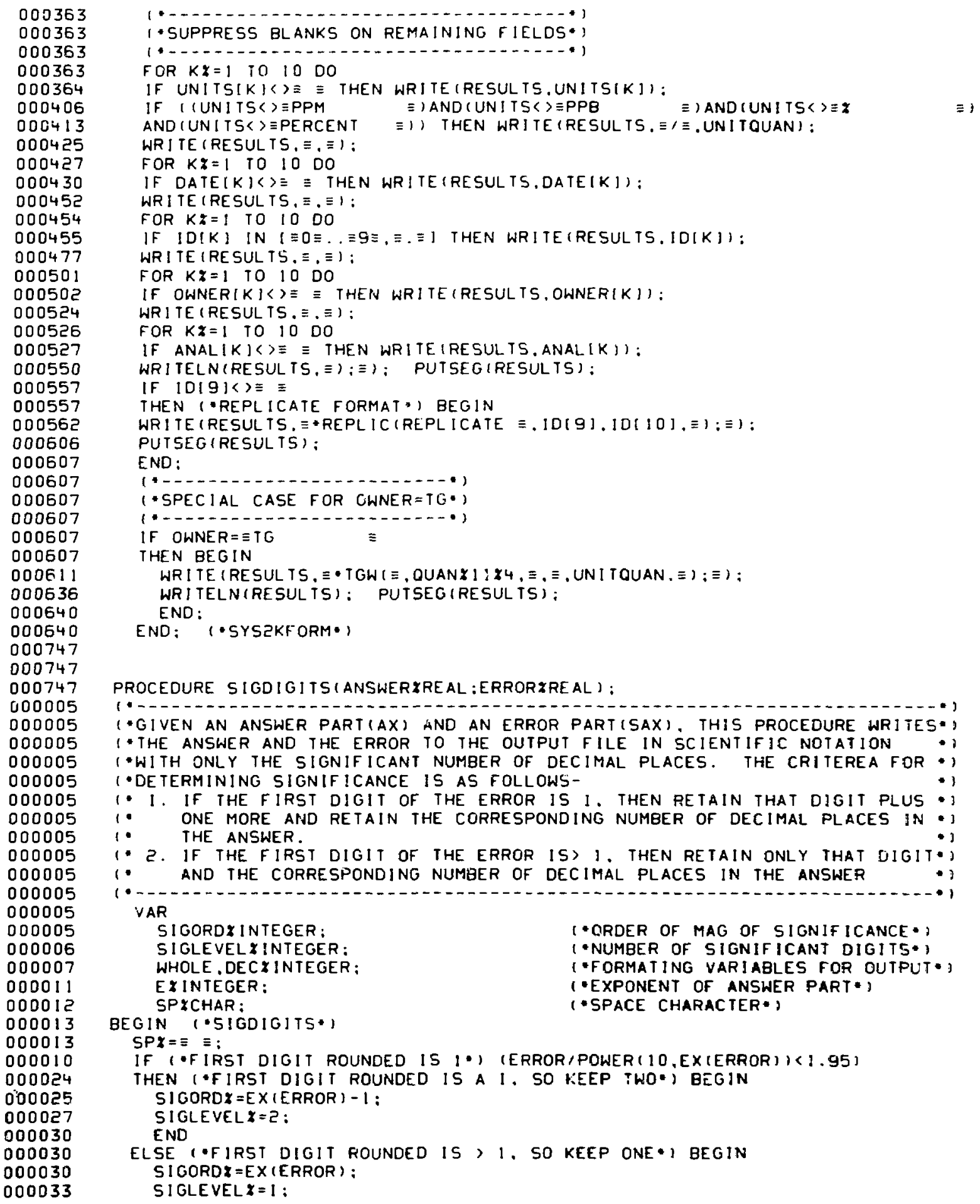




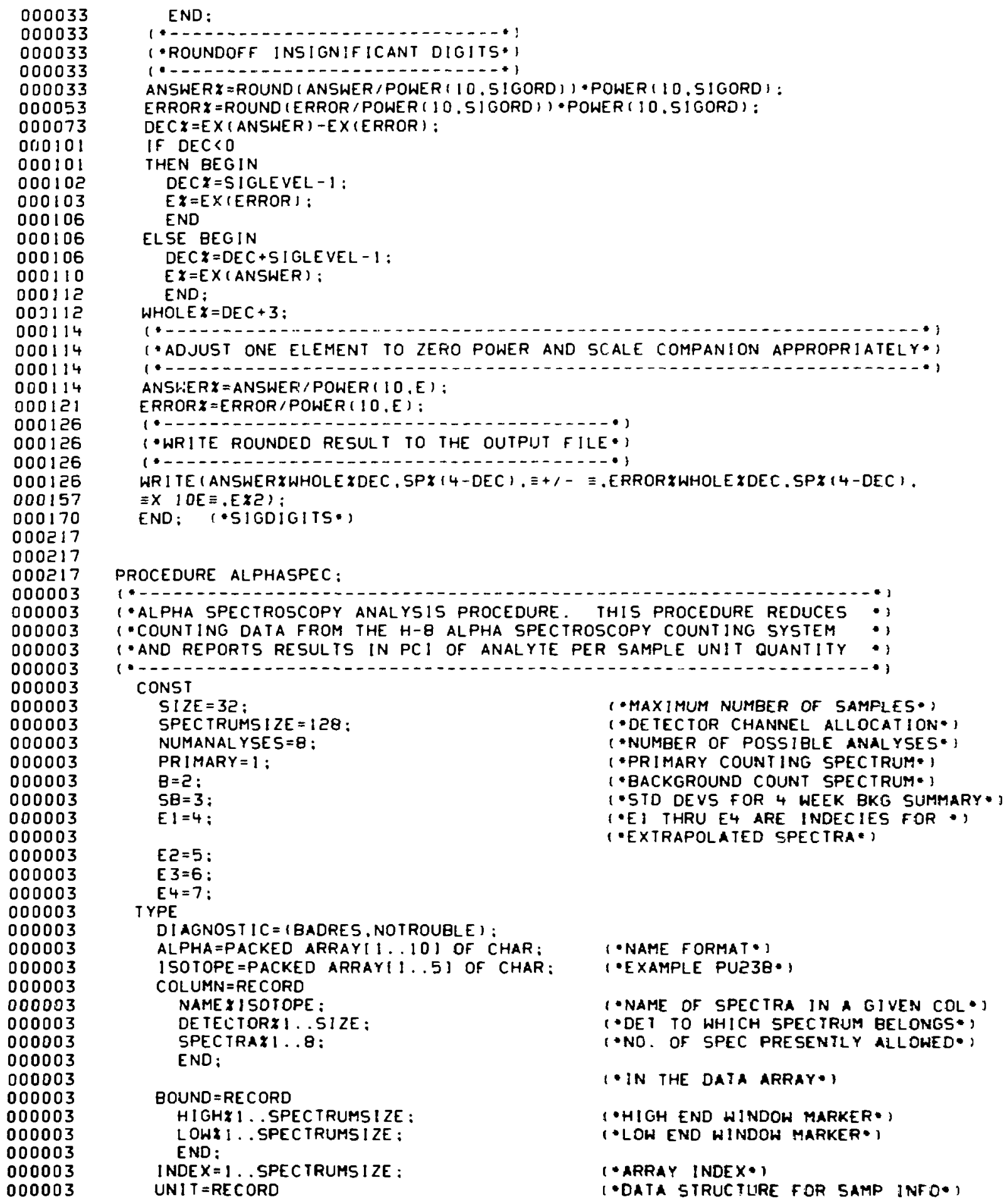

(- MAXIMUM NUMBER OF SAMFIES*) (- DETECTOR CHANNEL ALLOCATION-) (*NUMBER OF POSSIBLE ANALYSES*) 1.PRIMARY COUNTING SPECTRUM*I 1.BACKGROUND COUNT SPECTRUM.] 1 - STD DEVS FOR 4 WEEK BKG SUMMARY * 1.E; THRU E4 ARE INDECIES FOR •) (-EXTRAPOLATED SPECTRA'?

I NAME OF SPECTRA IN A GIVEN COL * (-DE 1 TO WHICH SPECTRUM BELONGS *) ? + NO. OF SPEC PRESENTLY ALLOWED*?

I. in the data array=!

1.HIGH END WINDOW MARKER*) 1-LOW END HINDOW MARKER・I

1*ARRAY INDEX*)

(-DATA STRUCTLIRE FOR SAMP INFO-) 
000003

000003

000003

000003

000003

000003

000003

000003

000003

000003

000003

000003

000003

000003

000003

000003

000003

000003

000003

000003

000004

000005

000705

070705

070706

070707

071707

071717

071720

071721

071722

071723

071724

071725

071726

071727

071730

071731

071732

071733

071734

071735

071736

071777

071777

072000

072000

072001

072031

072032

072033

072033

072033

000004

000004

000004

000004

000004

000011

000015

000021

000025

000031

000035
IDZPACKED ARRAY $11 \ldots 101$ OF CHAR:

OWNERYALFA :

ANALYSISZARRAY [1,3] OF ISOTOPE:

TRACERXISOTOPE :

IRACERDPMIREAL:

TRACERUNCER YREAL :

SAMPOUANXREAL:

ALOTFRAC XREAL:

UNI TSXCHAR:

SEPDATE XALPHA :

RESOLUTIONXREAL:

RECOVERYYREAL :

END :

COEFFS $=$ RECORD

FCOEFF YREAL :

A $Z R E A L$;

BXREAL:

END:

VAR

BUFFERX I SOTOPE :

WORDXALFA:

SAMPLEXARRAY $(1 \ldots$ SIZE) OF UNIT:

- ALFA WORD HDLDER*)

(-SAMPLE INFO ARRAY *)

DATAXARRAY [ $1 \ldots 7,1 \ldots 51 Z E, 1 \ldots$ SPECTRUMSIZE ] OF INTEGER: $\quad$ "CDUNTING DATA*] LNUMXINTEGER:

PTRY INTEGER:

(*DUMMY FOR LINE NUMBER READ*?

( MCA CHANNEL NUMEER INDICATOR*)

PEAKXARRAY [ $1 \ldots$ SIZE, $1 \ldots$ NUMANALYSES ] OF BOUND: (*PEAK BOUNDRY TABLE *)

LOCATIONXARRAYI1. NUMANALYSES ] OF 1 . SPELTRUMSIZE ; IPEAK LOCATION TABLE *I

CTSECXINTEGER:

CHANNEL $\boldsymbol{X}$ INTEGER :

CTIINTEGER:

CITIINTEGER;

CBT XREAL:

CXIINTEGER:

CIXXINTEGER:

CBXIREAL :

SCBT XREAL:

SCBXXREAL:

TXXREAL:

STXXREAL:

AXXREAL:

SAXXREAL:

KEVCHXREAL:

COLXARRAY $[1 \ldots 11\}$ OF COLUMN:

NUMSPEC $₹$ INTEGER :

AOD I T IONXINDEX:

F! TYARRAYI 1.. NUMANALYSESI OF COEFFS:

PXI . SPEC TRUMSIZE ;

SHIF T XINTEGER:
( MCA COUNT TIME IN SEC *)

1 MCA CHANNEL *)

1. TOTAL tRaCER COUNTS*)

1-TOT CTS INTERFERE ING W/TRACER PEAK *

1. TRACER BACKGROUND*?

1. TOTAL CTS FOR ANALYSIS PEAK*J

1- TOT CTS INTERF W/ANALYSIS PEAK*;

I.ANALYSIS PEAK BKG"!

1.STD DEV OF TRACER BKG*1

(-STD DEV OF ANALYSIS BKG*)

? INTERFERENCE RATIO FOR ANALY PEAK *

( STD DEV OF INTERF RATIO*)

(*STD DEV OF SAMPLE ACTIVITY*)

(*alPHa eNERGY SCALE *)

i Number of cols that MaY BE *

(*LOADED HITH OUTPUT DATA*)

1. INDEXING VARIABLE FOR SPECTRAL $\equiv$ (-OUTPUT *)

:NO. OF SPECTRA ADOED AFTER $A *$ )

(-COEFFS FROM EF IT PROCEDURE *)

(-CHANNEL POINTER *)

(*CALIBRATION SHIFT FOR ALPHA DEJ *)

1.PASS OF THE COLUMN SCHEDULER*)
( SAMP ACTIVITY IN PCI/UNIT QUAN *

FUNCT ION ISCODE (NAMEX ISOTOPE) $*$ INDEX:

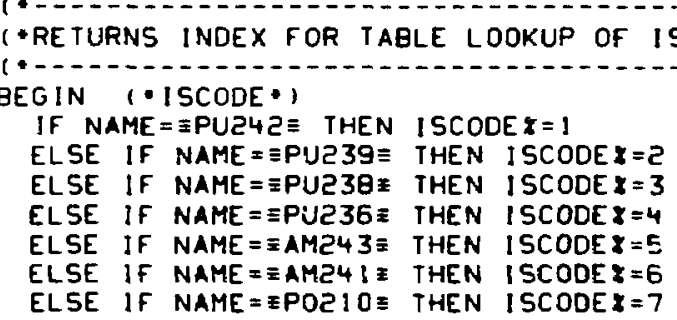




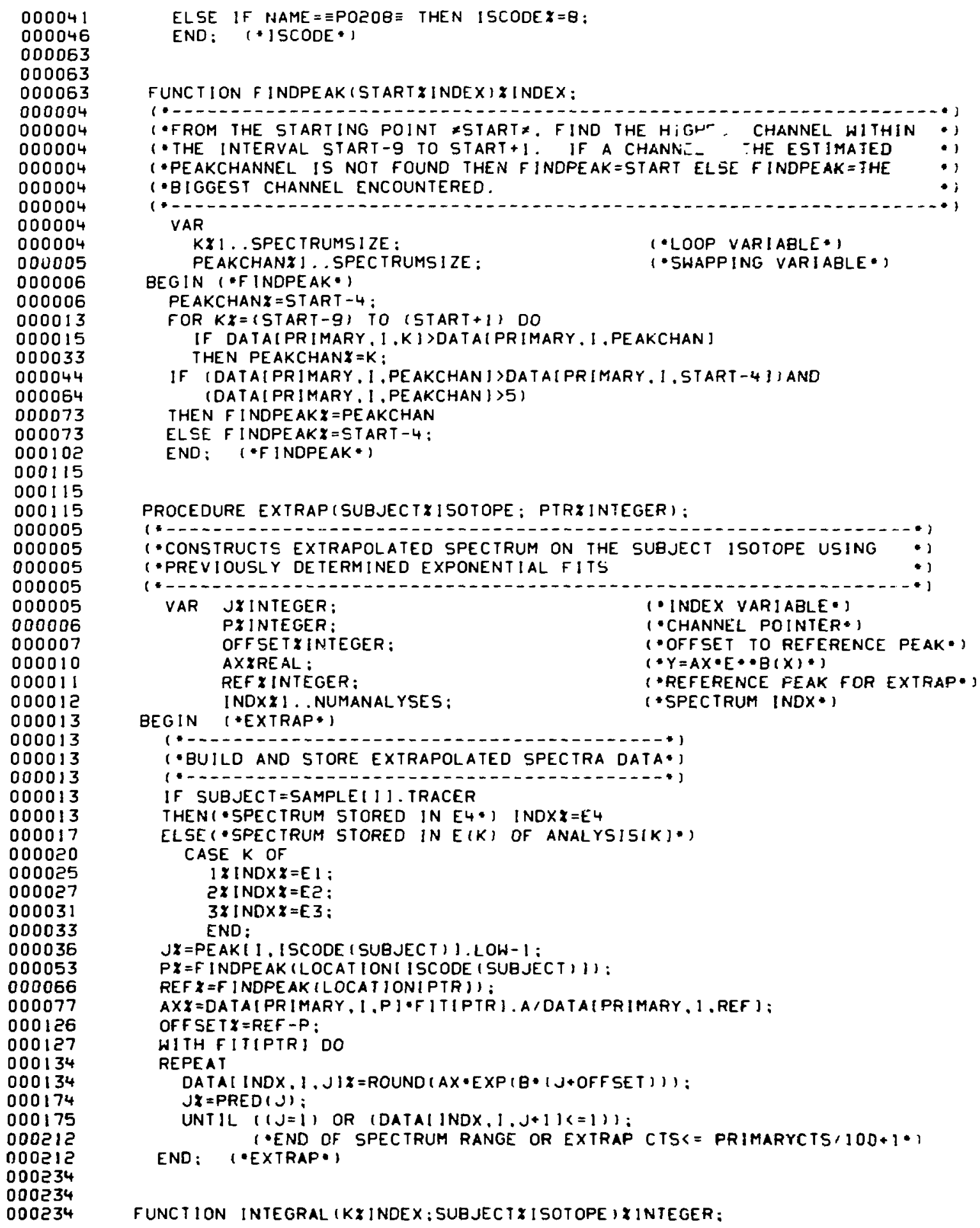




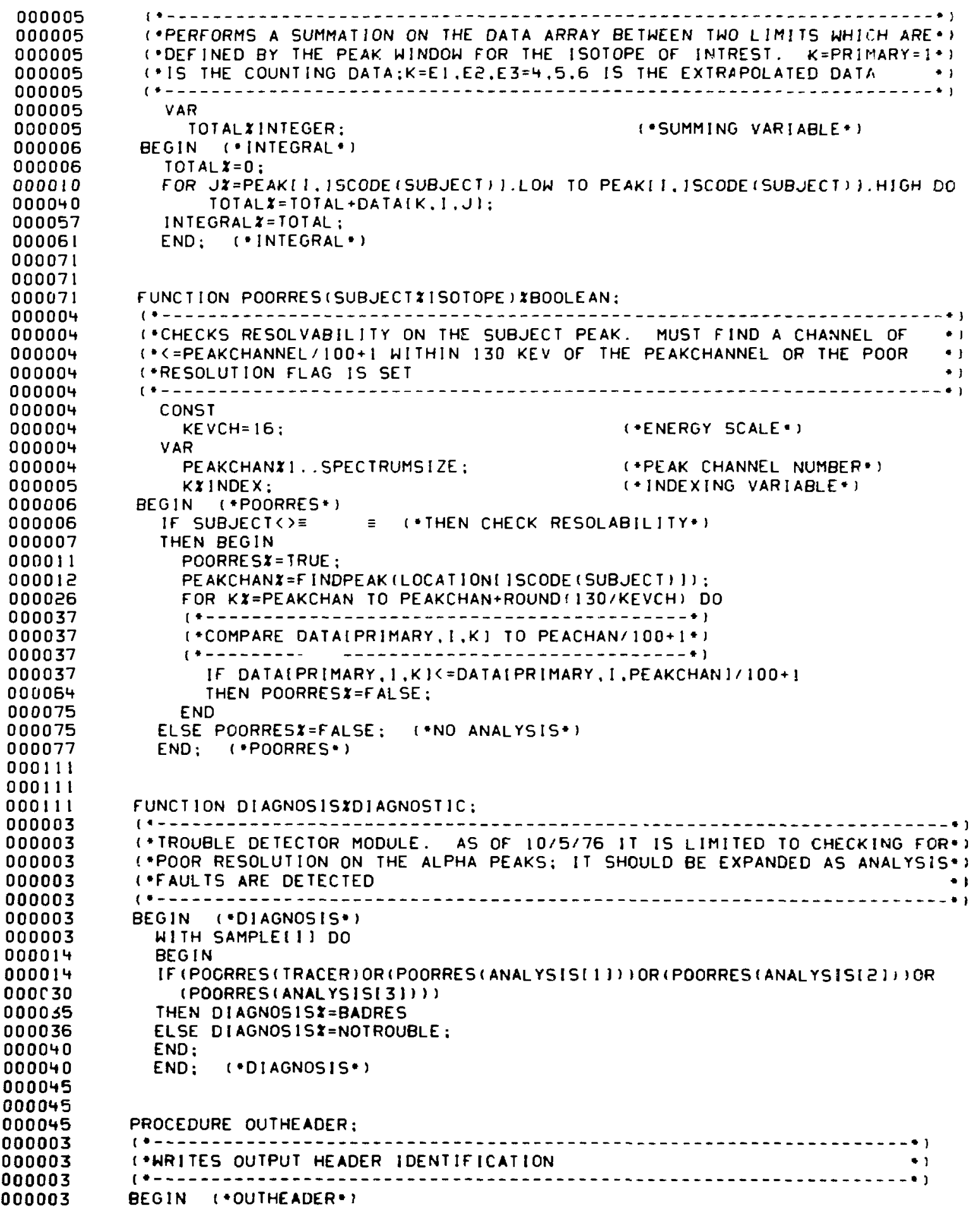




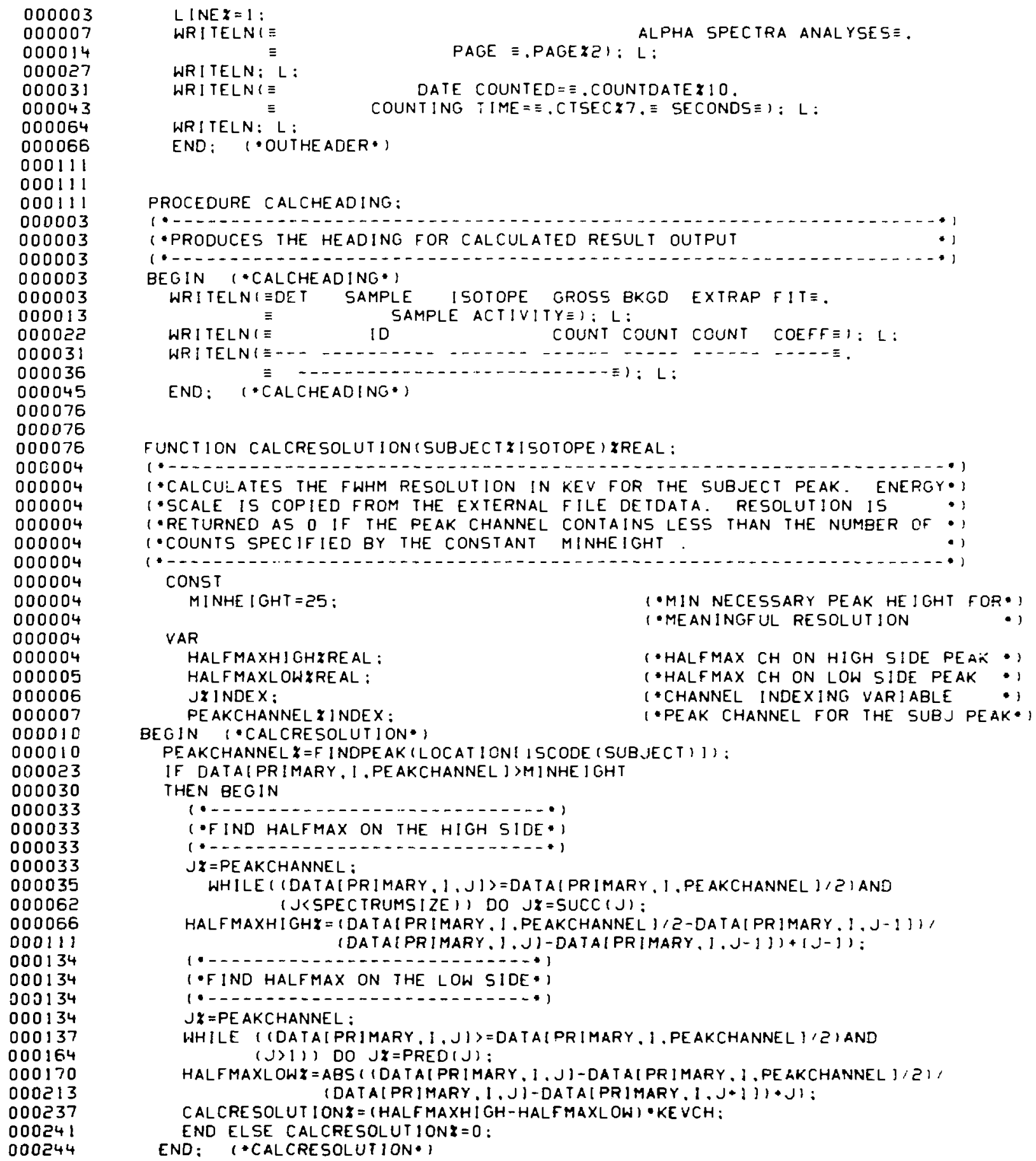

PROCEDURE INTERFRATIO(SUBJECT\&ISOTOPE; VAR TX\&REAL: VAR STXYREAL): 


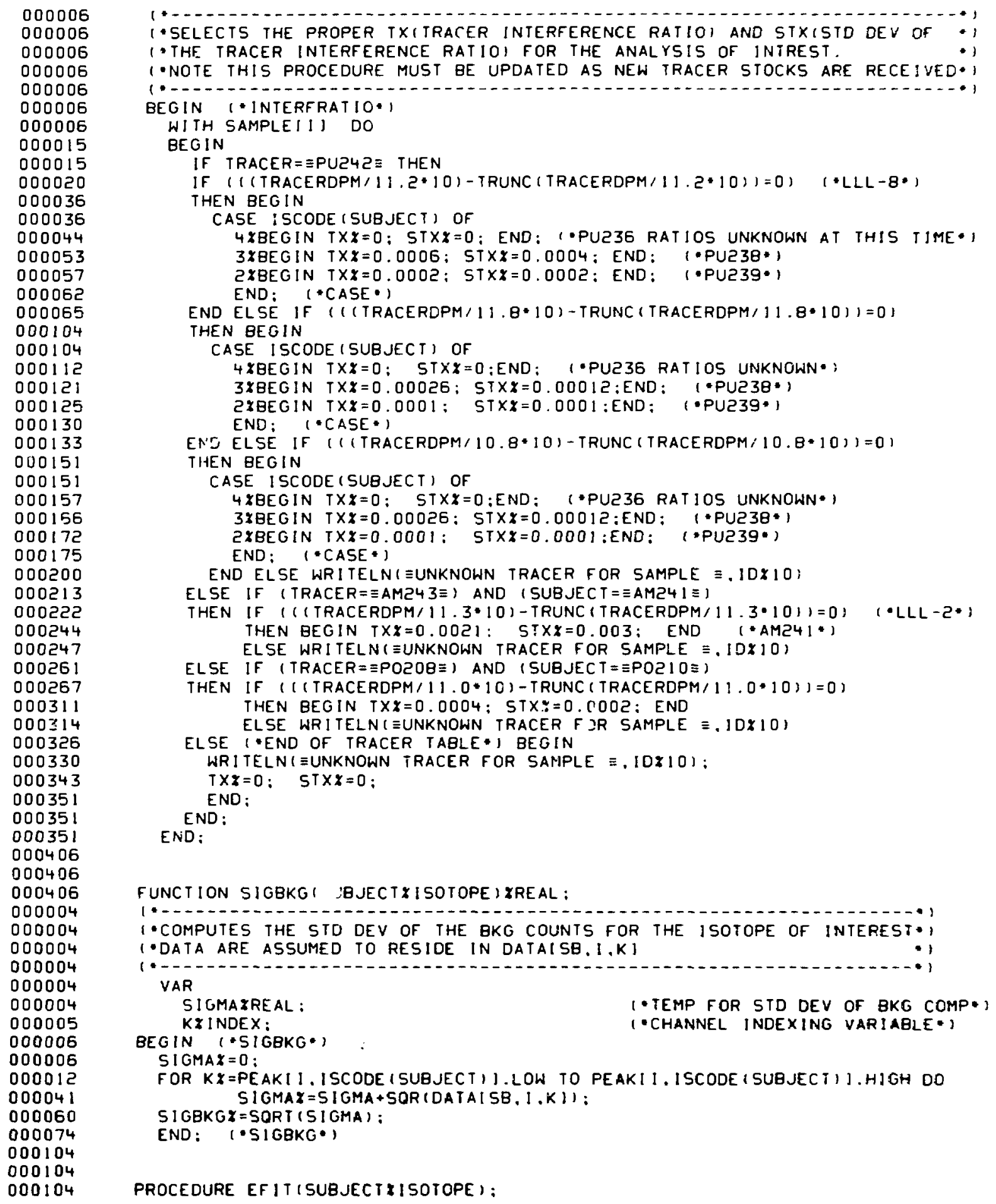

PROCEDURE EFIT(SUBJECTIISOTOPE): 


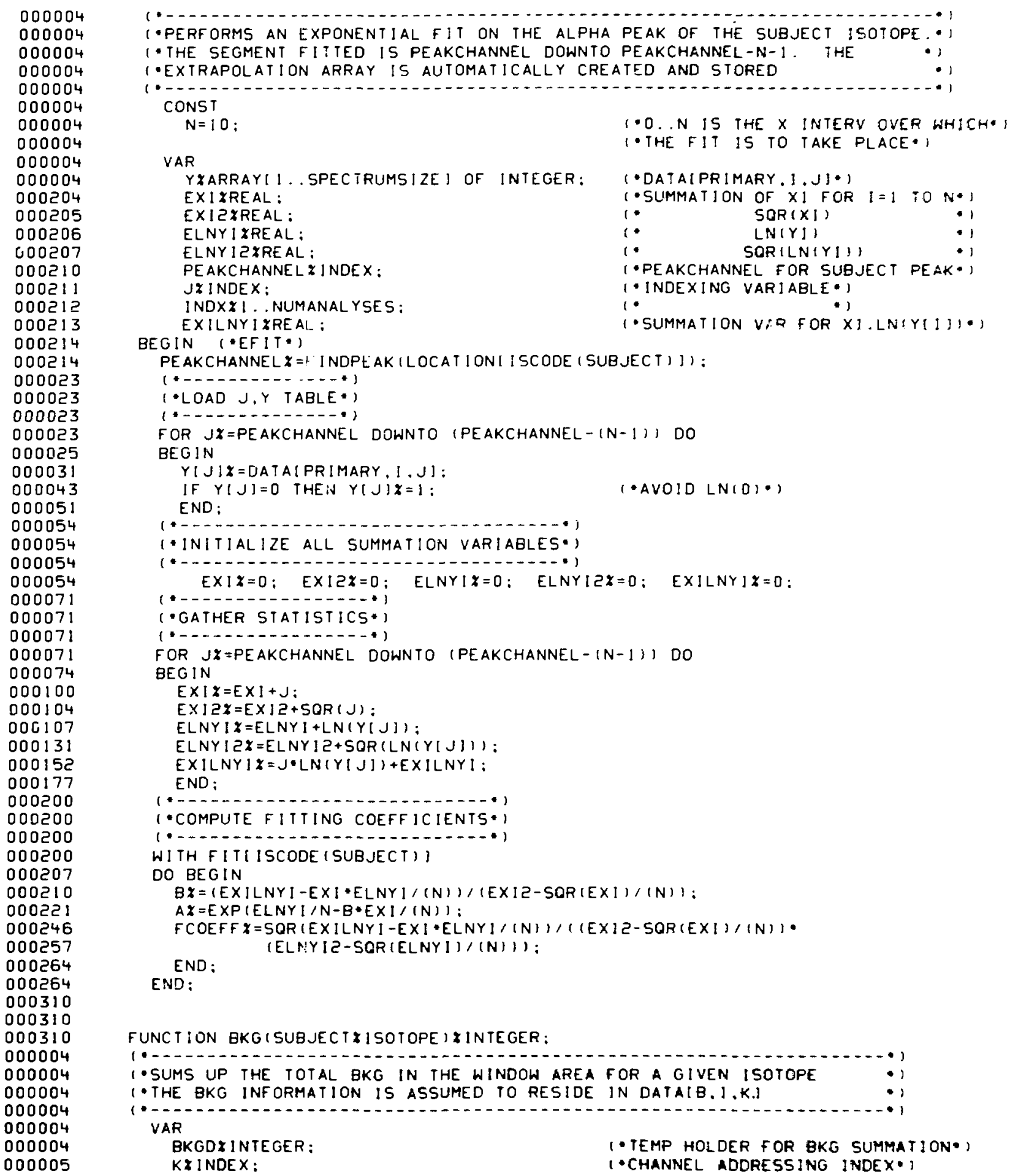

1. TEMP HOLDER FOR BKG SUMMATION*) (* CHANNEL ADDRESSING INDEX*) 


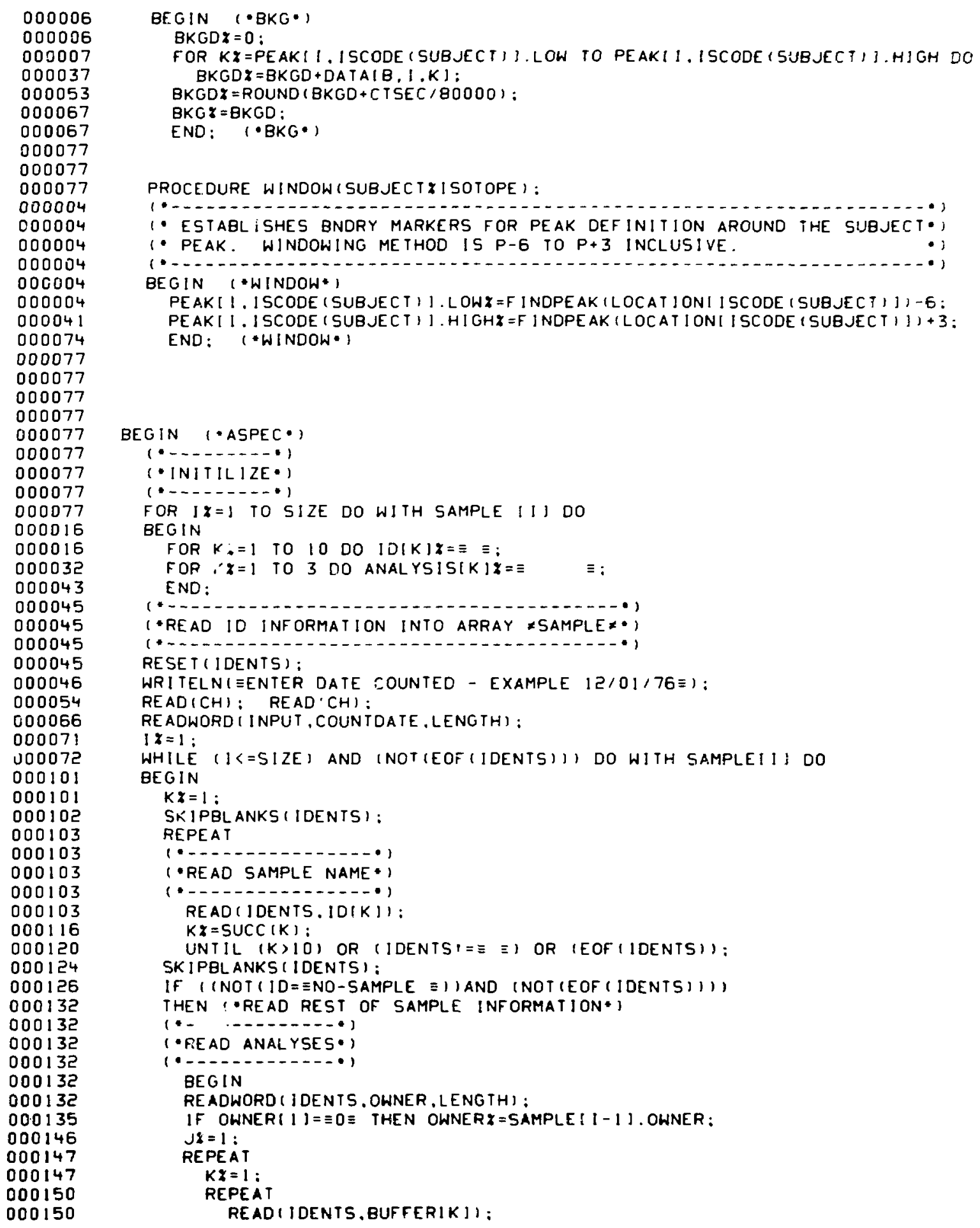

000006 000006 000007 000037 000053 000067 000067 000077 000077 000077 000004 000004 000004 000004 000004 000004 000041 000074 000077 000077 000077 000077 000077 000077 000077 000077 000077 000016 000016 000032 000043 000045 000045 000045 000045 000046 000054 000066 000071 ט00072 000101 000101 000102 000103 000103 000103 000103 000103 000116 000120 000124 000126 000132 000132 000132 000132 000132 000132 000135 000146 000147 000147 000150 000150 


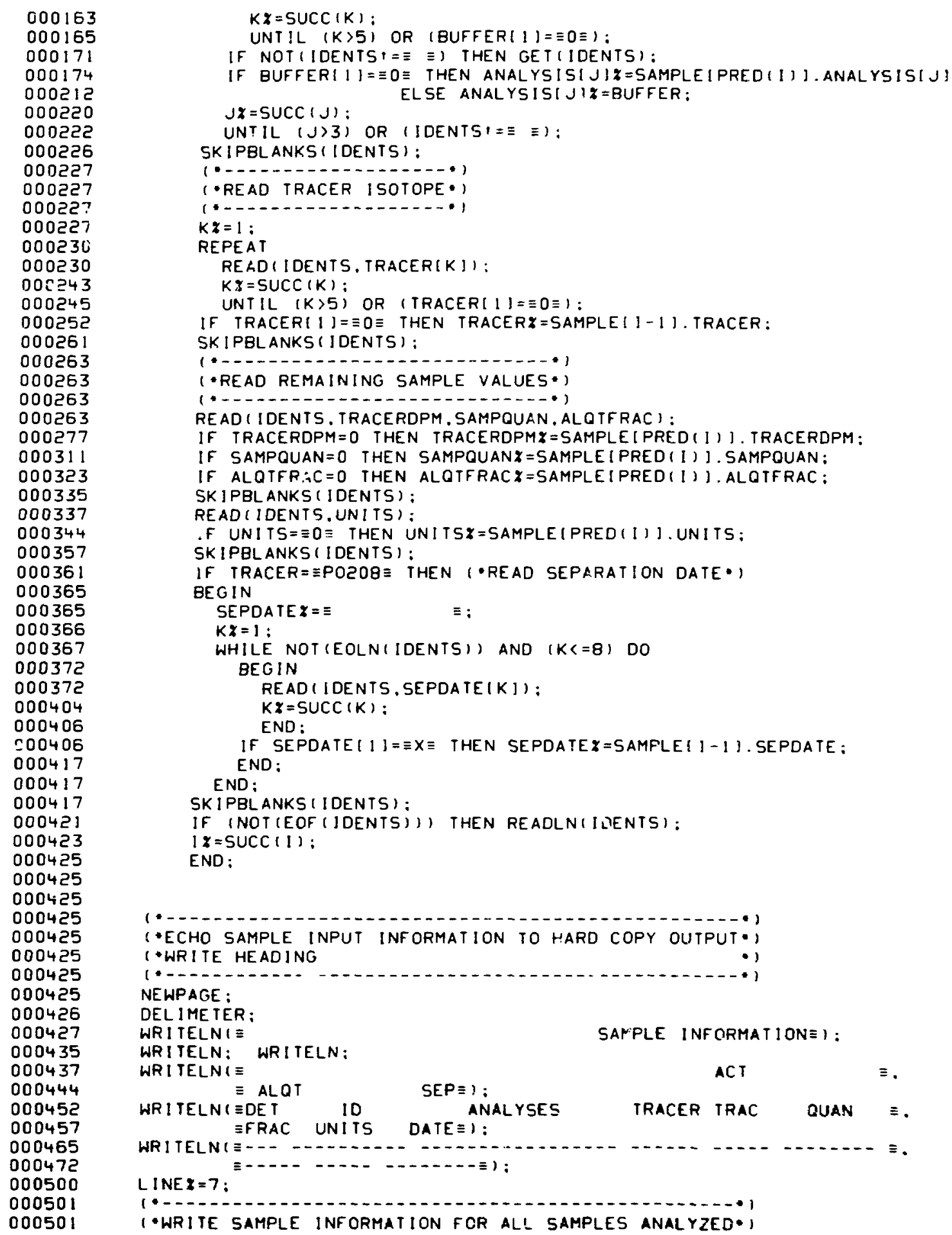

000163 000165 000171 000174 000212 000250 000222 000226 000227 000227 $00025 ?$ 000227 000230 000230 002343 000245 000252 000261 000263 000263 000263 000263 000277 000311 000323 000335 000337 000344 000357 000361 000365 000365 000366 000367 000372 000372 000404 000406 500406 000417 000417 000417 000421 000423 000425 000425 000425 000425 000425 000425 000425 000425 000426 000427 000435 000437 000444 000452 000457 000465 000472 000500 000501 00050 ! 


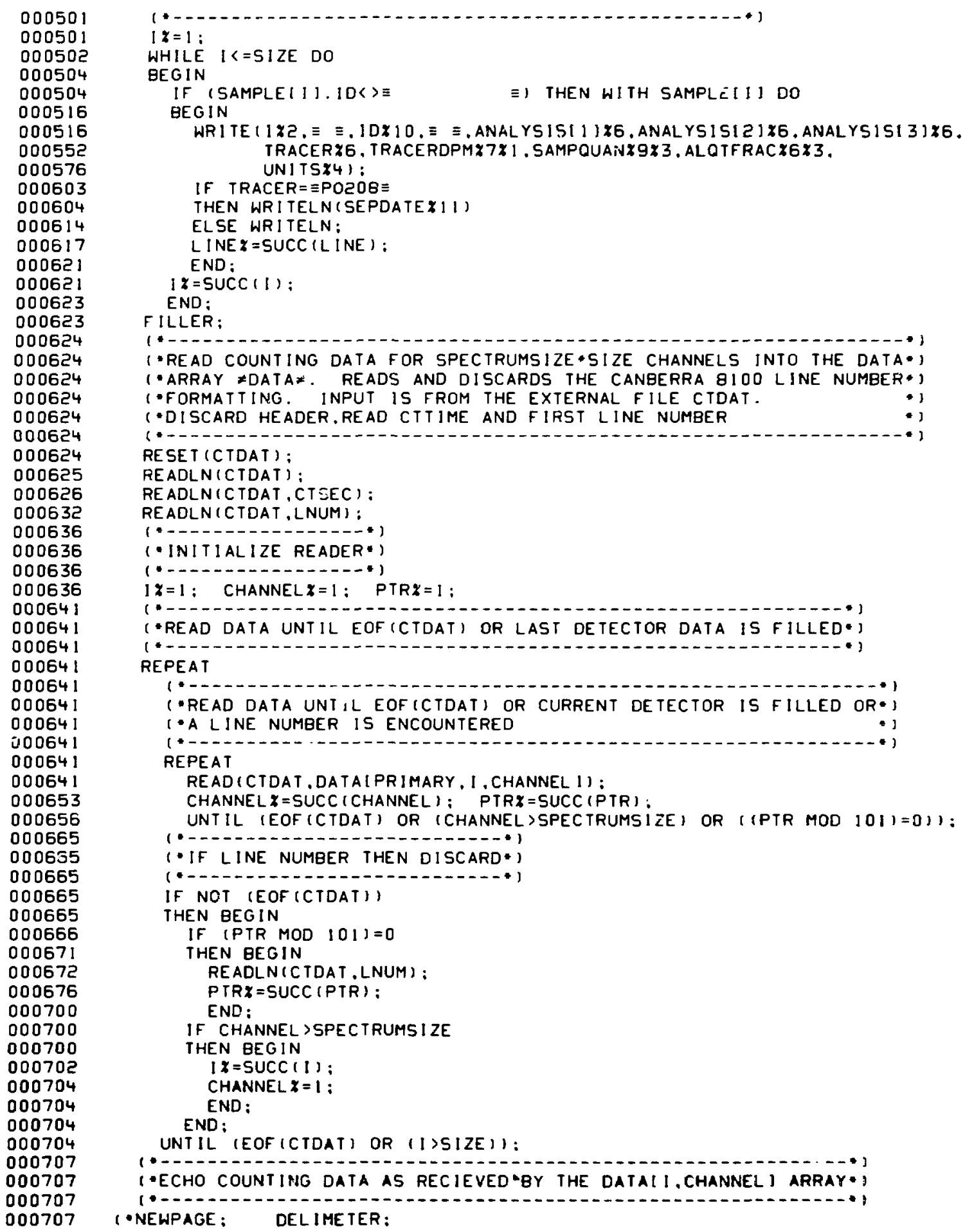




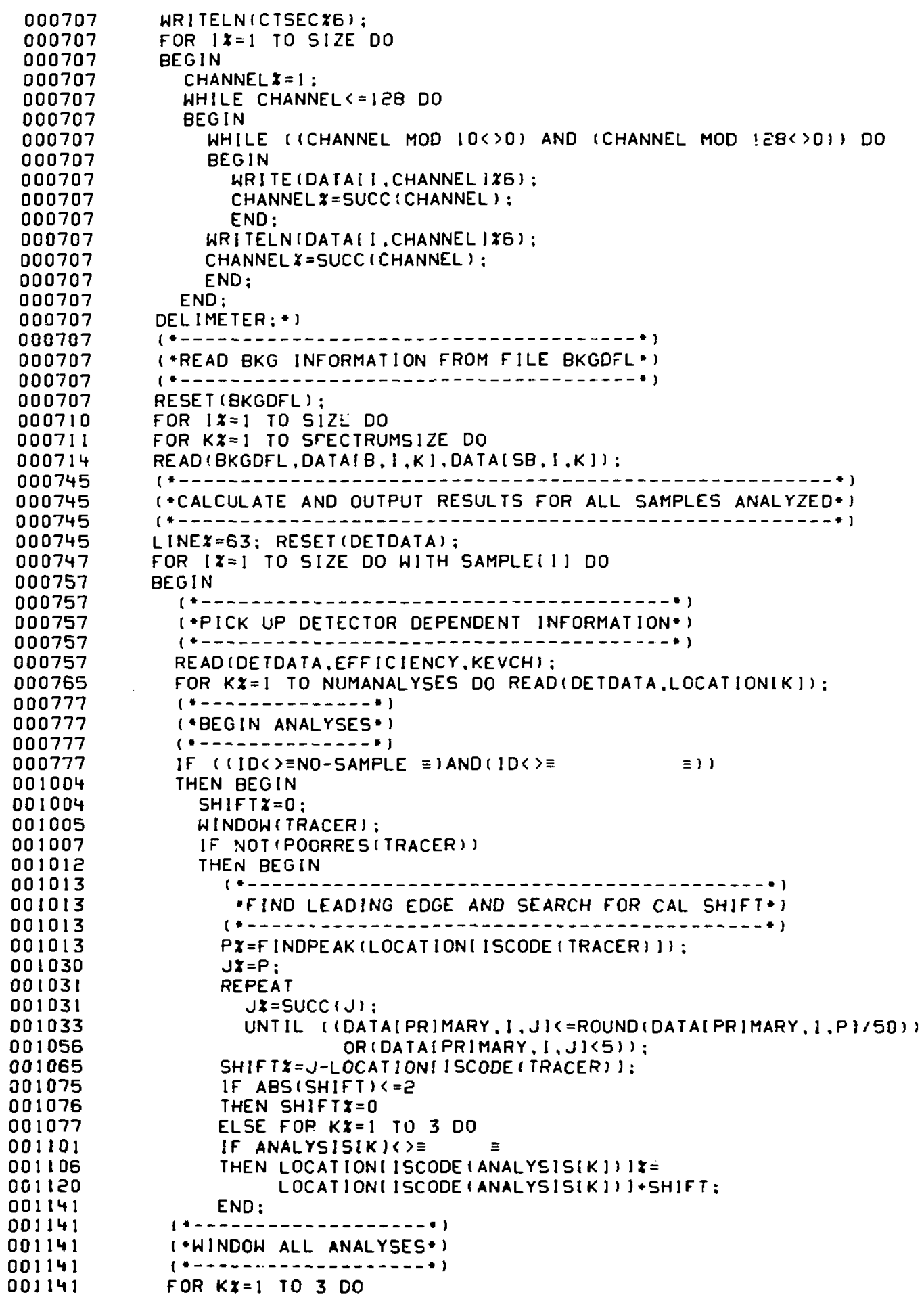




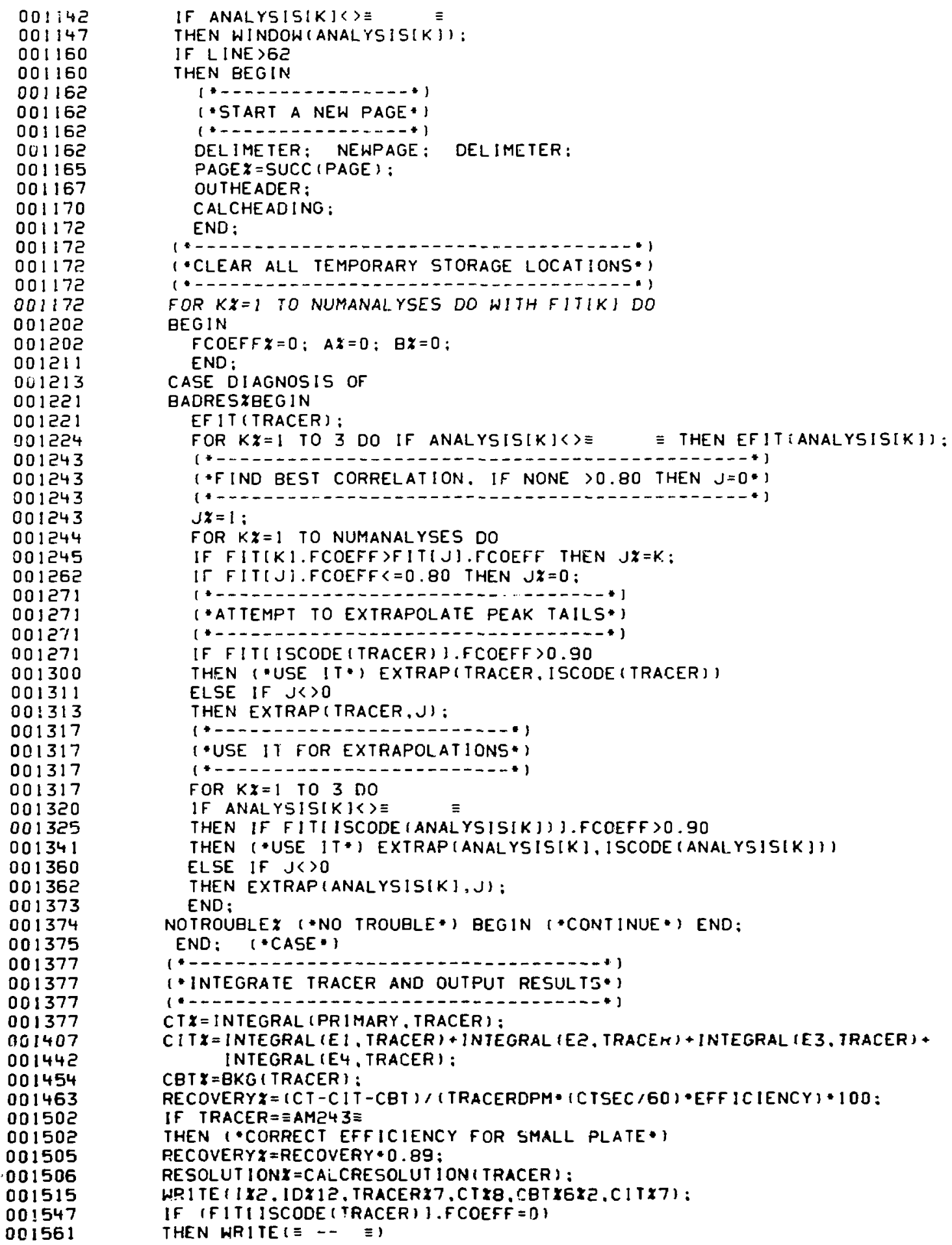


001566

001604

001613

001613

001613

001613

001614

001621

001624

001633

001656

001704

001714

001723

001736

$00 ! 75 !$

001761

001774

001777

002002

002005

002043

002043

002043

002043

002053

002060

002075

002111

002121

002145

002145

002145

002145

002177

002511

002221

002242

002245

002247

002263

002270

002271

002305

002327

002343

002346

002350

002350

002352

002353

002354

002354

002354

002354

002355

002357

002357

002361

002362

002372

002374

002376

002377

ELSE WRITE IFITI ISCODE (TRACER) ].FCOEFF :5\%2):

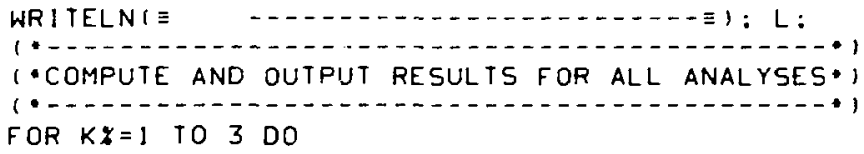




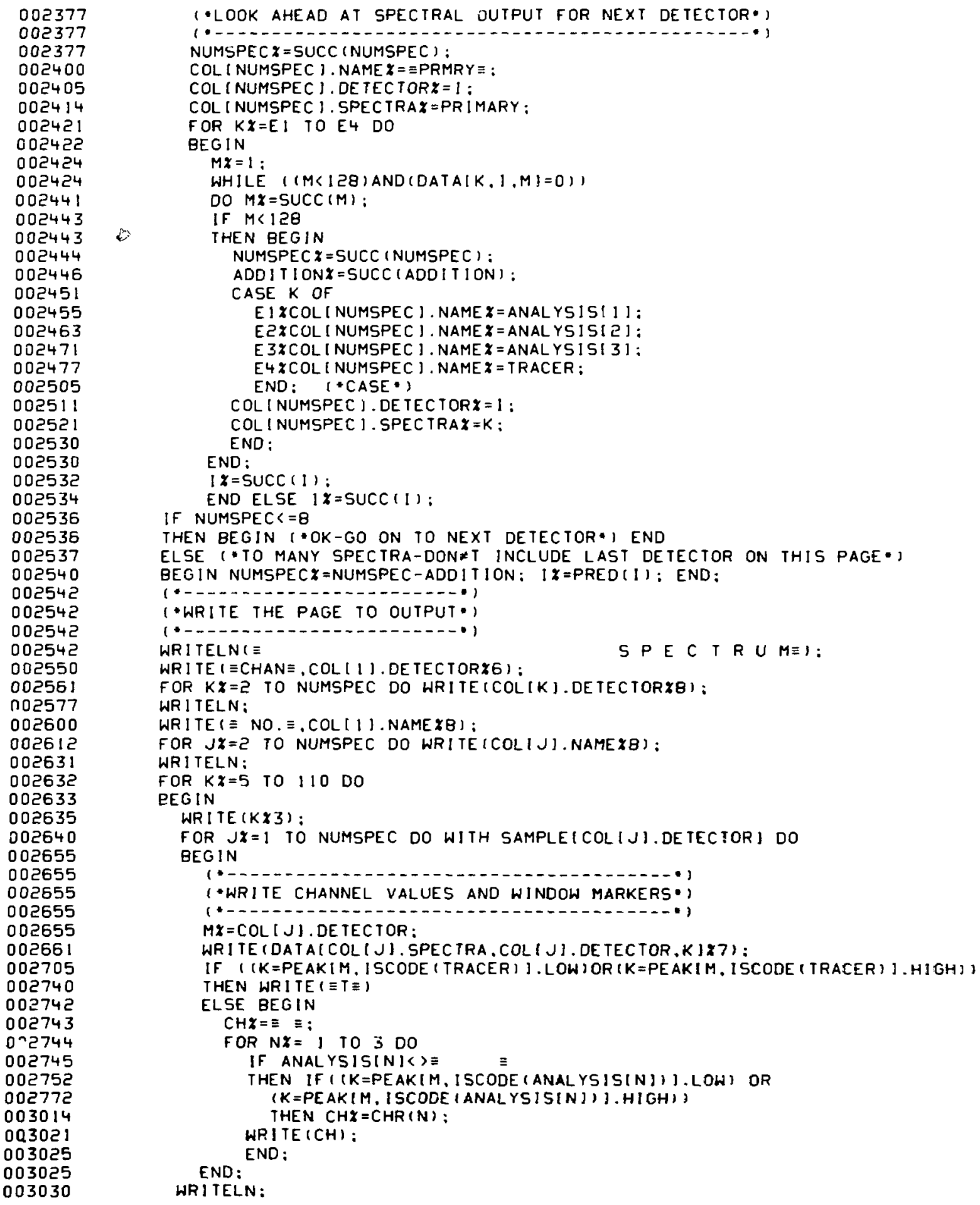


003031

003033

003034

003035

003035

003035

003035

003035

003035

003036

003045

003045

003045

003047

003047

003051

003055

003056

003065

003074

003103

003103

003110

003110

003135

003137

003137

$003 ! 41$

003143

003332

003332

003332

000003

000003

000003

000003

000003

000003

000003

000003

000003

000003

000003

000003

000003

000003

000003

000003

000003

000004

000005

000007

000010

000011

000012

000013

000014

000015

000016

000017

000020

000021

000052

001342
END:

DEL I ME TER :

END :

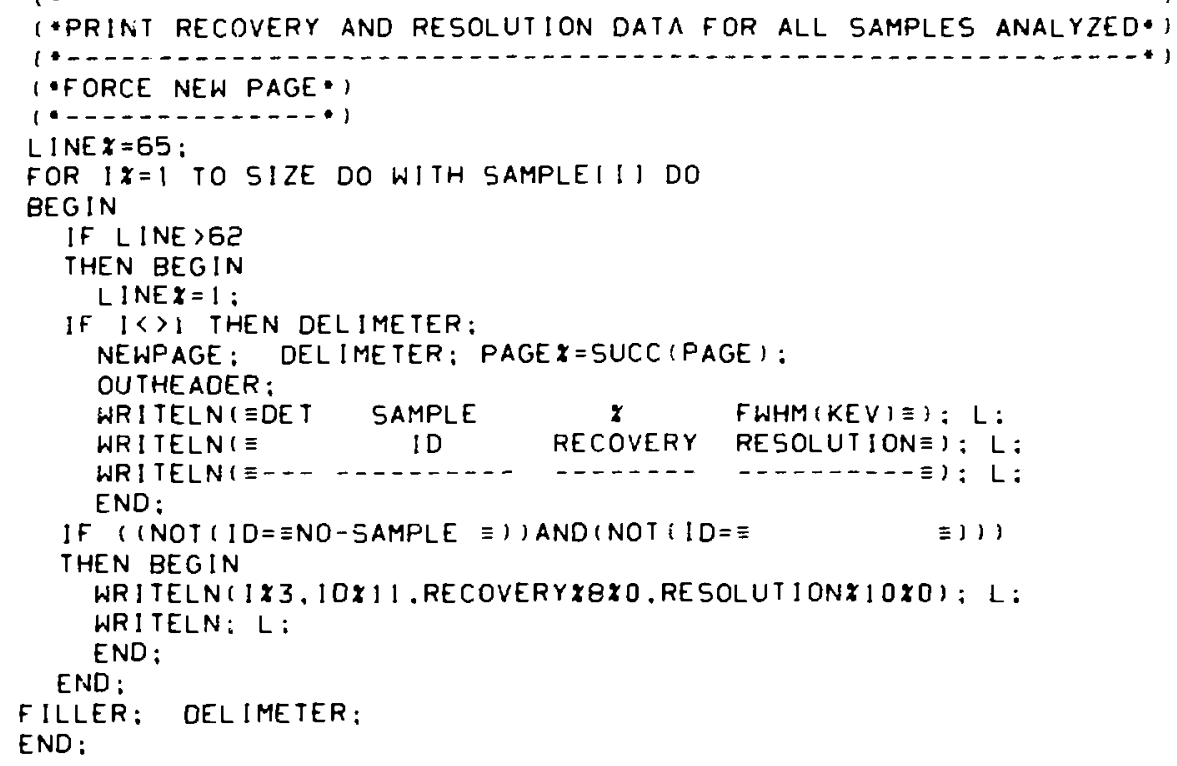




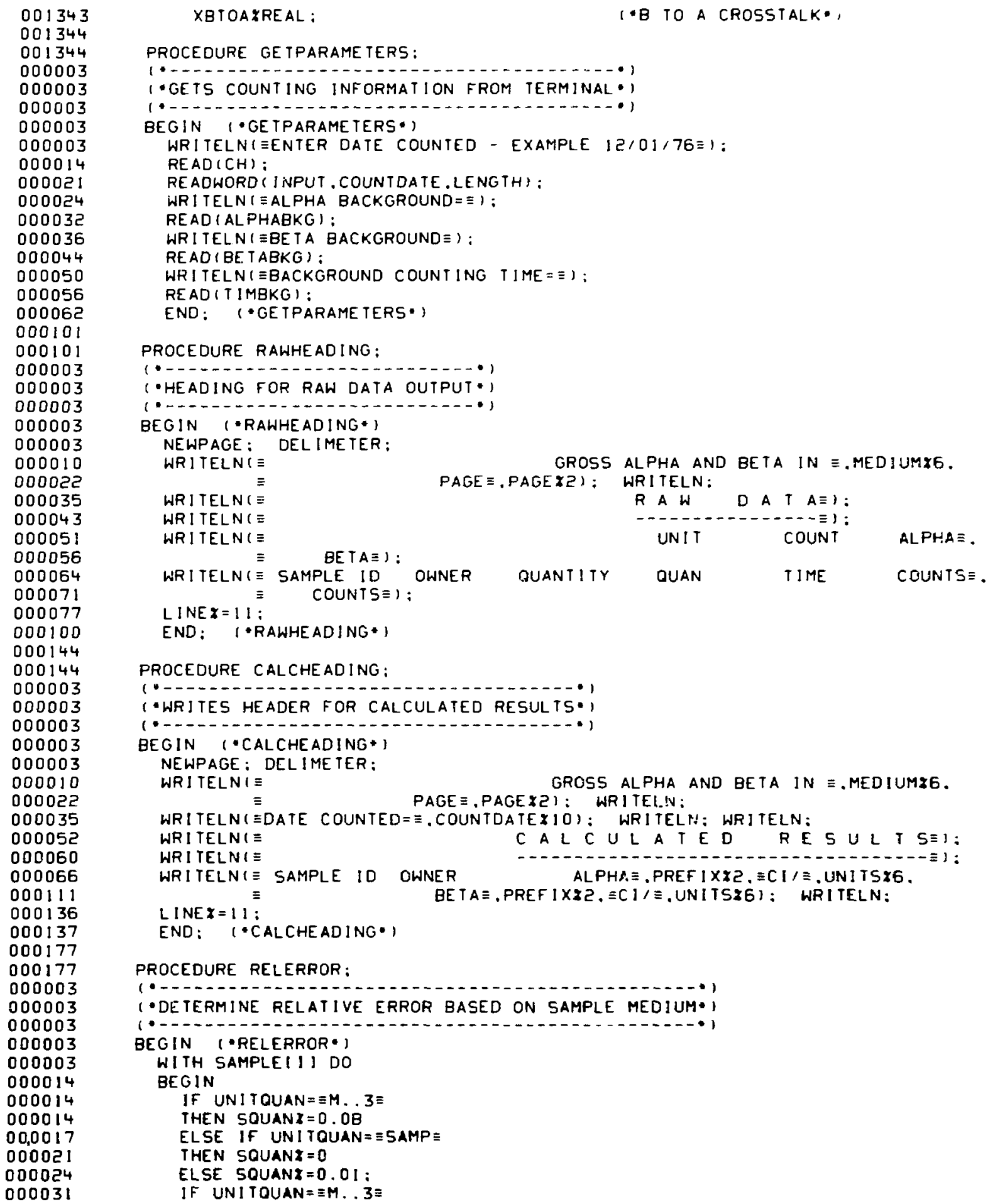




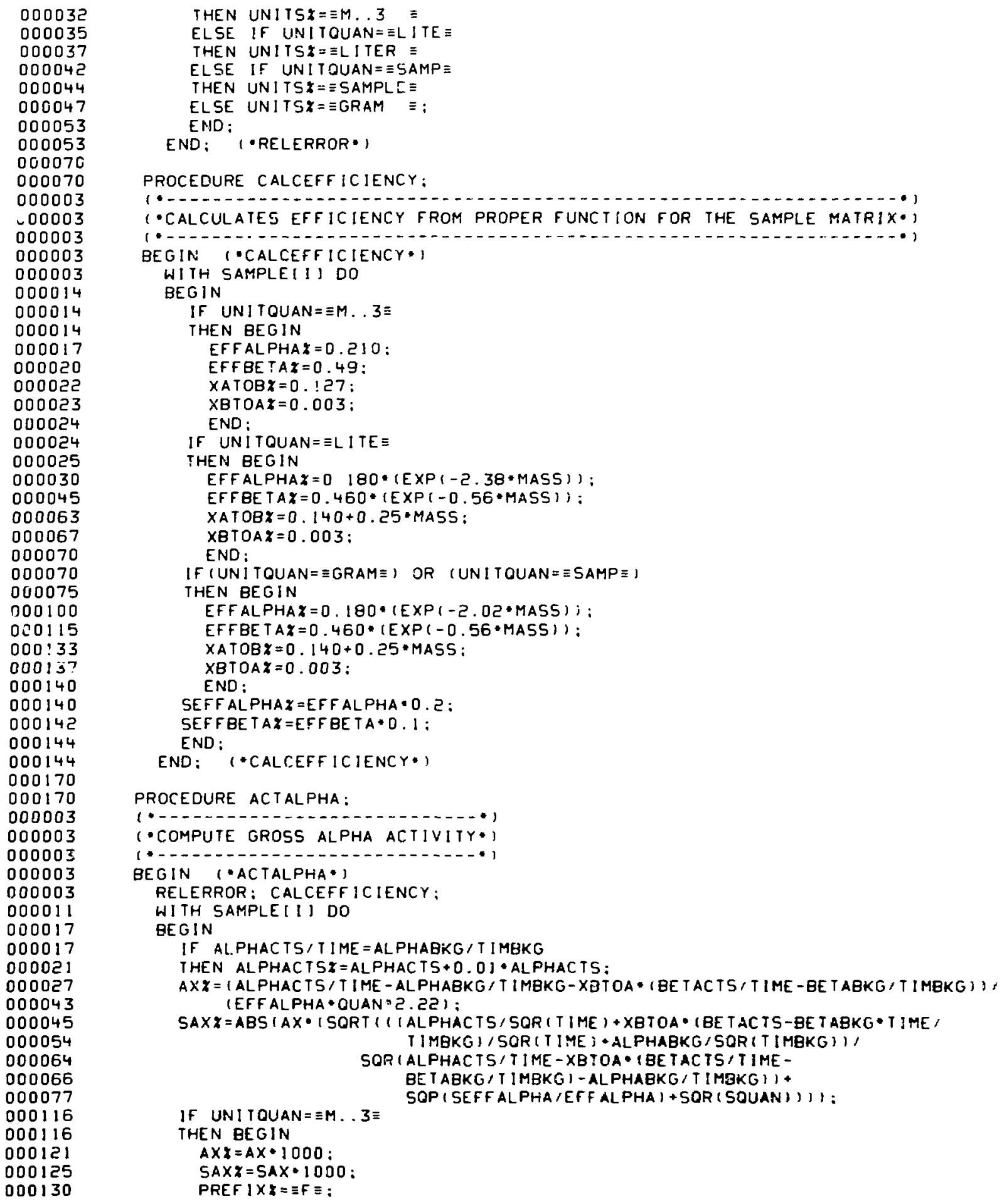




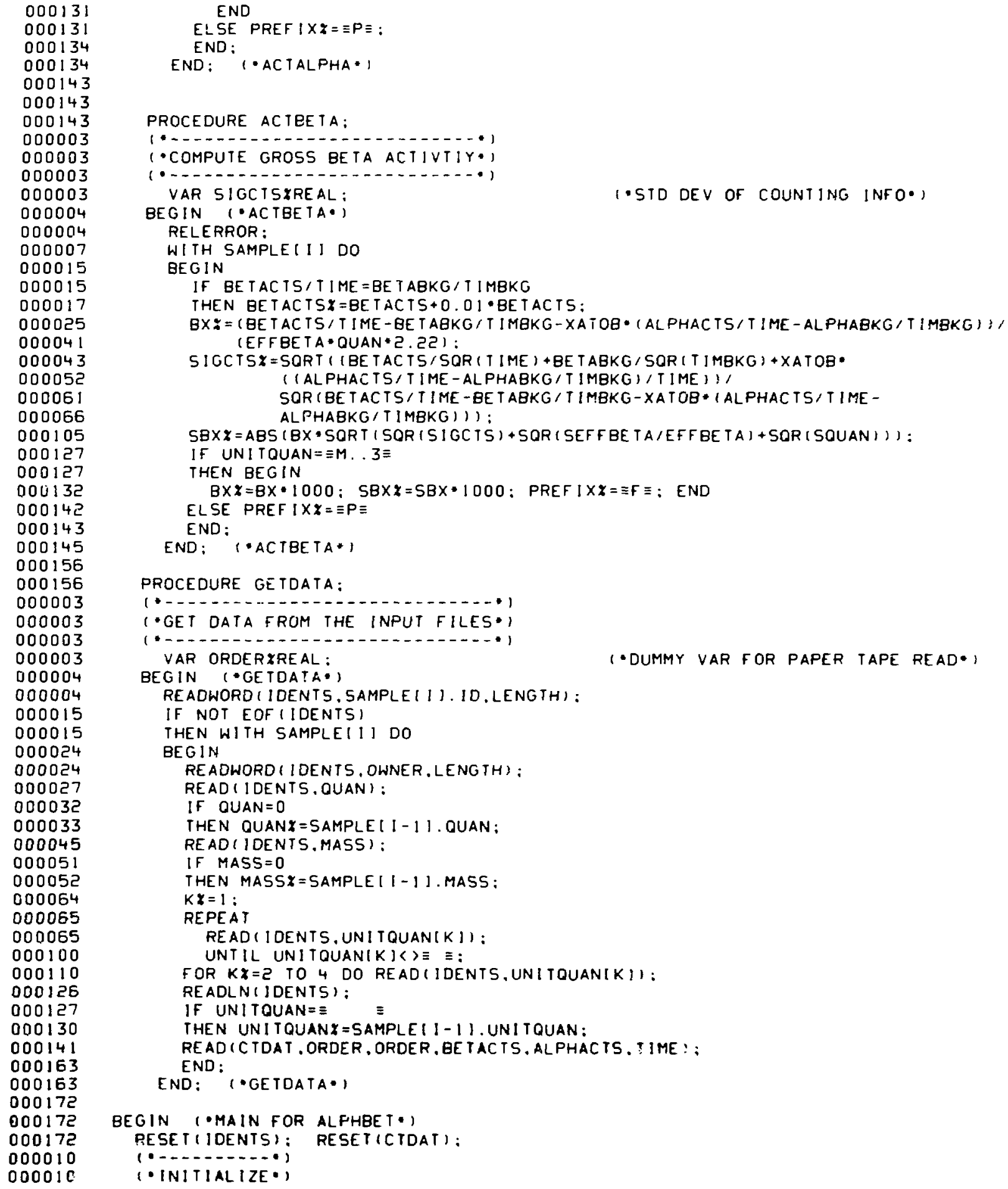

PROCEDURE ACTEETA: 


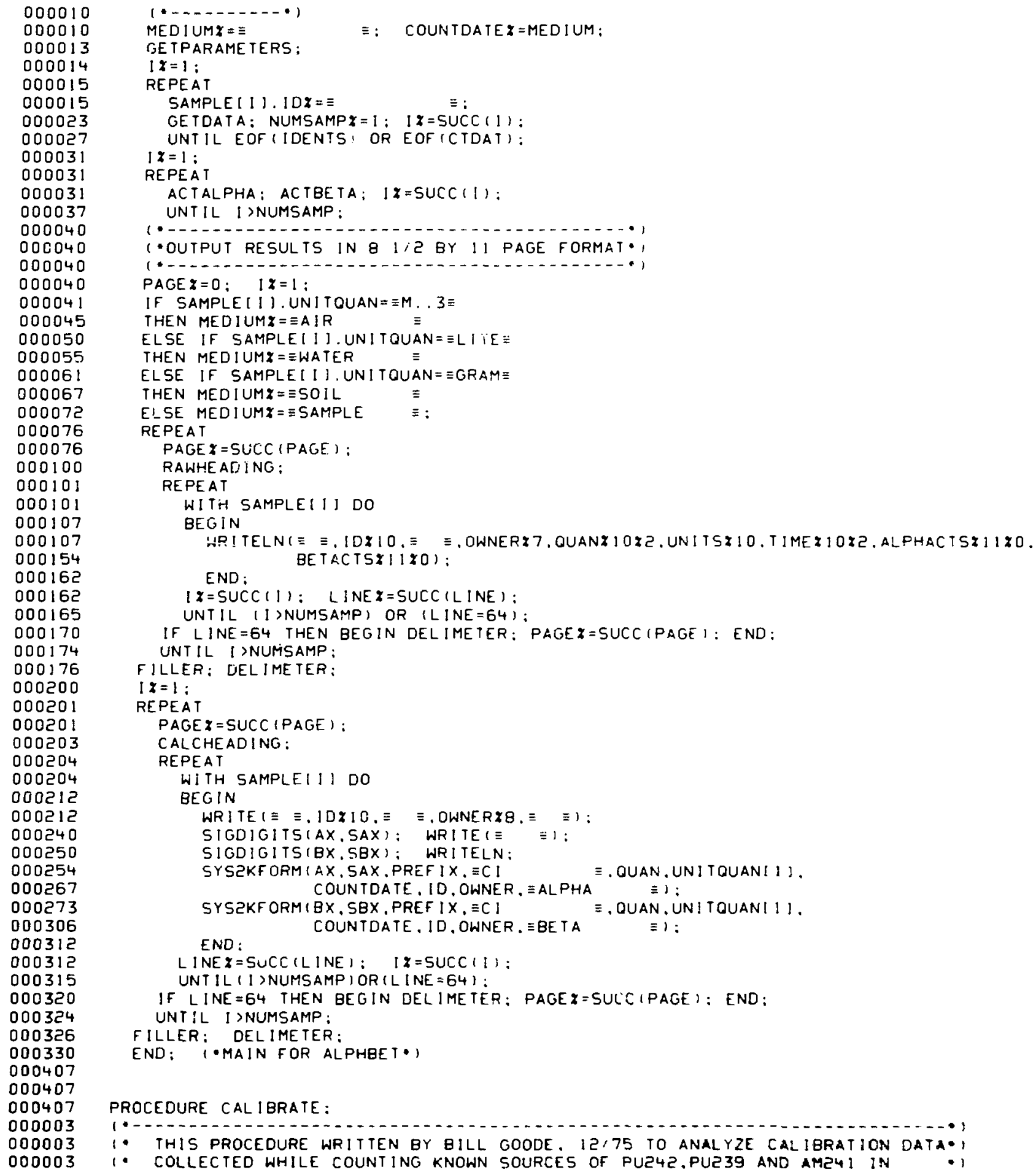




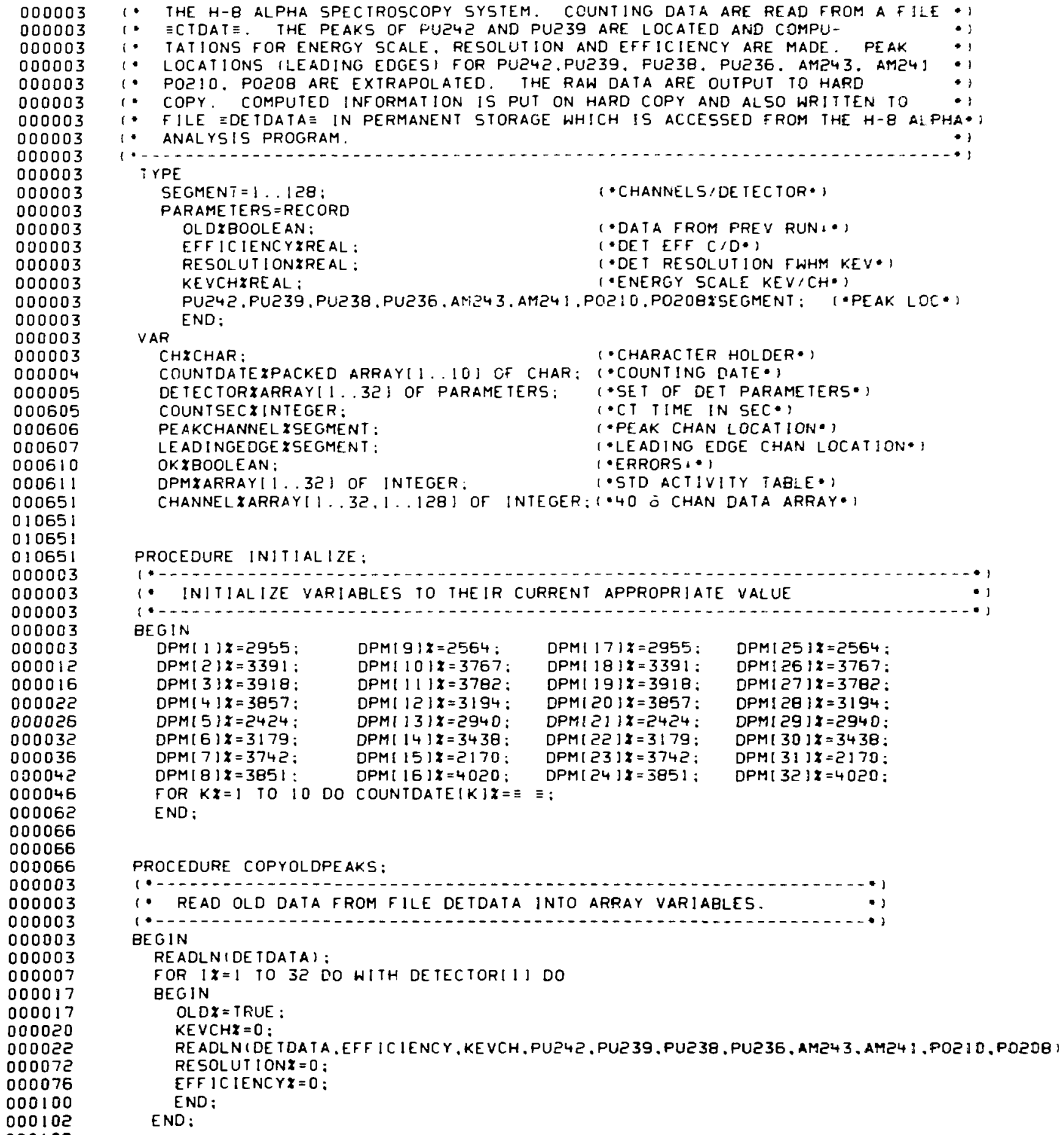




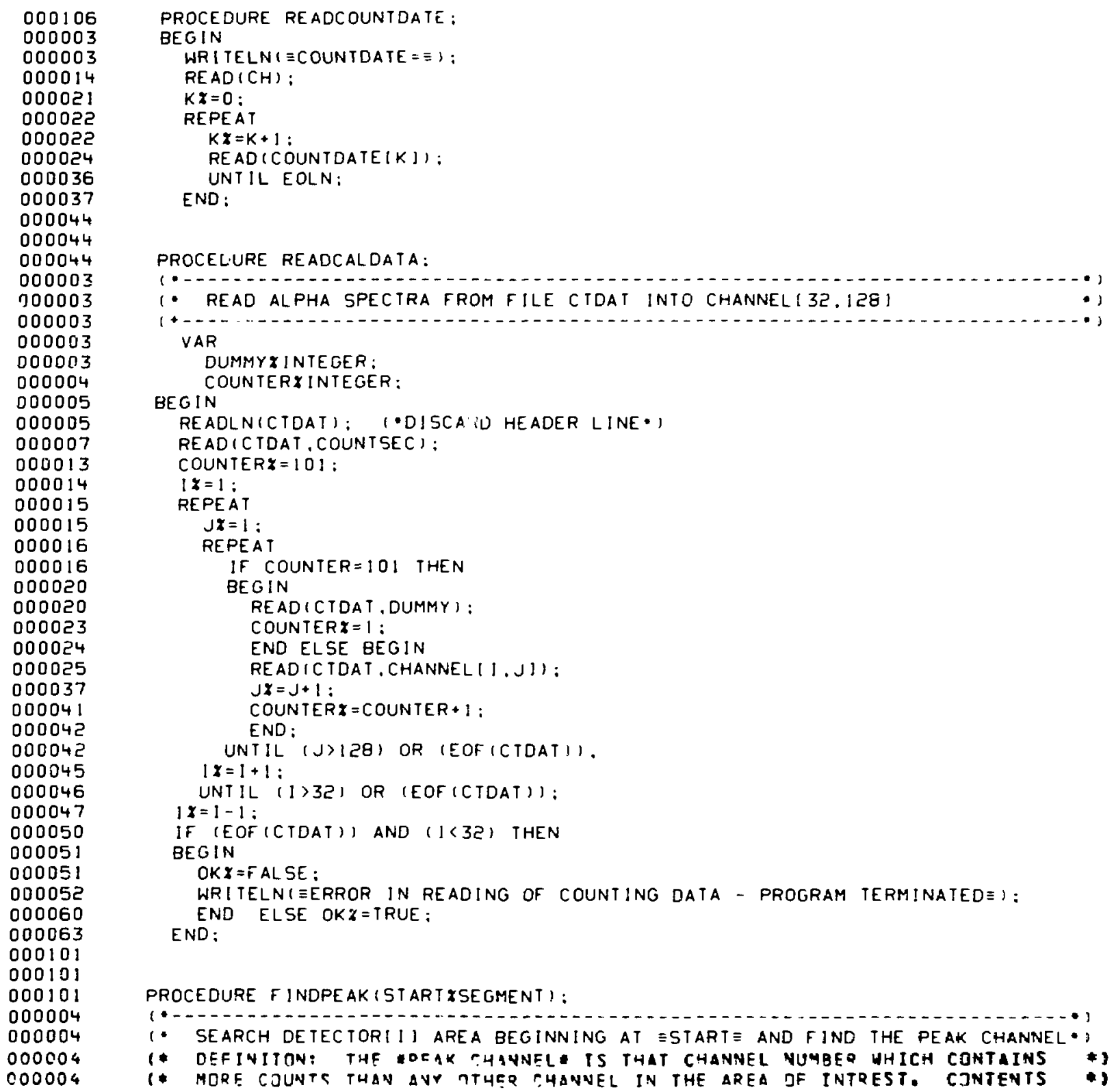




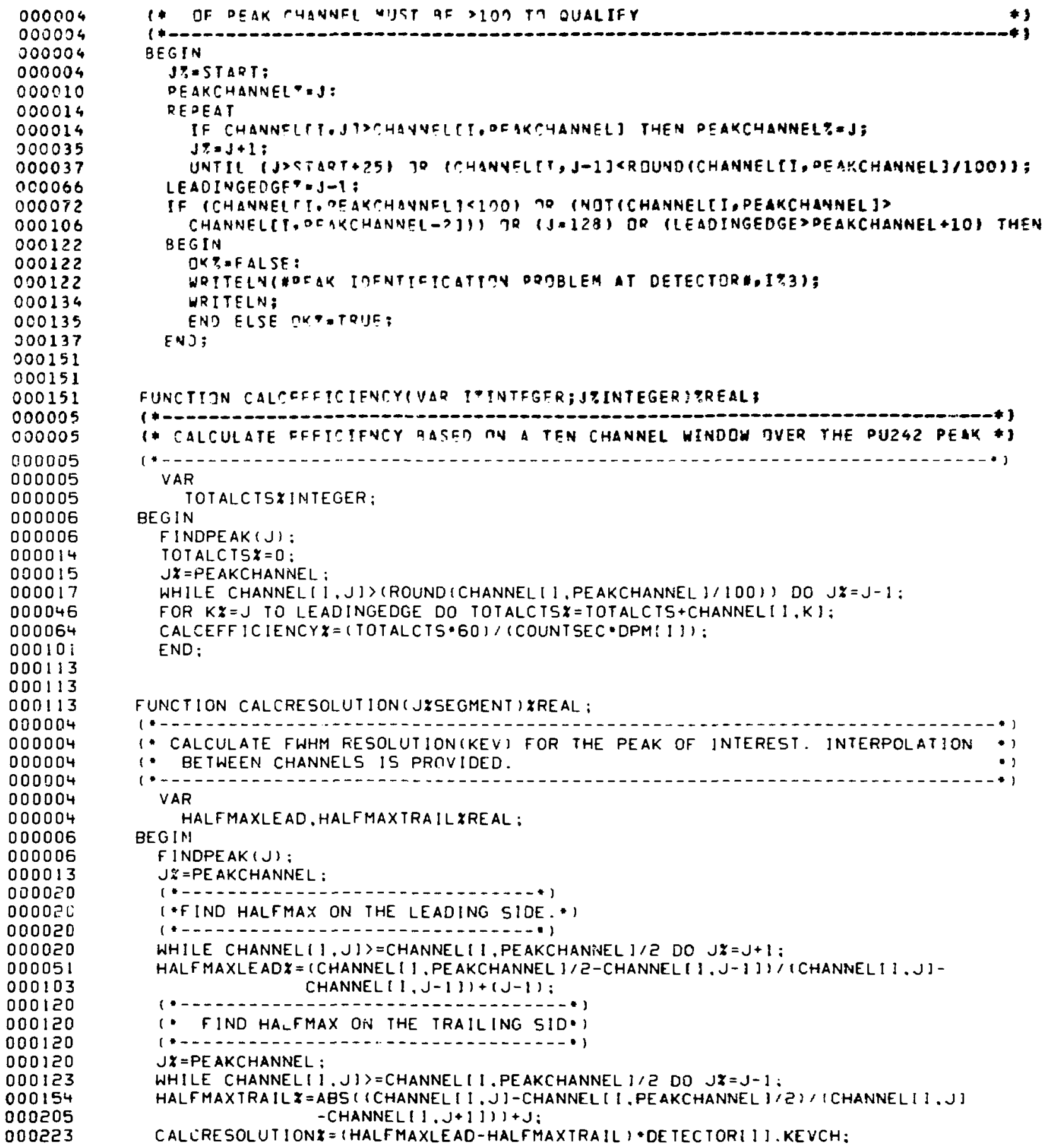


: ( $\forall 1 \forall 0130) \exists 11$ I

1.: $5 \times \forall 3 d 070 \wedge d 0 J .1$

$: \forall \perp \forall 07 \forall \supset 0 \forall \exists \forall$

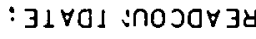

: ONJ

$$
: 1 \equiv-\cdots-----D
$$

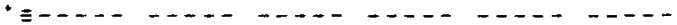

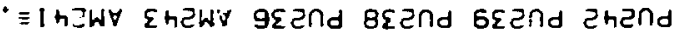

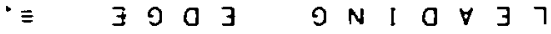

$$
\begin{aligned}
& : \text { C OIZJiROINOOJ } \equiv=31 \forall 0
\end{aligned}
$$

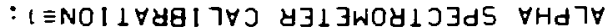

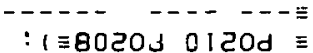

HJ גONJI NOII $\forall I \forall O{ }^{\circ}$ ONEINTJII $: 1 \equiv S 73 N N \forall H J \equiv$

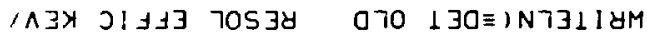
:N73114M $\equiv I N 7 \exists \perp I M M$ $\equiv N 7 \exists 11$ I N! 139

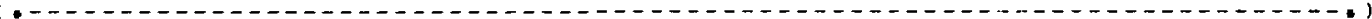
(. SNOI 1 SnO I

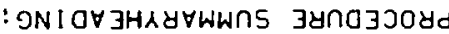

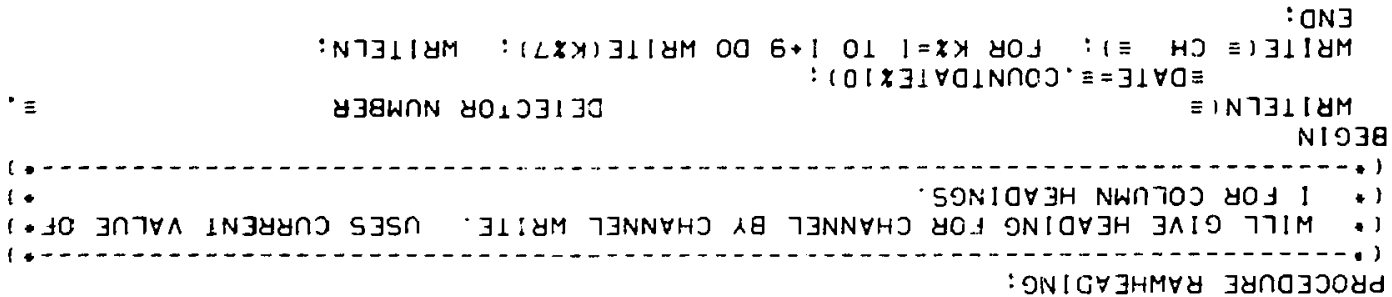

: ON 3 $\angle 11000$

901000

h $\angle 0000$

$\varepsilon 90000$

$£ 90000$

$\varepsilon 90000$

$\varepsilon 90000$

h50000

$\angle \mathrm{H} 0000$

$\angle h 0000$

$9+0000$

टh0000

S£0000

S₹0000

मE 0000

Oع 0000

Oع 0000

I 20000

$\angle 10000$

$\angle 10000$

$\angle 10000$

$\angle 10000$

910000

910000

h 10000

ट 10000

210000

टा0000

ट10000

010000

I h 1000

I hI 1000

I hI000

I +1000

I $\angle 0000$

$\Sigma 90000$

990000

050000

$\varepsilon+0000$

SEOOOC

Oह000O

L20000

h10000

$\varepsilon 00000$

$\varepsilon 00000$

$\varepsilon 00000$

$\varepsilon 00000$

$\varepsilon 00000$

$\varepsilon 90000$

$\Sigma 90000$

$\Sigma 90000$

$9+0000$

920000

$\varepsilon 10000$

$\varepsilon 00000$

$\varepsilon 00000$

E00000

$\varepsilon 00000$

$\varepsilon 00000$

$\Sigma 00000$

टh2000

$\mathrm{Ch} 2000$

टhट000

OEटOOO 


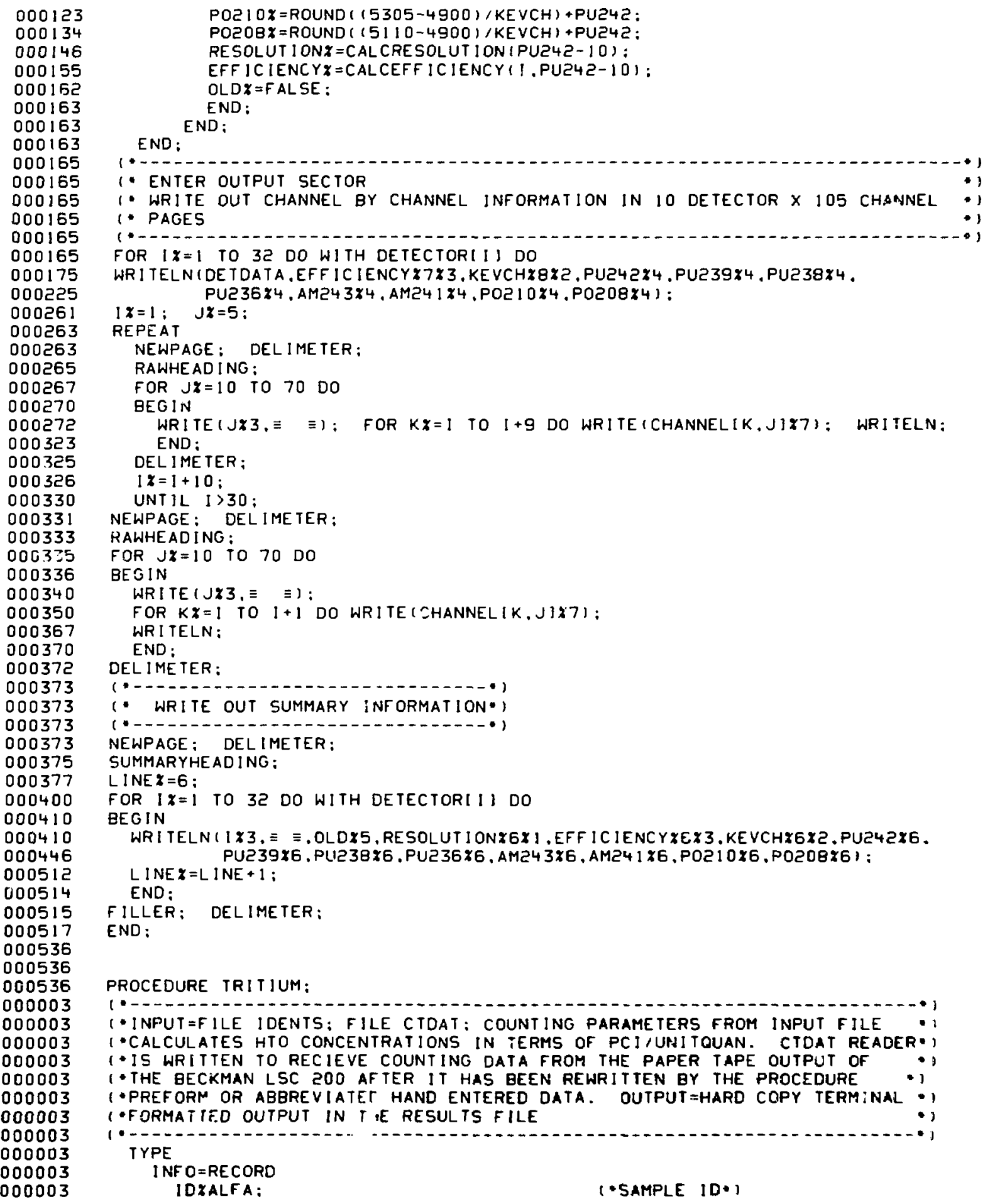




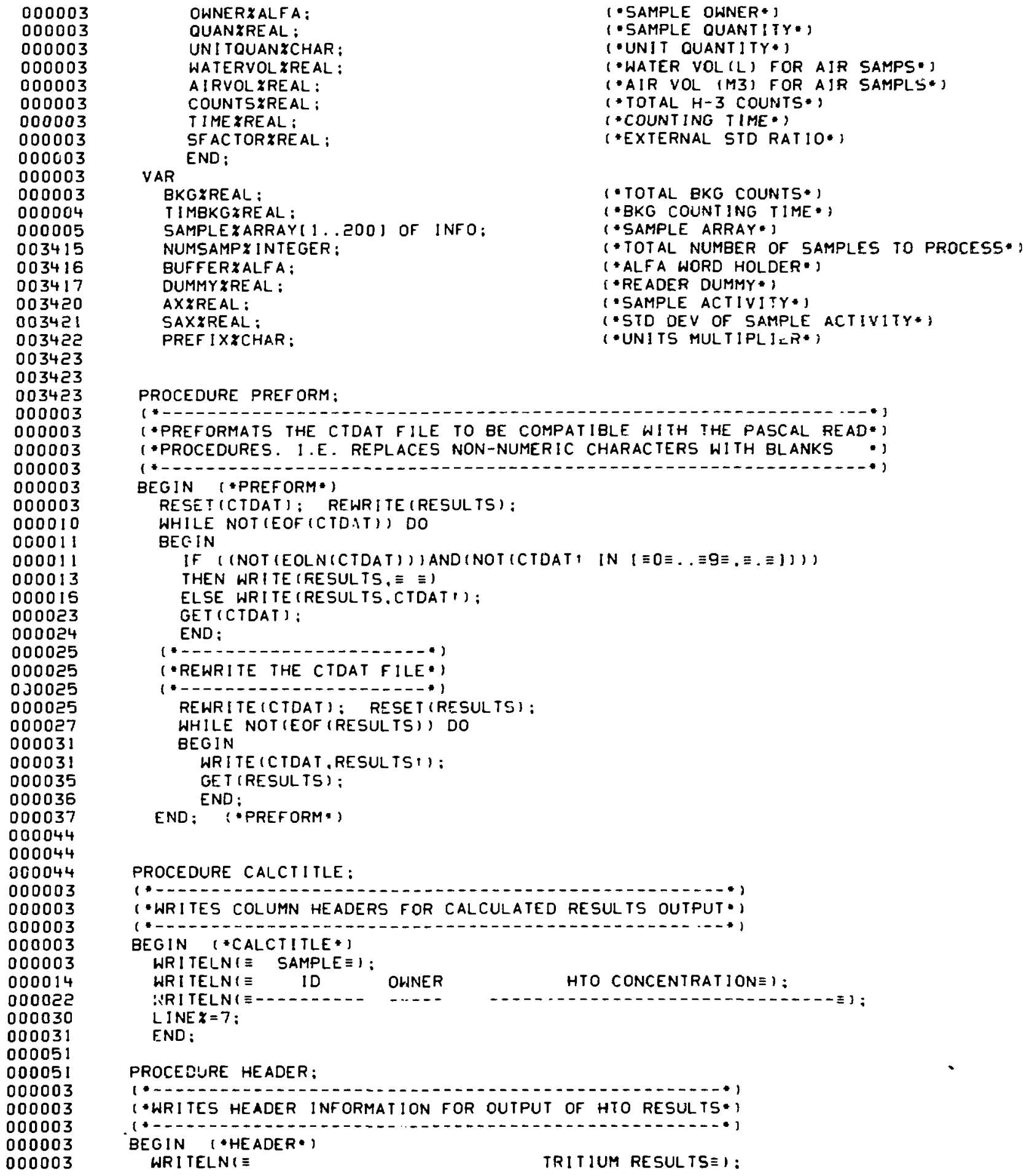

(-SAMPLE OWNER*) 1. SAMPLE QUANTITY*) ("UNIT QUANTITY*)

1. Water vol (L) for aif SAMPS*) 1.AIR VOL (M3) FOR AIR SAMPLS*] 1. TOTAL H-3 COUNTS.? (*COUNTING TIME*) (*EXTERnal STD RAT10*) SFACTORZREAL ; VAR

BKG ZREAL :

TIMBKG XREAL :

SAMPLEXARRAY $(1 \ldots 200)$ OF INFO: NUMSAMPXINTEGER:

BUFFERXALFA:

DUMMYXREAL :

AXXREAL:

SAXXREAL:

PREF I XYCHAR:

("TOTAL BKG COUNTS*)

1.BKG COUNTING TIME*?

("SAMPLE ARRAY*)

( TOTAL NUMBER OF SAMPLES TO PROCESS*

(*ALFA WORD HOLDER*)

I *READER DUMMY*)

1. SAMPLE ACTIVITY*1

(-STD DEV OF SAMPLE ACTIVITY*)

1. UNITS MULTIPLIIR*) 


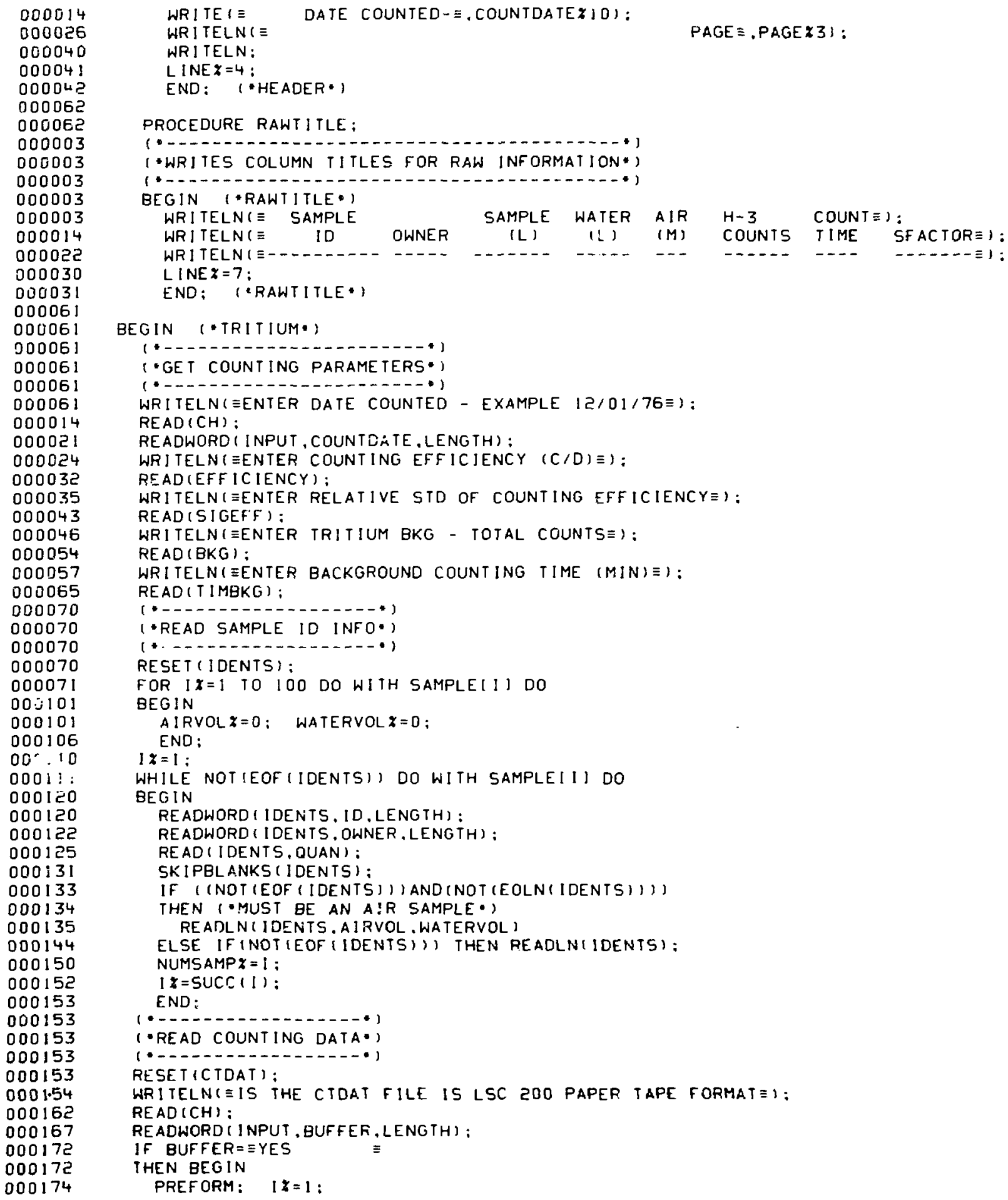

000014 000026 000040 00004 ! 000042 000062 000062 000003 000003 000003 000003 000003 000014 000022 000030 000031 00006 $00006 !$ 000061 00006 00006 ! 00006 000014 000021 000024 000032 000035 000043 000046 000054 000057 000065 000070 000070 000070 000070 000071 005101 000101 000106 $00^{\circ} .10$ 0001: : 000120 000120 000122 000125 $000: 31$ 000133 000134 000135 000144 000150 000152 000153 000153 000153 000153 000153 0001.54 000162 000167 000172 000172 000174

WR ITE I $\equiv$ WRI TELNC DATE COUNTED- $\equiv, C O U N T D A T E$ IDI: WRI TELN :

LINE $Z=4$ :

END: ("HEADER*)

PROCEDURE RAWTITLE: 


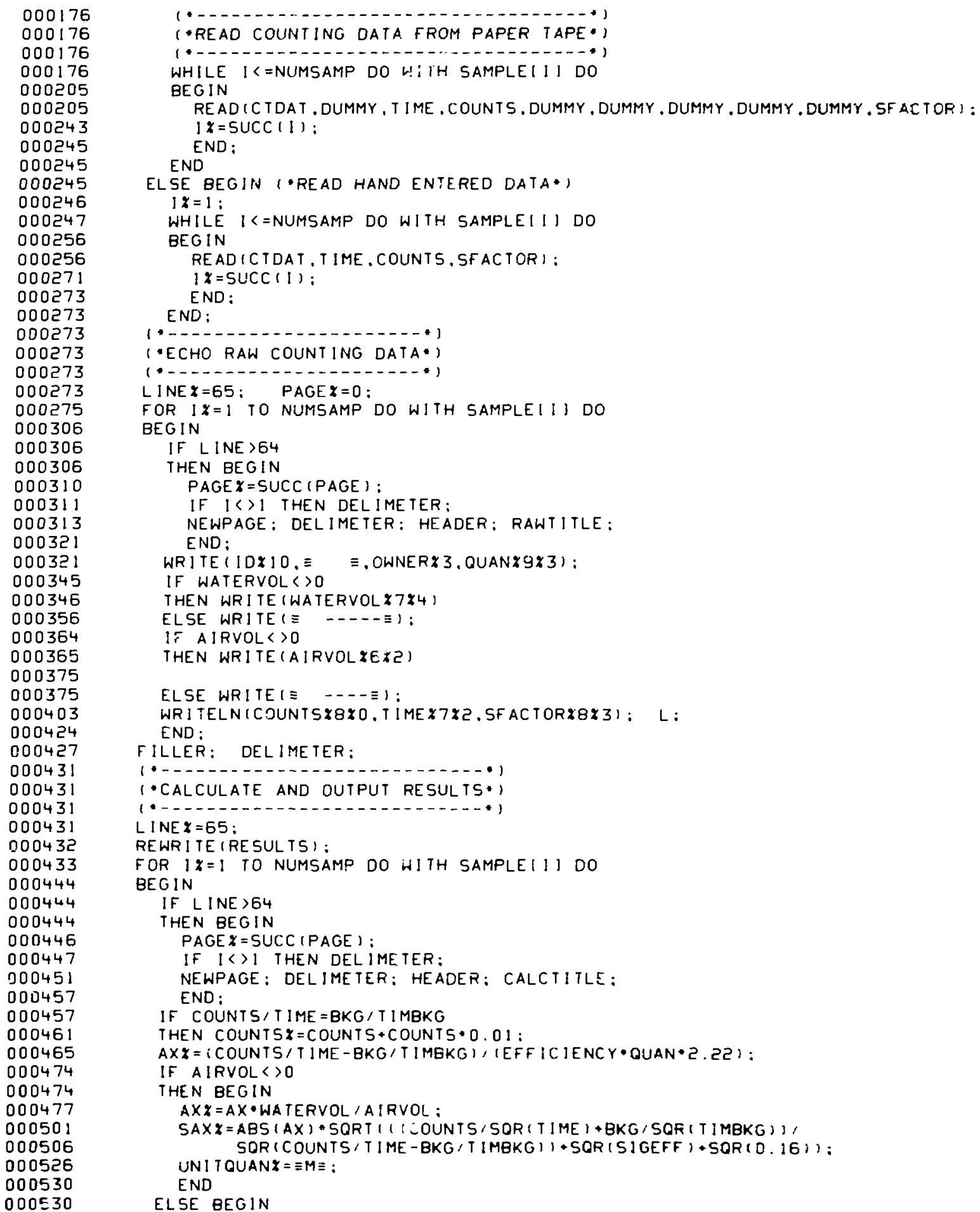




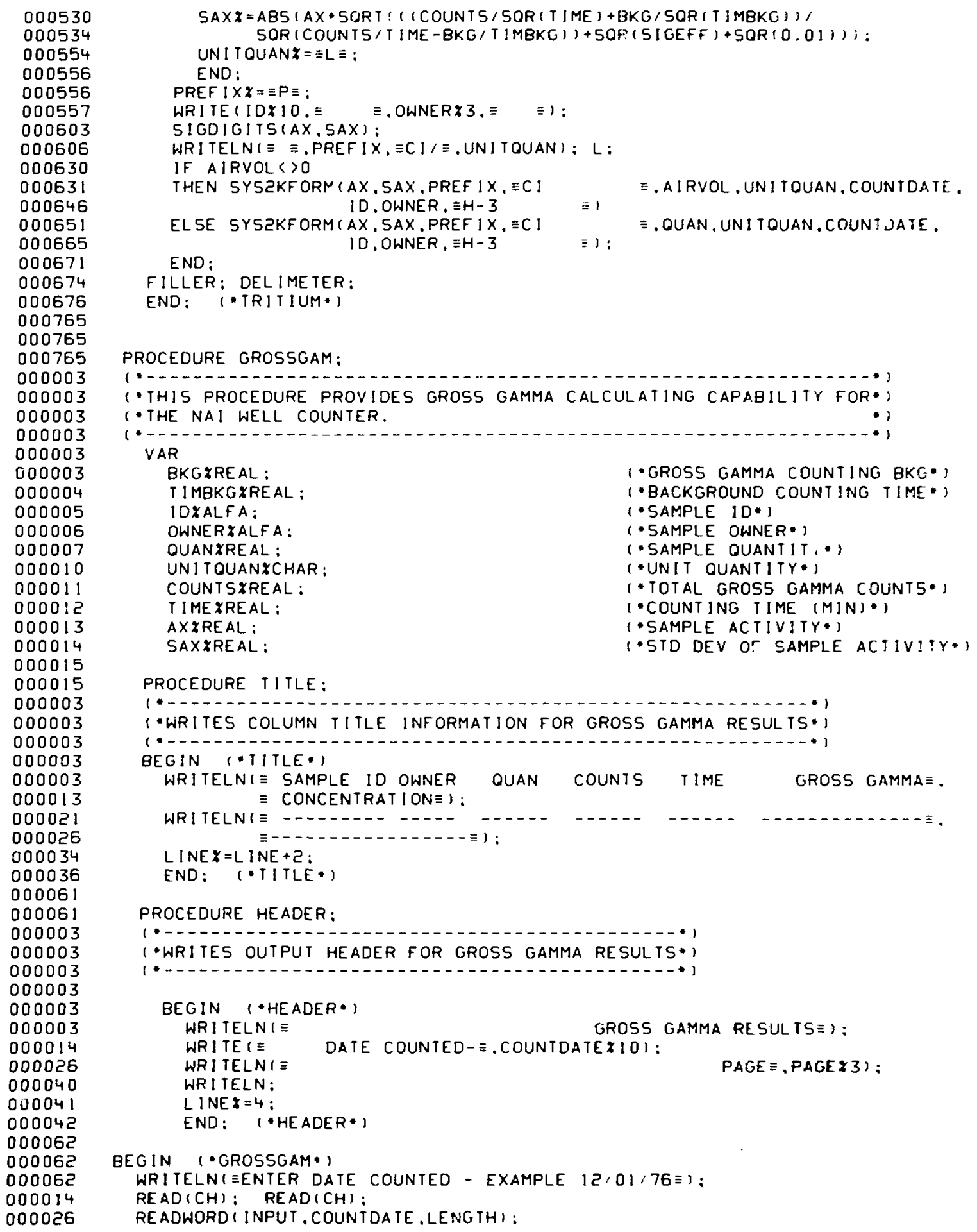

000530 000534 000554 000556 000556 000557 000603 000606 000630 000631 000646 000651 000665 000671 000674 000676 000765 000765 000765 000003 000003 000003 000003 000003 000003 000004 000005 000006 000007 000010 00001 000012 000013 000014 000015 000015 000003 000003 000003 000003 000003 000013 000021 000026 000034 000036 00006 ! 00006 000003 000003 000003 000003 000003 000003 000014 000026 000040 000041 000042 000062 000062 000062 000014 000026

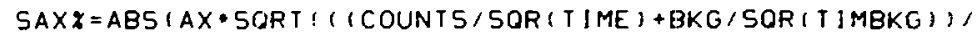
SOR (COUNTS/ T IME -BKG / T IMBKG I) + SOF: ( S IGEFF) +SOR ( 0.01 ) ) : UNI TOUANZ $=$ I $\equiv:$ END:

PREF IXX $=\equiv P \equiv$ :

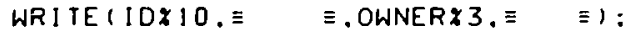

SIGDIGITSIAX.SAXI:

WRITELN ( $\equiv \equiv, P R E F I X, \equiv C I / \equiv, U N I T O U A N) ; L$ :

IF AIRVOL $<O$

THEN SYSZKFORM (AX, SAX, PREF $1 X, \equiv C$ I ID. OWNER, $\equiv H-3$

ELSE SYSZKF ORM ( AX, SAX, PREF IX. $\equiv C$ I

END; ID. OWNER, $\equiv \mathrm{H}-3$ 政 झ AIRVOL , UNI TOUAN, COUNTDATE. Ð . OUAN, UNI TOUAN, COUNI JAIE.

FILLER; DEL IMETER:

END: ( TRRITIUM*)

PROCEDURE GROSSGAM:

(- THIS PROCEDURE PROVIOES GROSS GAMMA CALCULATING CAPABIL

(-THE NAI WELL COUNTER.

(.....

VAR

BKGXREAL:

TIMBKGXREAL :

IDXALFA :

OWNER XALFA:

OUANXREAL:

UNITOUANXCHAR:

COUNTSYREAL:

TIMEXREAL :

AXXREAL:

(-GROSS GAMMA COUNTING BKE・ ("BACKGROUND COUNT ING TIME*) (*SAMPLE ID*J

(* SAMPLE OWNER* $)$

("SAMPLE OUANTIT:")

(*UN I T OUANT ITY*)

("TOTAL gROSS gamma COLNTS*)

SAXIREAL:

1. COUNTING TIME (MIN)*)

1. SAMPLE ACTIVITY*]

1.5TD DEV OT SAMPLE ACTIV!?Y*I

PROCEDURE TI TLE:

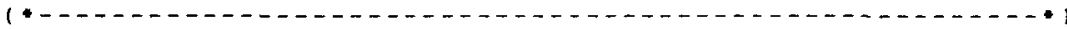

(*WRITES COLUMN TITLE INFORMATION FOR GROSS GAMMA RESUL TS*)

1.............

BEGIN $(* T I T L E \cdot)$

WRITELNI SAMPLE ID OWNER QUAN COUNTS TIME GROSS GAMMAE. $\equiv$ CONCENTRAT ION I:

WRI TELN $\equiv \ldots \ldots \ldots \ldots \ldots \ldots$

LINE $X=L, N E+2$;

END: $\quad(\cdot T / T L E *)$

PROCEDURE HEADER:

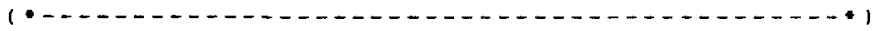

(*WRITES OUTPUT HEADER FOR GROSS GAMMA RESULTS*)

1...

BEGIN (*HEADER *

WRITELNI $\equiv$ GROSS GAMMA RESULTS : :

WRITE( $\equiv$ DATE COUNTED- . COUNTDATEZ101:

WRITELNI

WR!TELN:

LINEX $=4$ :

END : $\quad 1 *$ HE ADER*1

BEGIN (*GROSSGAM*)

WRITELNI ENTER DATE COUNTED - EXAMPLE 12/01/76ミ1;

READ (CH): READ (CH) :

READWORDI INPUT , COUNTDATE , LENGTHI: 
000031 000037

000042

000050

000053

000053

000053

000053

000056

000060

000062

000062

000065

000070

000102

000104

000112

000114

000120

000123

000126

000145

000145

000145

000145

000145

$000 ! 47$

000151

000160

000160

000220

000223

000236

000252

000255

000256

000257

000260

000325

000325

000325

000003

000003

000003

000003

000003

000003

000003

000003

000003

000003

000003

000003

000003

000003

000003

000003

000003

000003

000003

000003

000003

000003

000003

WRITELNI $E$ ENTER GROSS GAMMA BKG - TOTAL COUNTS I:

READ (BKG):

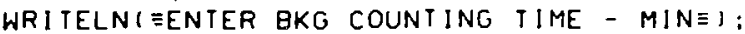

READ (T IMBKG):

(1:

(*READ INPUT.CALCULATE AND OUTPUT RESULTS ONE SAMPLE AT A IIME*)

1*-.

RESET(IDENTS); RESET(CTDAT); REWRITE (RESULTS):

LINE $X=67$; PAGE $X=0$;

WHILE (INOTIEOF (IDENTSI)) AND(NOTIEOF ICTDAT)))

DO BEGIN

READWORD I IDENTS, ID, LENGTH!:

READWORD (IDENTS, OWNER, LENGTH):

READ (IDENTS, OUAN); SKIPBL.ANKS (IDENTS); READ (IDENTS. UNITOUAN):

IF NOT (EOF (IDENTS)) THEN READLN(IDENTS):

READ (CTDAT, COUNTS. TIME):

IF NOT (EOF ICTDATI) THEN READLN(CIDAT):

$A X X=$ I COUNTS/TIME-BKG/TIMBKG I / OUAN:

IF ( (COUNTS/TIME) $=(B K G / T$ IMBKG) THEN COUNIS $X=$ COUNT $5+$ COUNTS $0.00001:$

SAXX = ABS (SORT ( (COUNTS/SOR (TIME) +BKG /SOR (TIMBKG))

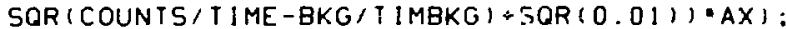

1....................................

(*OUTPUT RAW AND CALCULATED INFORMATION*)

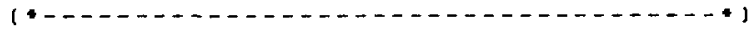

IF L INE >65

THEN BEGIN

PAGE $X=$ SUCC (PAGE) : LINE $X=1$ :

DELIMETER: NEWPAGE; DEL IMETER; HEADER: TITLE:

END:

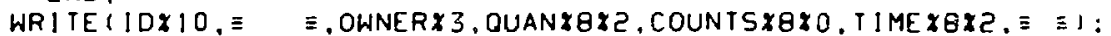

SIGDIGITS $(A X, S A X)$ :

WR ITELN ( $\equiv$ NCPM/, UN!TQUAN): L:

SYSZKFORM (AX, SAX, $\equiv \equiv$. NCPM , QUAN, UNITOUAN, COUNTDATE, IO.

END: OWNER, $\equiv \quad$ GAMMA $\equiv 1$ :

FILLER:

DEL IME TER:

END: $\quad$ (*GROSSGAM:)

PROCEDURE SR9O:

1. PROCEDURE FOR HANDLING SR-90 DATA REDUCTION. INPUT DATA ARE MANLALLY

:BUILT INTO A FILE IDENTS*. OTHER INPUT DATA ARE ENTERED FROM

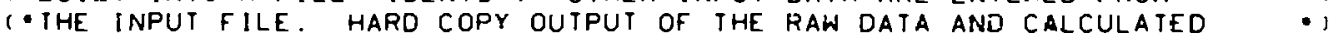

1-RESULTS ARE PROVIDED. RESULTS ARE ALSO FORMED FOR SYSTEM 2000 ')

1.AND WRITTEN TO THE *RESULT * FILE

1.

CON5T

ARS I ZE $=50$ :

BLANKS $=\equiv$

TYPE

DATA $=$ RECORD

IDXALFA:

OWNER I ALF A :

OUANYREAL:

UN! TOUANZCHAR:

CTDURXREAL :

CTSXREAL:

SEPDATEXALFA:

SEPHRY INTEGER:

SEPMINZINIEGER:

1- SAMPLE JD

1.5AMPLE OWNER

1. SAMPLE QUANTITY

1. UNIT DUANTITY

DURATION IN MIN

BE TA COUNTS

(- SEParation Date

1 5EPARATION HOUR OF DAY

i.separation MIN Of hOUR 


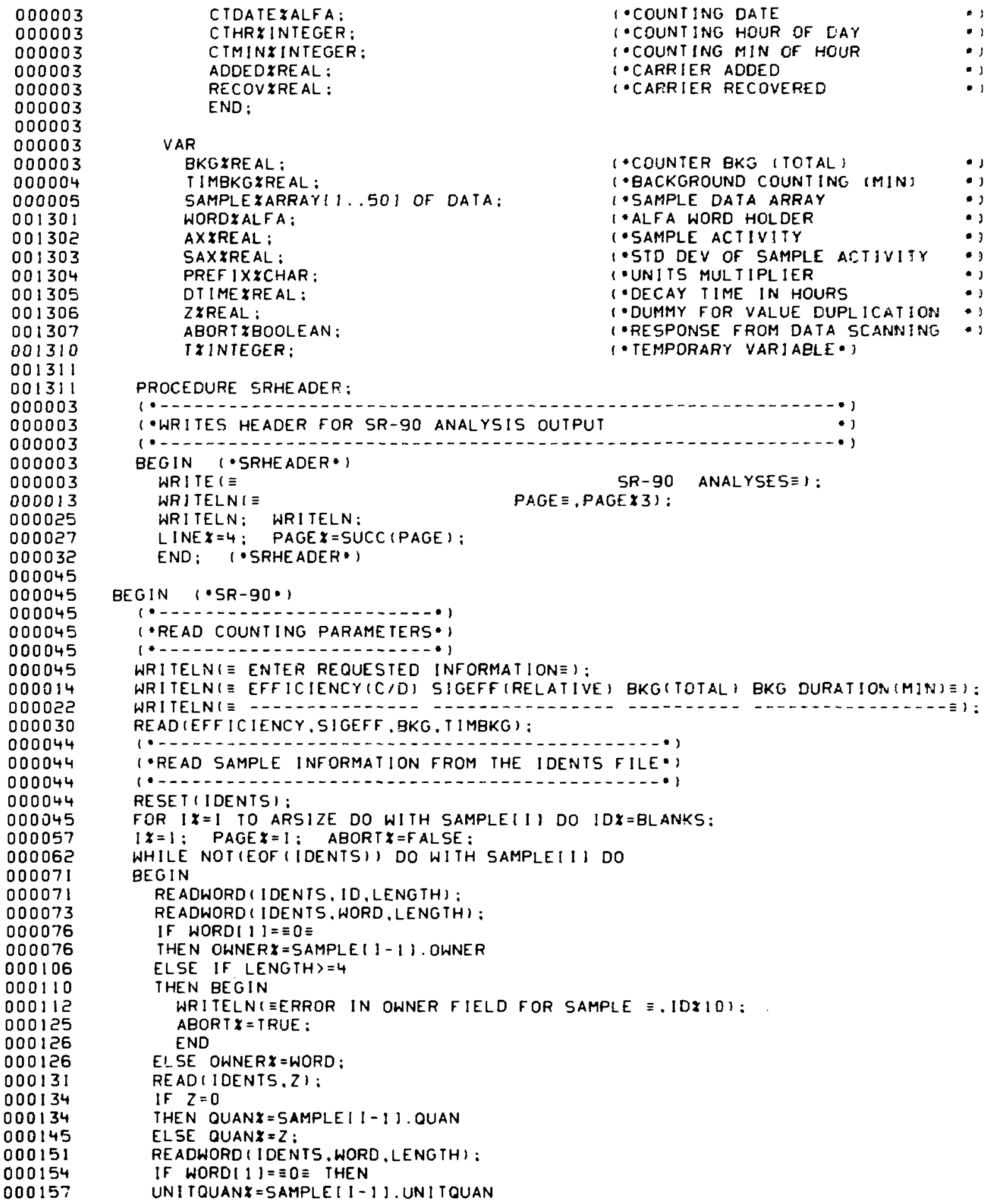

000003 000003 000003 000003 000003 000003 000003 000003 000003 000004 000005 001301 001302 001303 001304 001305 001306 001307 001310 001311 001311 000003 000003 000003 000003 000003 000013 000025 000027 000032 000045 000045 000045 000045 000045 000045 000014 000022 000030 000044 000044 000044 000044 000045 000057 000062 000071 000071 000073 000076 000076 000106 000110 000112 000125 000126 000126 000131 000134 000134 000145 000151 000154 000157

CTDATEXALFA:

CTHRZINTEGER:

CTMINZINTEGER;

ADDED XREAL :

RECOV $\% R E A L$ :

END :

VAR

BKG XREAL:

TIMBKGXREAL :

SAMPLEXARRAY $\{1 \ldots 501$ OF DATA:

WORD\& AL FA:

AXXREAL ;

SAXXREAL

PREF $1 \times 2$ CHAR:

DT IME XREAL:

Z KREAL :

ABORT YBOOLEAN :

TIINTEGER:

1. COUNTING DATE

- COUNTING HOUR OF CAY

1. COUNTING MIN OF HOUR

- CARRIER ADDED

1. CAFRIER RECOVERED

PROCEDURE SRHEADER:

WRI TELNI PAGE $\equiv$,PAGE $\times 3\}$ :

(*COUNTER BKG (TOTAL) (*BACKGROUND COUNTING IMIN) 1.5AMPLE DATA ARRAY ") 1. ALFA WORD HOLDER (-SAMPLE ACTIVITY :? 1.5TD DEV OF SAMPLE ASTIVITY :? 1- UNITS MULTIPLIER 1.DECAY TIME IN HOURS 1-DUMMY FOR VALUE DUPLICATION (-RESPONSE FROM DATA SCANNING -? 1. TEMPORARY VARIAELE*?

WRI TELN: WRI TELN:

LINE $X=4$; PAGE $X=$ SUCC (PAGE) ;

END: ('SRHEADER *)

BEG IN $1 \cdot 5 R-90 \cdot 1$

(1.-.

1.READ COUNTING PARAMETERS *

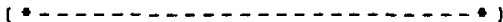

WRITELN(

WRI TELNI E EFFICIENCY(CID) SIGEFF (RELATIVE) BKG(TOTALI BKG DURATIONIMIN] I: WRI TELNI READ (EFF ICIENCY, SIGEFF, BKG. TIMBKG):

1...........................

1"READ SAMPLE INFORMATION FROM THE IDENTS FILE*)

(•-........

RESET (IDENTS):

FOR I $x=1$ TO ARSIZE DO WITH SAMPLEII) DO ID $x=B L A N K S$ :

I $x=1$ : PAGE $x=I$ : ABORT $x=F$ ALSE :

WHILE NOTIEOF (IDENTS)) DO WITH SAMPLEII I DO

BEGIN

READWORD ( IDENTS, ID, LENGTH) :

READWORD (IDENTS, WORD. LENGTH):

IF WORDI I] $=\equiv 0 \equiv$

THEN OWNER $X=$ SAMPLE $(1-1)$. DWNER

ELSE IF LENGTH $>=4$

THEN BEGIN

WRITELNI $\equiv E R R D R$ IN OWNER FIELD FOR SAMPLE $\equiv . I D Y I D I:$ ABORT $\%$ = TRUE :

END

EL.SE OWNER $X=$ WORD :

READ (IDENTS.Z):

IF $Z=0$

THEN OUAN $X=$ SAMPLE $[1-1\}$. QUAN

ELSE QUANX $=Z$ :

READWORD (IDENTS, HORD, LENGTH):

IF WORDI 1 I =\$OD THEN

UN I TQUANX = SAMPLE $[1-1]$. UN I TOUAN 


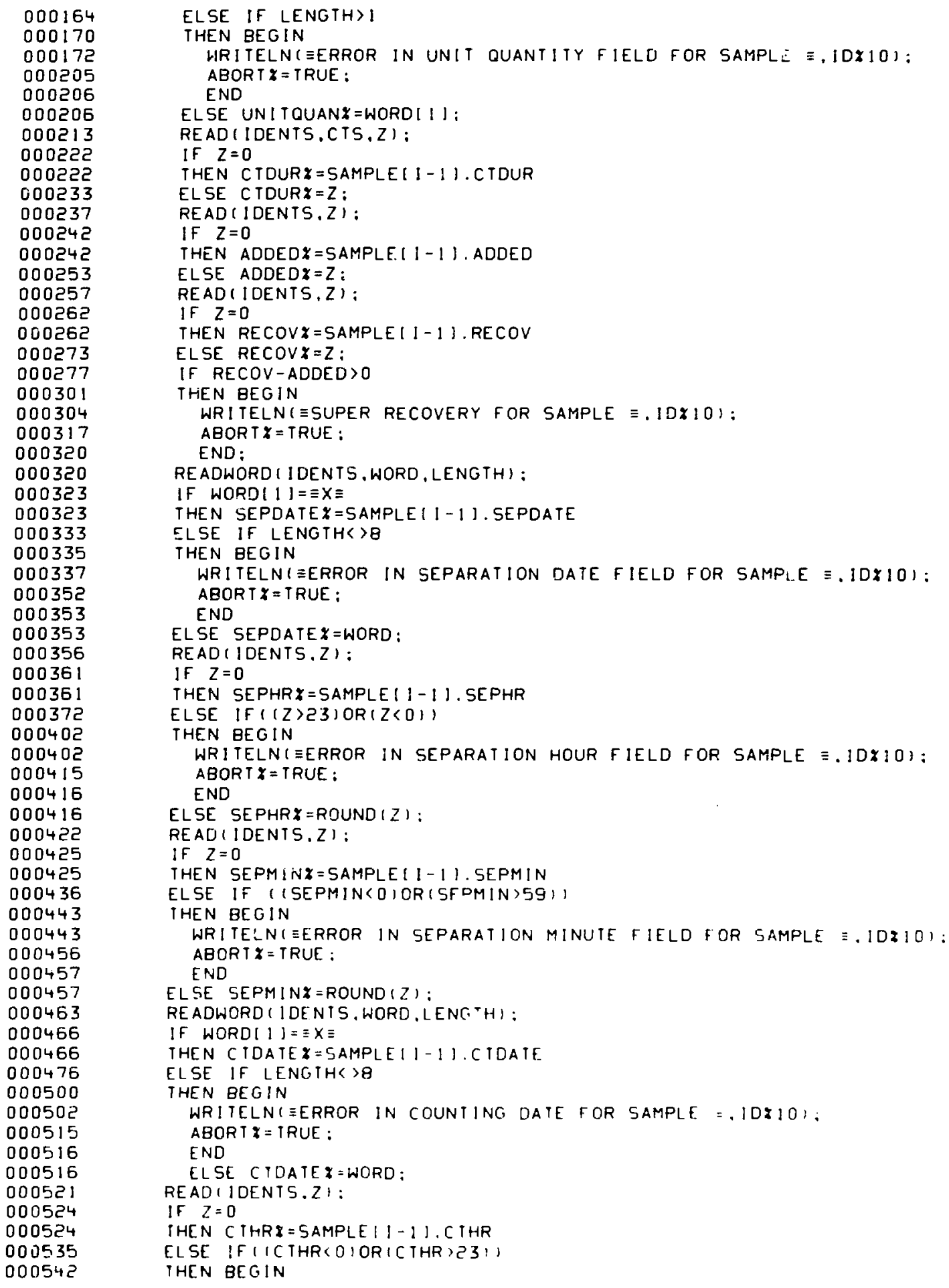




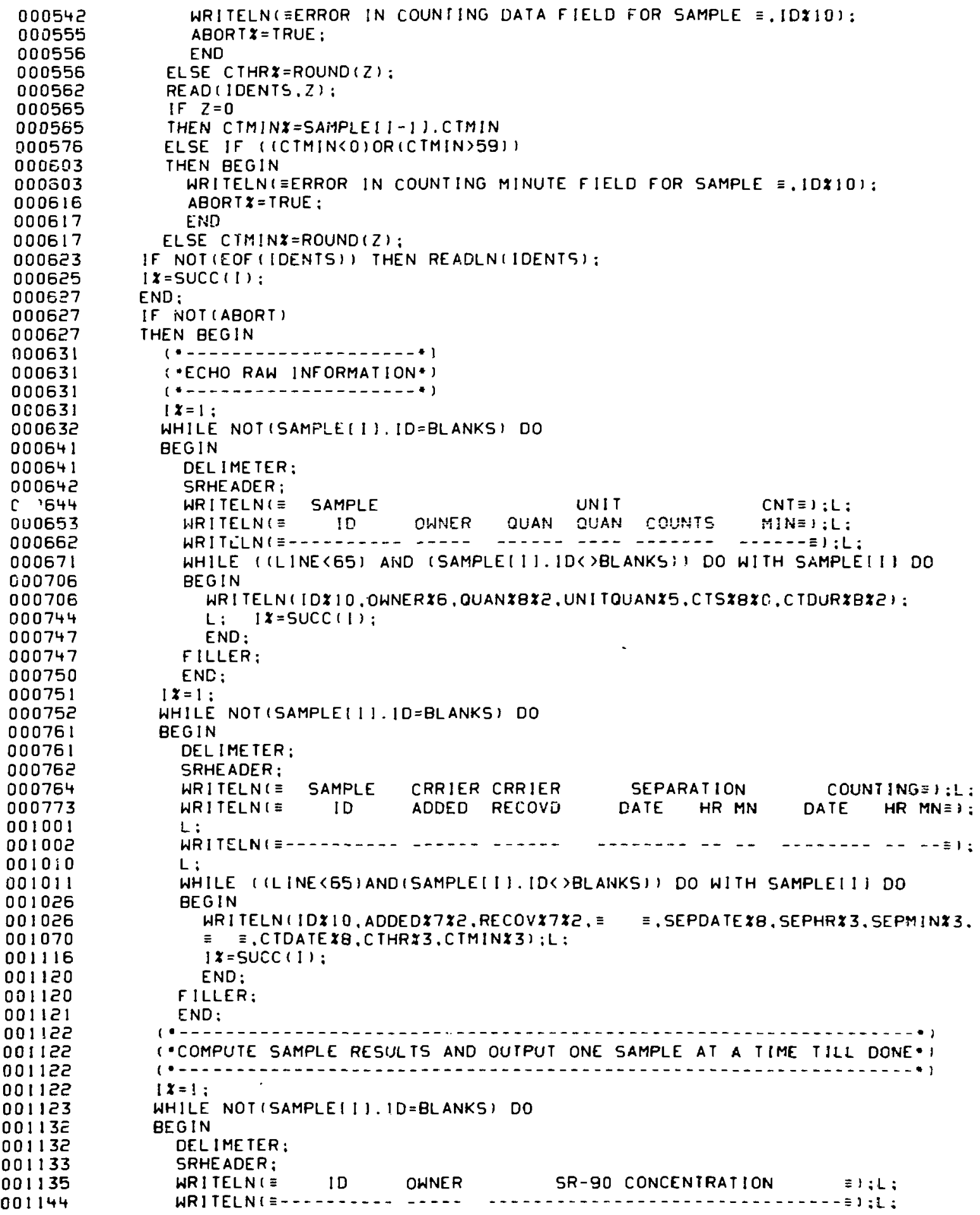




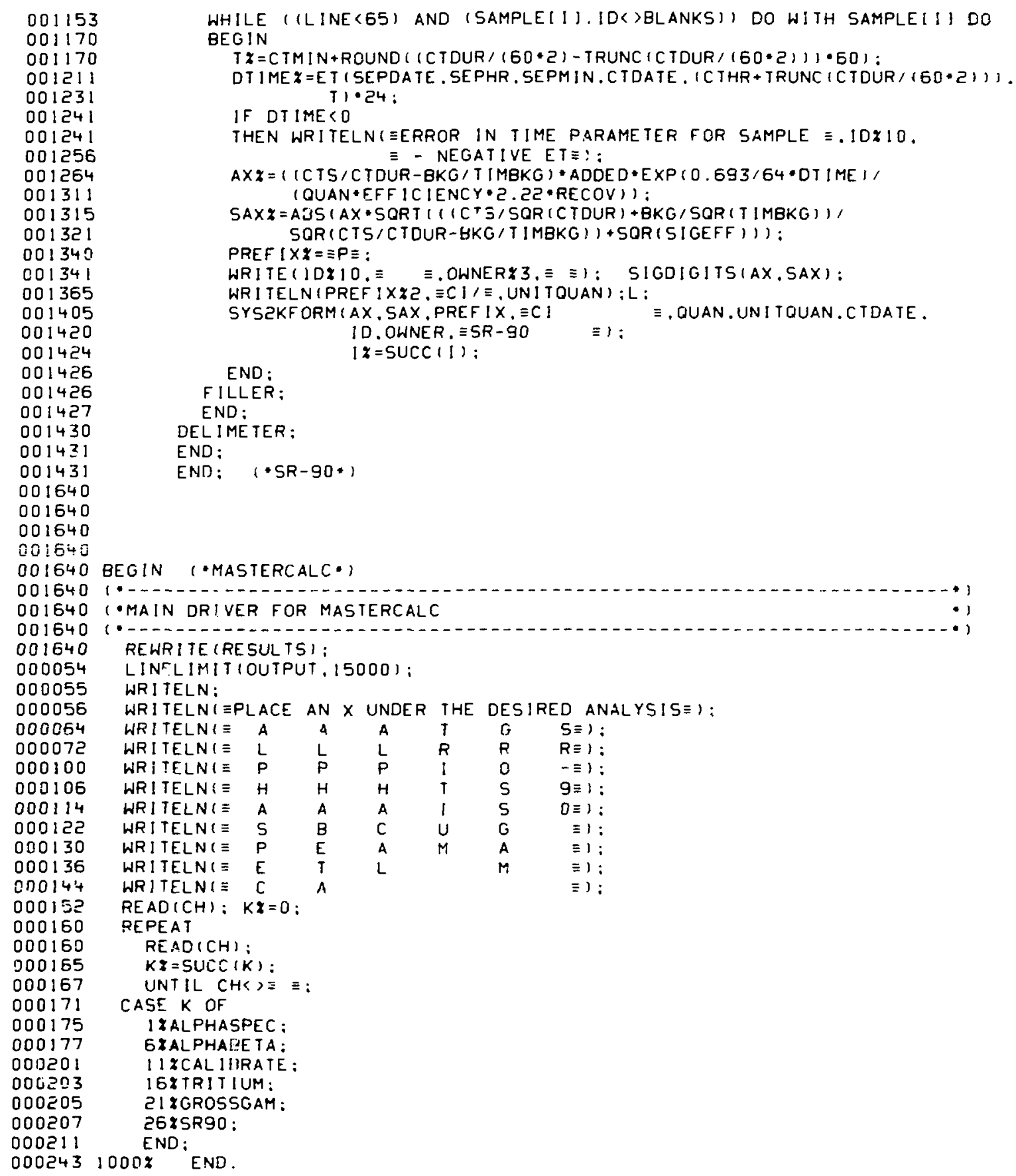

001153

001170

001170

001211

001231

001241

001241

001256

001264

001311

001315

001321

001340

001341

001365

001405

001420

001424

001426

001426

001427

001430

001431

001431

001640

001640

001640

001640

001640

001640

001640

001640

000054

000055

000056

000054

000072

000100

000106

000114

000122

000130

000136

000144

$00015 ?$

000160

000160

000165

000167

000171

000175

000177

000201

000503

000205

000207

000211

$0002431000 \%$ 
PROCRAM BKGOE IINPUI, OUTPUT, TAPE 3, IAPE4, IAPT51

DIMENSION IDATAIIZ8.32.41, CBIIZ8.321. SOCBI128.321. ICHANI 321 DIMENSION IFEGI(32.4), IREGE 132.4$)$, 1 TOT132.41, 1GI14), ITEMPI4096

1,

COMMON LINE, I. J. K, Ka. IDATE

THIS PROGRAM IS MODIF ICATION OF SM LOMgAROOS PROCRAM TO MUA YZE ALPHA SPEC IROME TRY BACKGROUNO INFORMATIONO WRITIEN BY BILL GOOOE 12/75. CLRRENT BACKGROUND CONTING DATA ARE READ FROM A FILE CTDAT HARD COPY INSORMATION IS GIVEN MNO PERTFILES APE MAINTAINED WHICH KEF.P (1) A FOUR WEEK RECORO OF PAST BKGOS (2) A COMPILATION OF AVE AND STD OEVIATION VALUES FOR EACH CHANEL OF EACH DETECTOR AREA BASED ON THE FOUR WEEK PERIOD (F ILE BKGOFL). THE FILE EXGOFL SUPPORIS THE ALPHA AMALYSIS COOE.

$151 Z E=32$

CALL GETPF (5HTAPE 3.5HCTDAT)

CALL GETPF (5HTAPE 4, 4HEKGXI

CALL GETPF (5HTAPE5.6HEKGOFL)

REWINO 3

REWIND 4

REWIND 5

\section{ENTEP IMPUT SECTOR}

READ NEW BKG DATA

READ $\{3.350)$ :

READ 13.360$)$ CTTIME

$K=-9$

TALLY $Y$ 1:

$I E N D=15 ! Z E=128 / 10+151 Z E \cdot 128 / 100+2$

DO $90 \quad !=1$. IEND

$K=K+10$

IF (TALLY.EQ.11) 80.10

READ ELEMENTS INTO ITEMP

10 IF (1.ED.IEND) 20,60

20 IF (ISIZE.EQ.32) 30,40

$30 \quad k 2=k+4$

60 To 50

$K 2=k+6$

50 READ 13,370$)$ (ITEMP(J),J=K,K2)

GO TO 70

$60 \quad K 2=K+9$

READ (3.380) (ITEMPIJ).J=K,KE)

70

$T A L L Y=T A L L Y+1$

GO TO 90

RE AD L INE NUMBER ANO DISCARD

BD

RE AD 13.390 ) LNMM

TALL $Y=$ ?

$K=K-10$ 


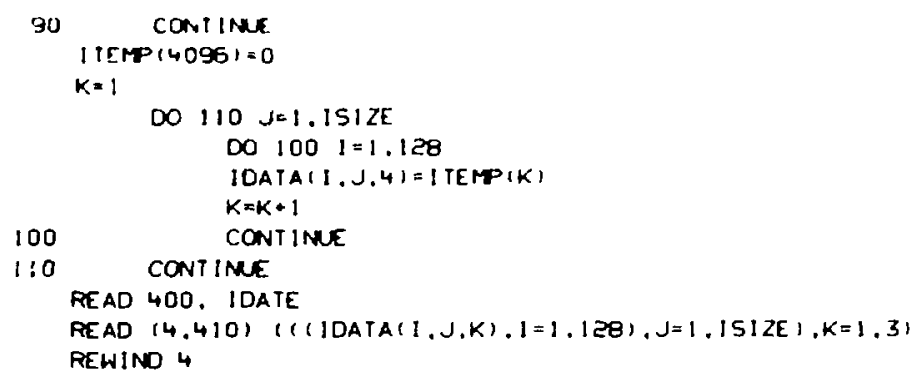

REWIND 5

CALL REPLACE (5HTAPES, GHBKGDFL)

OUTPUT RAW COUNIING DATA IN 60 CHAN $\times 8$ DE FCTOR PAGES

GO TO 400

ISTOP $=1512 E / 8$

$K=-7$

DO $200 \mathrm{~N}=1 .$, ISTOP

$M=5$

$k=k+8$

$K 2=K+7$

$180 \quad M 2=M+60$

CALL NEWPG

CALL DEI IMIR 


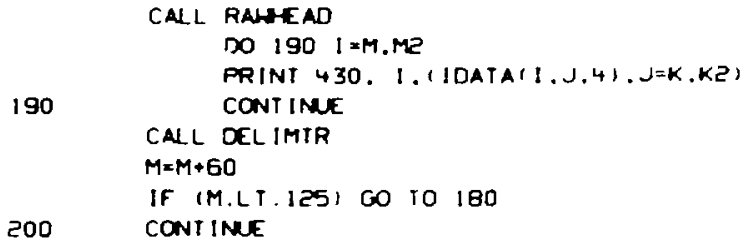

\section{WRITE OUT SUMMARY INFORMATION}

\section{WRITE QUT SUTMAY INFORMATION}

CALL NEWPG

CALL OELIMTR

PRINT 44D. IDATE

PRINT 450

LINE $=6$

OD $240 \mathrm{~J}=1.1 \mathrm{SIZE}$

DO $230 \quad K=1.4$

[RE $G](J, K)=0$

IREGD I J.K $\mid=0$

DO $210 \quad I=54.64$

210

|REG I (J.K) = IREG I (J.K) + JDATA $($ I.J.K)

DO $220 \quad 1=32.42$

220

230

240

CONTINUE

$\operatorname{IREGZ}(J, K)=\operatorname{IREG}(J, K)+|D A T A| 1, U, K$,

$\infty 270$

$\infty 260 k=1,4$

[ $\operatorname{rot}(J . K)=0$

DO $250 \quad 1=1,128$

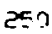

260 CONT INEE

I TOT (J,K) = ITOT (J,K) + IDATA I I.U.K)

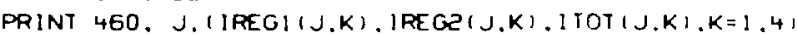

CALL LINEUP

270 CONTINUE

DO $290 \mathrm{~K}=1.4$

$1 G T(K)=0$

DO $280 \quad J=1.1512 E$

280

290

IGT $(K)=I G T(K) \cdot 1$ TGT $(J . K)$

CONTINUE

PRINT 470, (IGT (K), K $=1.4)$

CALL LINEUP

OPTIONAL LISTING OF ALL CHANNELS AVERAGING OI COUNT BACKGRONND

OP

PRINT 480

CALL LINEUP

CALL LINEUP

DO $310 \mathrm{~J}=1.151 \mathrm{ZE}$

$00300 \quad l=1.128$

IF (CB $(1, J) . L E .1)$ GO TO 300

PRINT 490. J,I.CB(1,J)

300

CALL LINEUP

310 CONIINUE

CALL FILLER

CALL DELIMTR

GO TO 570

DO $340 \mathrm{~J}=1,1512 \mathrm{ZE}$

DO $330 \quad 1=1.128$ 


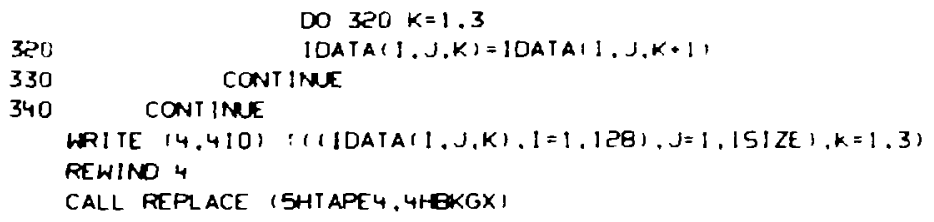


SUERTUTINE RALHE AD

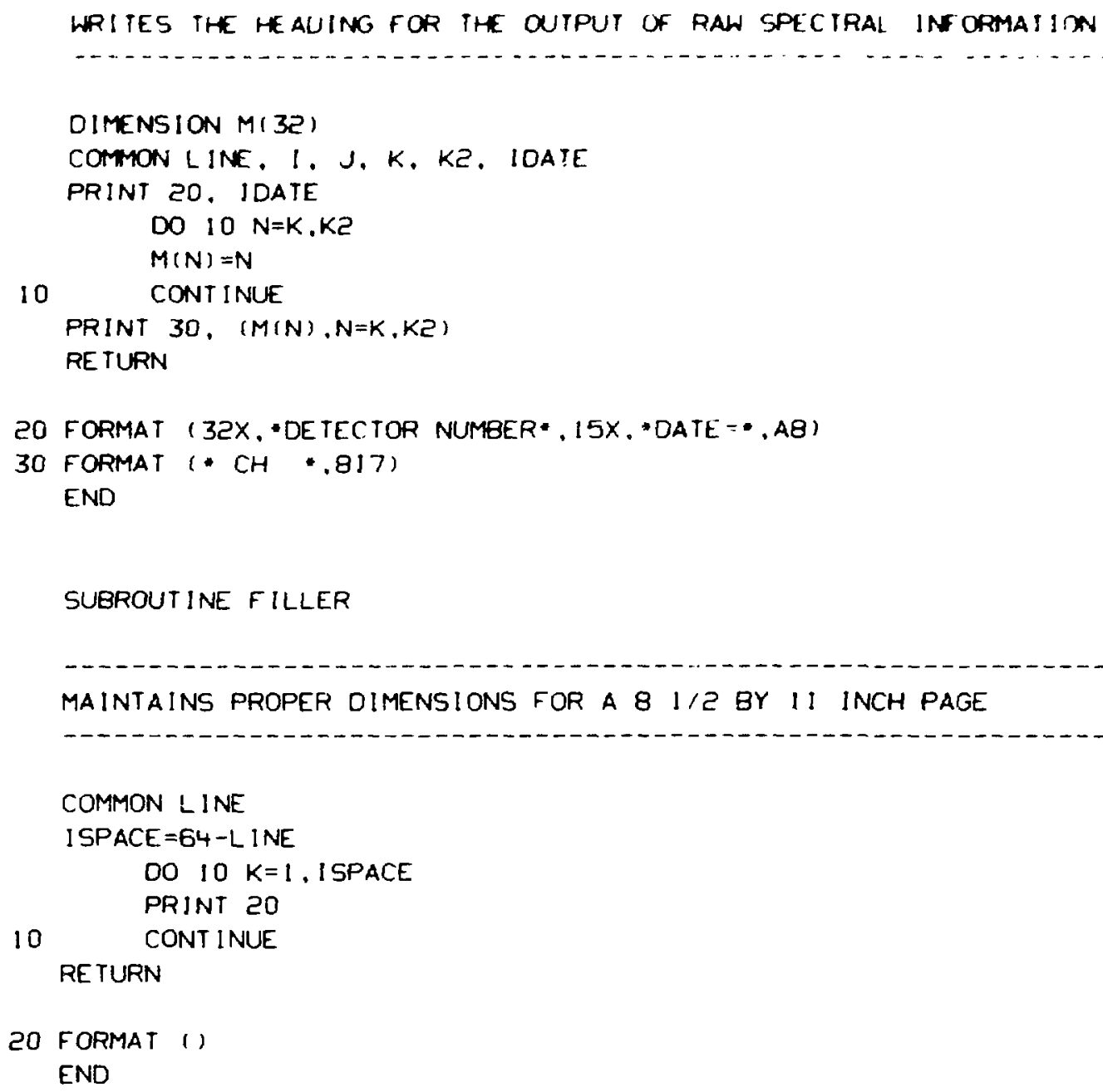

